\title{
NOT A TYPICAL FIRM: \\ THE JOINT DYNAMICS OF FIRMS, LABOR SHARES, AND CAPITAL-LABOR SUBSTITUTION
}

\author{
Joachim Hubmer \\ Pascual Restrepo \\ Working Paper 28579 \\ http://www.nber.org/papers/w28579 \\ NATIONAL BUREAU OF ECONOMIC RESEARCH \\ 1050 Massachusetts Avenue \\ Cambridge, MA 02138 \\ March 2021, Revised November 2022
}

We thank Daron Acemoglu, David Autor, Hugo Hopenhayn, Loukas Karabarbounis, Dirk Krueger, Stephen Terry, and conference and seminar participants at Bank of Mexico, Barcelona GSE Summer Forum, Boston College, Columbia University Junior Conference, Copenhagen, Cornell, Dartmouth, Edinburgh, Essex, Fed Richmond, Glasgow, IIES, IMF, MMF Workshop on Macroeconomic Consequences of Technical Change, NBER Summer Institute, Oslo Macro Conference, Peking University, Philadelphia Fed, SED Minneapolis, Toronto, and Virtual Macro Seminar Series for their comments. Restrepo thanks the National Science Foundation for its support under award No. 2049427. The views expressed herein are those of the authors and do not necessarily reflect the views of the National Bureau of Economic Research.

NBER working papers are circulated for discussion and comment purposes. They have not been peerreviewed or been subject to the review by the NBER Board of Directors that accompanies official NBER publications.

(C) 2021 by Joachim Hubmer and Pascual Restrepo. All rights reserved. Short sections of text, not to exceed two paragraphs, may be quoted without explicit permission provided that full credit, including (c) notice, is given to the source. 
Not a Typical Firm: The Joint Dynamics of Firms, Labor Shares, and Capital-Labor Substitution Joachim Hubmer and Pascual Restrepo

NBER Working Paper No. 28579

March 2021, Revised November 2022

JEL No. E22,E23,E24,E25

\section{ABSTRACT}

While the US labor share has declined, especially in manufacturing and retail, the labor share of a typical firm in these sectors has risen. This paper introduces a model where firms incur fixed costs to automate tasks. In response to lower capital prices, the model reproduces the labor share patterns observed in the data: large firms automate more tasks, reducing the aggregate labor share; while the median firm continues to operate a labor-intensive technology with a rising labor share. Using our model, we decompose the labor share decline and the rise in sales concentration in each sector into a part driven by lower capital prices and a part driven by reallocation to higher-markup firms. Reallocation played a minor role in explaining the labor share decline in manufacturing and some role in retail and other sectors during 1982-2012.

Joachim Hubmer

University of Pennsylvania

$133 \mathrm{~S}$ 36th St

Philadelphia, PA 19104

jhubmer@sas.upenn.edu

Pascual Restrepo

Department of Economics

Boston University

270 Bay State Road

Boston, MA 02215

and NBER

pascual@bu.edu 
A striking fact of the recent past is the fall of labor's share of GDP in the United States and other countries. ${ }^{1}$ After being stable for much of the last century, the US labor share declined from $62 \%$ in the 1980 s to $55 \%$ in 2012 , as seen in the left panel of Figure 1 . The decline is not driven by changes in industry composition: holding industry shares in GDP constant at their 1982 levels leads to a more pronounced labor share decline. As the right panel shows, the fall in the US labor share is mostly driven by a sizable decline dating back to the early 80 s of the labor share in retail of 12 percentage points and in manufacturing of 20 percentage points, and a more recent decline since the year 2000 for wholesale, utilities, and transportation.
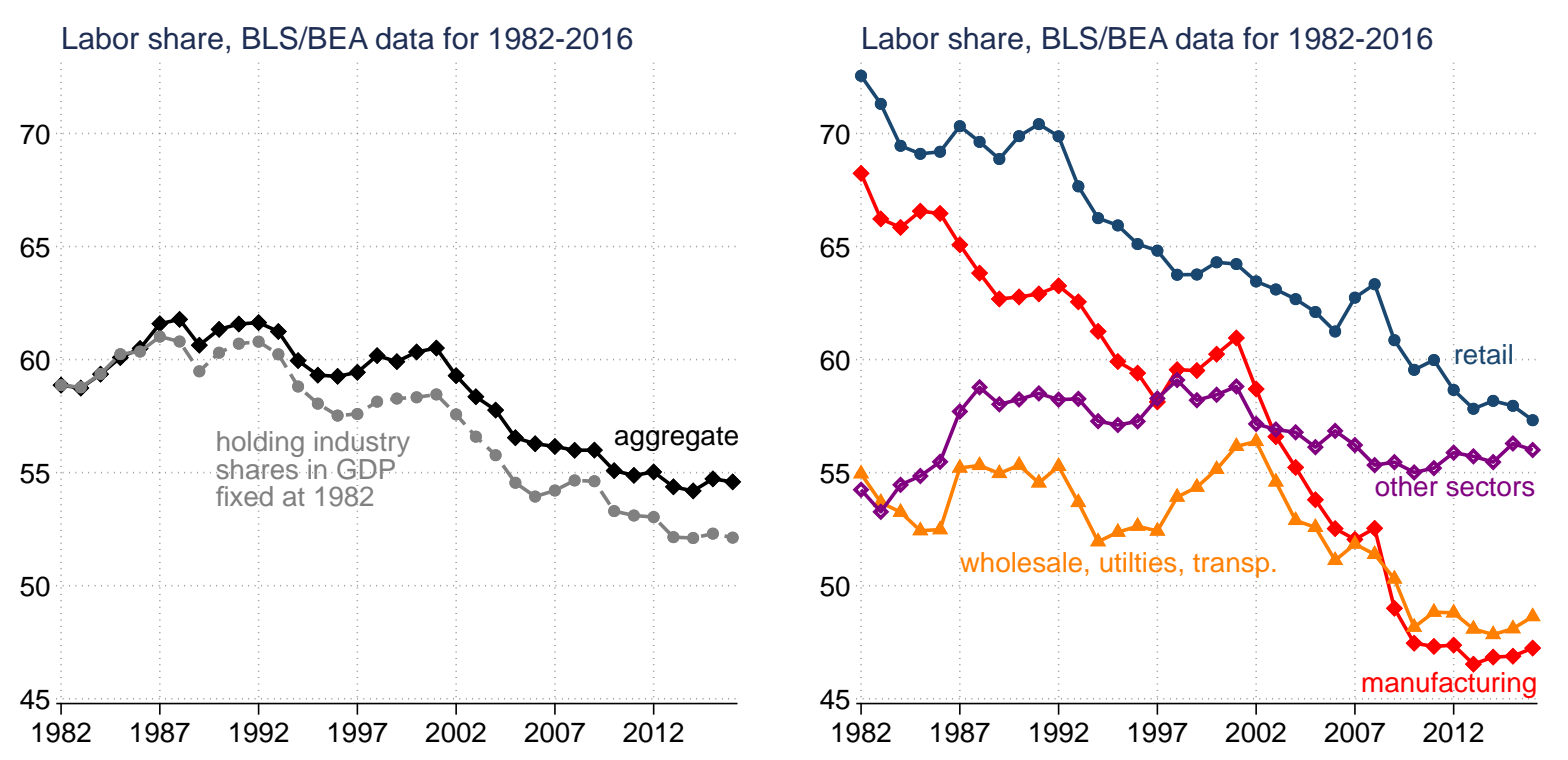

FigURE 1: US LABOR SHARE. Left panel plots the US labor share for the private nonfarm sector and a counterfactual series holding industry GDP shares constant at 1982 values. Right panel plots labor shares for manufacturing, retail, a composite of wholesale, utilities, and transportation, and a composite of other industries. Data from BEA-BLS integrated industry-level production accounts (Eldridge et al., 2020).

One set of explanations of the labor share decline points to technological developments that favored the substitution of capital for labor. This substitution can take place along an aggregate production function with an elasticity of substitution greater than one (Karabarbounis and Neiman, 2013; Hubmer, 2020) or within tasks as a widening range of tasks are automated (Acemoglu and Restrepo, 2018). These explanations receive some support from the fact that the decline in the labor share is more pronounced in manufacturing, and within

\footnotetext{
${ }^{1}$ See for instance Elsby, Hobijn and Şahin (2013); Karabarbounis and Neiman (2013); Piketty (2014); Dao, Das and Koczan (2019). For a different perspective arguing that the decline in the labor share is a US phenomenon, see Gutierrez and Piton (2020). There is also debate on how the exact magnitude of the decline is affected by the treatment of self-employment (Elsby, Hobijn and Şahin, 2013) and income shifting by business owners (Smith et al., 2019).
} 
that sector, in more capital-intensive sub-industries and in firms adopting new automation technologies. ${ }^{2}$

This evidence notwithstanding, recent studies show that the decline in labor shares is not uniform across firms. While the aggregate labor share has declined, the labor share of the typical US firm has risen or remained unchanged. In manufacturing, the median labor share across firms rose from $71 \%$ to $74 \%$ and the unweighted mean labor share decreased slightly (Autor et al., 2020; Kehrig and Vincent, 2020). A similar pattern holds for other sectors and countries (Autor et al., 2020).

These new firm-level facts cast doubt on explanations of the labor share decline based on capital-labor substitution, since a simple version of these theories in which firms operate the same technologies implies a uniform decline in labor shares. These firm-level facts favor a second set of explanations that emphasize the role of rising reallocation of sales towards top firms in an industry. This reallocation, which could be the result of increased competition or winner-takes-all dynamics, reduces the aggregate labor share because top firms have higher markups and lower labor shares (Autor et al., 2020; Baqaee and Farhi, 2020b; Barkai, 2020; De Loecker, Eeckhout and Unger, 2020). ${ }^{3}$

This paper shows that explanations of the labor share decline based on capital-labor substitution can generate the aggregate and firm-level patterns documented by Autor et al. (2020) and Kehrig and Vincent (2020) if the adoption of capital-intensive technologies to automate additional tasks entails fixed costs. When we account for the observed heterogeneity in technology adoption by calibrating this fixed cost to match available micro evidence, we find that task-based models of capital-labor substitution can account for the aggregate and firm-level facts quantitatively, especially in manufacturing.

As our starting point, Section 1 reviews evidence showing that the adoption of capitalintensive technologies used for automation (i.e., robots, specialized software, and dedicated equipment) concentrates on large firms. Using a new module in the Annual Business Survey (ABS) covering firms across all US sectors, Acemoglu et al. (2021) show that the largest

\footnotetext{
${ }^{2}$ Acemoglu and Restrepo (2020) document that US industries with greater possibilities for automation and use of industrial robots experienced a larger labor share decline. Hubmer (2020) shows that the decline of the labor share is more pronounced in equipment and IT intensive industries. For firms, Acemoglu, Lelarge and Restrepo (2020) and Cheng et al. (2021) document that firms adopting robots in France and China experienced a large reduction in their labor shares; Kogan et al. (2021) find that US firms patenting labor-replacing technology see a reduction in their labor shares; and Acemoglu et al. (2021) document that adopters of a wide range of automation technologies have lower labor shares across all US sectors.

${ }^{3} \mathrm{~A}$ different narrative is that weaker anti-trust enforcement has eroded competition, allowed firms to raise markups, and led to bad concentration (see, for example, Philippon, 2019). The available estimates (as well as our estimates in Section 3.4) suggest that the increase in markups is not due to within-firm changes, but due to the reallocation across firms with different markups.
} 
firms in an industry are 1.7 times more likely to use automation technologies than the median firm. We complement this evidence with estimates of output elasticities for firms in Compustat. We show that the largest firms in each industry (especially in manufacturing) have experienced a large increase in their output-to-capital elasticity, indicating that their production processes have become more capital-intensive over time. Smaller firms have not become more capital-intensive in recent years.

Motivated by these facts, in Section 2 we build a firm-dynamics model with monopolistic competition and CES demand augmented with costly automation decisions across tasks (as in Zeira, 1998; Acemoglu and Restrepo, 2018). The key innovation is that firms must incur fixed costs to automate tasks, which allows us to match the evidence in Section 1.

We use the model to study the effects of a permanent decline in the effective price of capital - or a $q$ shock - , which captures technological advances increasing the productivity of capital or lowering the cost of producing equipment and software. We show that a $q$ shock can reduce the aggregate labor share at the same time as the median firm labor share rises. The new mechanism driving this result is as follows: in response to a $q$ shock, large and growing firms find it profitable to incur the fixed cost to automate additional tasks, becoming more capital-intensive. In these firms, capital and labor become substitutes, driving the decline of the aggregate labor share. Instead, due to the fixed cost of adoption, the median firm does not automate tasks and continues to operate a labor-intensive technology. For the median firm, capital and labor remain complements, explaining why the labor share rises for the typical firm. ${ }^{4}$

Our analytical results show that our model can generate the empirical trends documented in the recent literature. To gauge potential magnitudes, we focus on the manufacturing sector and work with a calibrated version of our model where the fixed cost of automation is calibrated to match the adoption gradient by size in the ABS. We treat the economy in 1982 as being in a steady state - since this period precedes the decline in the manufacturing labor share - and calibrate relevant parameters to match the distribution of firm sales in manufacturing, average markups in the pre-1982 steady state, and other moments. We then use our model to explore the implications of $q$ shocks during 1982-2012.

We consider two types of $q$ shocks: a uniform decline in the price of capital across all tasks and a skewed decline that is more pronounced at tasks previously assigned to labor.

\footnotetext{
${ }^{4} \mathrm{~A}$ different mechanism going back to Houthakker (1955) emphasizes the possibility that a decline in capital prices reallocates economic activity to more capital-intensive firms, even if firms do not change their factor intensities. Kaymak and Schott (2018) argue that this mechanism generates a third of the decline in the manufacturing labor share in response to lower corporate taxes. On the other hand, Oberfield and Raval (2021) show that this reallocation has a small negative effect on the manufacturing labor share.
} 
The second shock aligns with the definition of automation in Acemoglu and Restrepo (2019) while the first one is reminiscent of the type of shocks considered in the investment-specific technical change literature (Greenwood, Hercowitz and Krusell, 1997). We show that one can explain the aggregate facts for manufacturing via a combination of these $q$ shocks that matches the observed 20 pp decline in the manufacturing labor share during 1982-2012 and is consistent with available estimates of the average decline in capital prices for this period, placing the decline at $108 \log$ points. Our task model can generate these effects even when the elasticity of substitution between capital and labor is below 1 (as estimated, for example, in Oberfield and Raval, 2021).

In response to these $q$ shocks, the model reproduces the firm labor share moments observed in the data, even though these are not targeted. The model generates an aggregate labor share decline at the same time as the median labor share and the unweighted mean labor share remain roughly unchanged. As in the Melitz-Polanec decomposition in Autor et al. (2020), the decline in the manufacturing labor share is driven by a more negative covariance between the market share of firms and their labor share. In turn, the more negative covariance reflects the fact that firms automate during periods of expanding sales, which aligns with the dynamics of changes in value added and labor shares for manufacturing firms documented in Kehrig and Vincent (2020). The uneven use of automation technologies accounts for all the increase in TFP dispersion and $75 \%$ of the increase in sales concentration observed in manufacturing during 1982-2012.

Our baseline model in Section 2 abstracts from the role of rising competition and reallocation in driving the labor share decline. To put both explanations on equal footing and quantify their contributions, in Section 3 we extend the model to an environment with a non-CES demand system where markups increase with firm size. ${ }^{5}$ Following Autor et al. (2020), we model rising competition as resulting from an increase in the mass of customers that a firm can access - a $\lambda$ shock. This leads to an increase in sales concentration, a reduction in within-firm markups (and an increase in firms' labor shares), and a reallocation towards large firms with high markups (and low labor shares). ${ }^{6}$ When the distribution of firm productivity is more log-convex than Pareto, the reallocation effect dominates and the

\footnotetext{
${ }^{5}$ Non-CES demand systems are widely used in trade (see Melitz and Ottaviano, 2008; Amiti, Itskhoki and Konings, 2019; Arkolakis et al., 2018). Recent works use these systems to quantify the distortions from markups (Edmond, Midrigan and Xu, 2018) and the gains from entry (Baqaee and Farhi, 2020a).

${ }^{6}$ Previous work has studied other driving forces that could affect concentration and markups. Aghion et al. (2019); Lashkari, Bauer and Boussard (2019); De Ridder (2020); Mariscal (2020); Hsieh and RossiHansberg (2019) study the role of ICT in allowing more productive firms to expand to new markets or scale their production. We see our market access shock as capturing some of these mechanisms in a reduced form way, since a $\lambda$ shock increases the sales that the most productive firms are able to make but reduces within-firm markups due to the tougher competition this induces. In line with Aghion et al. (2019), we find that $\lambda$ shocks have sizable effects on sales concentration but mild effects on the aggregate labor share.
} 
net effect of this shock is to reduce the labor share.

Both $q$ and $\lambda$ shocks can generate a pattern of rising sales concentration, a decline in the aggregate labor share, and a rise in the typical firm labor share. To gauge magnitudes, we use a calibrated version of the non-CES model, where we also calibrate the productivity dispersion and the demand system to match the distribution of firm sales in manufacturing, and the relationship between firm size and their labor share in the 1982 steady state. For this exercise we also look at retail and other non-manufacturing sectors, where the $\lambda$ shock might be more prevalent. For each sector, we calibrate the $q$ and $\lambda$ shocks to match the decline in the sectoral labor share, the average decline in capital prices in the sector, and the rise in sales concentration over 1982-2012. This exercise assumes that the observed trends across sectors are driven by a combination of these shocks, recovers the shocks needed to explain the data, and separates their independent contributions.

One can explain the sectoral trends in labor shares, concentration, and capital prices as resulting from different combinations of $q$ and $\lambda$ shocks, with these shocks playing different roles across sectors. In manufacturing, lower capital prices at tasks performed by labor result in a large drop in the aggregate labor share and explain almost all of the increase in sales concentration, with increased market access playing a small role. Our model with endogenous markups not only matches the aggregate trends but is also consistent with all the new firm-level labor share facts for manufacturing, including the transient behavior of firms' labor shares documented by Kehrig and Vincent (2020) and the labor share decline decompositions in Autor et al. (2020) and Kehrig and Vincent (2020). In retail, increased market access and the reallocation to high-markup firms accounts for $20 \%$ of the decline in the labor share between 1982-2012 and 90\% of the increase in sales concentration.

These conclusions align with estimates of firm-level markups from Compustat presented in Section 3.4. Allowing for differences in technology across firms of different size, we find that the aggregate manufacturing markup did not increase during this period. ${ }^{7}$ Outside of manufacturing, reallocation to high-markup firms reduced the labor share by $6 \%$.

\footnotetext{
${ }^{7}$ These conclusions also receive support from recent work by Foster, Haltiwanger and Tuttle (2022). Using establishment-level data from the Annual Survey of Manufactures for 1972-2014, these authors document that there are large differences in output elasticities across detailed industries and among firms in detailed industries. Once this heterogeneity is accounted for, they find no evidence of rising markups in US manufacturing. Instead, their findings point to an important role for technology in driving the decline in the manufacturing labor share.
} 


\section{The uneven Adoption of AUtomation TeChNologies}

The most comprehensive evidence on the uneven adoption of automation technologies by large firms comes from the 2019 module of the Annual Business Survey, which contains information on the adoption of robotics, dedicated equipment, specialized software, and artificial intelligence for 300,000 firms across all US economic sectors. Using the 2019 ABS, Acemoglu et al. (2021) show that, within detailed 6-digit industries, firms in the top percentile of the employment size distribution are 1.71 times more likely to use these technologies than firms between the 50th and 75th percentile. This strong size gradient is visible across sectors and when one conditions on firm age and productivity.

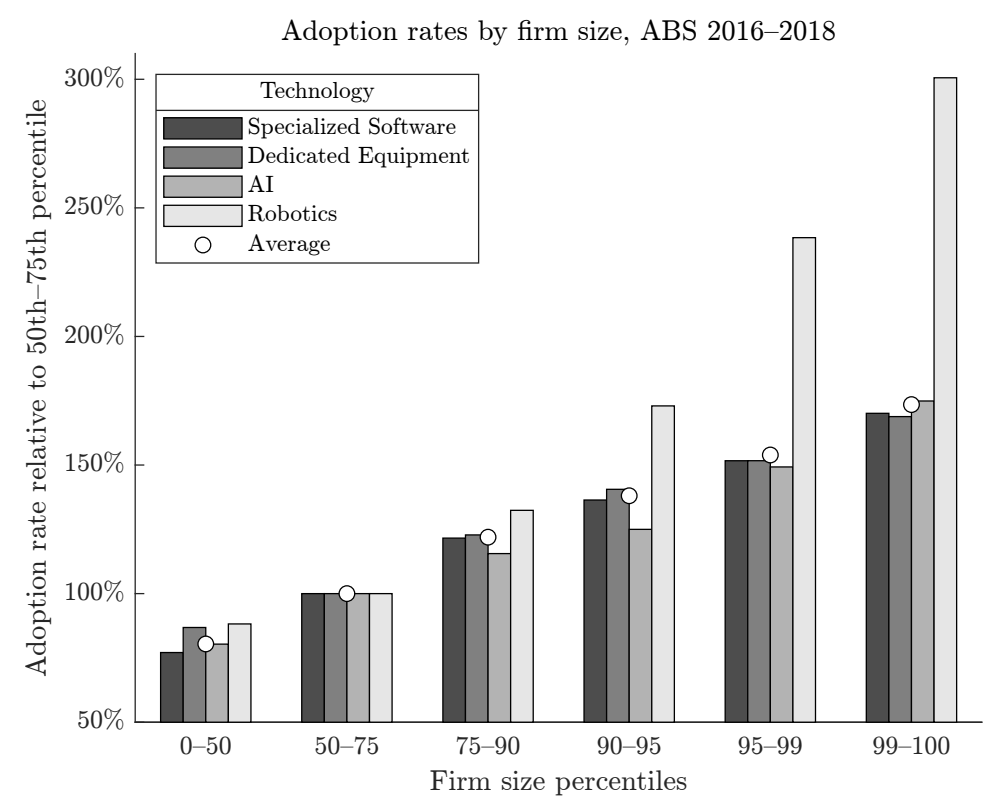

Figure 2: Adoption RAtes by firm size, ABS 2016-2018. The figure reports adoption rates for specialized software, dedicated equipment, artificial intelligence, and robotics relative to the adoption of each technology among firms in the 50th-75th percentiles of the employment size distribution. Data from Figure 4 in Acemoglu et al. (2021), reproduced here with their permission.

Figure 2 reproduces the evidence from Acemoglu et al. (2021) and plots for each of the technologies in the ABS its adoption rate across firms in different size percentiles within detailed 6-digit industries. To facilitate the interpretation, we report adoption rates relative to that of firms between the 50th and 75 th employment percentiles. The figure shows that adoption rates at the top are 1.68 (for specialized software) to 3 times higher (for robotics) than in the middle of the firm-size distribution, with a weighted average across technologies giving the 1.71 ratio that we will use as a target in our calibration.

This phenomenon is not unique to the US and is also visible in other datasets and countries. Using the Survey of Manufacturing Technologies from 1993, Dinlersoz and Wolf 
(2018) document that the adoption of various automation technologies among US manufacturing firms rises with size. More recently, a growing number of papers using data on industrial robot adoption among manufacturing firms in the US, Canada, and several European countries document that robot use rises sharply with firm size and that these differences by firm size are visible even within narrowly defined industries (see Koch, Manuylov and Smolka, 2019; Humlum, 2019; Bonfiglioli et al., 2020; Acemoglu, Lelarge and Restrepo, 2020; Wang, 2021; Dixon, Hong and Wu, 2020).

We complement this evidence with production function estimates from Compustat. We use the sample of Compustat firms to estimate their elasticity of output to capital-the percent increase in output generated by a percent increase in the stock of capital. The output-to-capital elasticity is the key object summarizing the capital intensity of a firm and the extent to which it has automated its tasks and processes. Our approach to estimating output-to-capital and output-to-variable input elasticities is detailed in Appendix A.1. Relative to the existing literature, we make two modifications. First, we estimate a revenue production function (given the lack of price data in Compustat), but we show that one can recover output elasticities by assuming constant returns to scale. Second, we allow output elasticities to vary not only over time and across industries (as in De Loecker, Eeckhout and Unger, 2020), but also across firm-size classes, which accounts for the differences in technology adoption across firm sizes in the ABS.

Figure 3 plots the estimated output-to-capital elasticities by size bin and time period. The left panel reports averaged elasticities for manufacturing industries, while the right panel reports averaged elasticities for non-manufacturing industries. In the $60 \mathrm{~s}$ and $70 \mathrm{~s}$, firms had similar output-to-capital elasticities ranging from 0.08 to 0.12 in both sectors. In the following decades, we estimate a pronounced increase in output-to-capital elasticities among the firms in the top quintiles of the size distribution. For the largest firms in manufacturing, the output-to-capital elasticity increases by 0.2 , going from 0.11 to 0.31 . Outside of manufacturing, we estimate a less pronounced increase in output-to-capital elasticities for large firms of 0.08 (from 0.09 to 0.17 ). In our numerical exercise, we use these estimates as untargeted moments and explore whether our model can match this rotation in output-to-capital elasticities over time.

In line with these estimates and the evidence on the uneven adoption of automation technologies, Appendix A.1 shows that large firms in Compustat have higher investment rates and other measures of capital intensity than smaller firms in their industries, and that some of these differences have become more pronounced over time.

The evidence in this section suggests that large firms differ in the extent to which their 

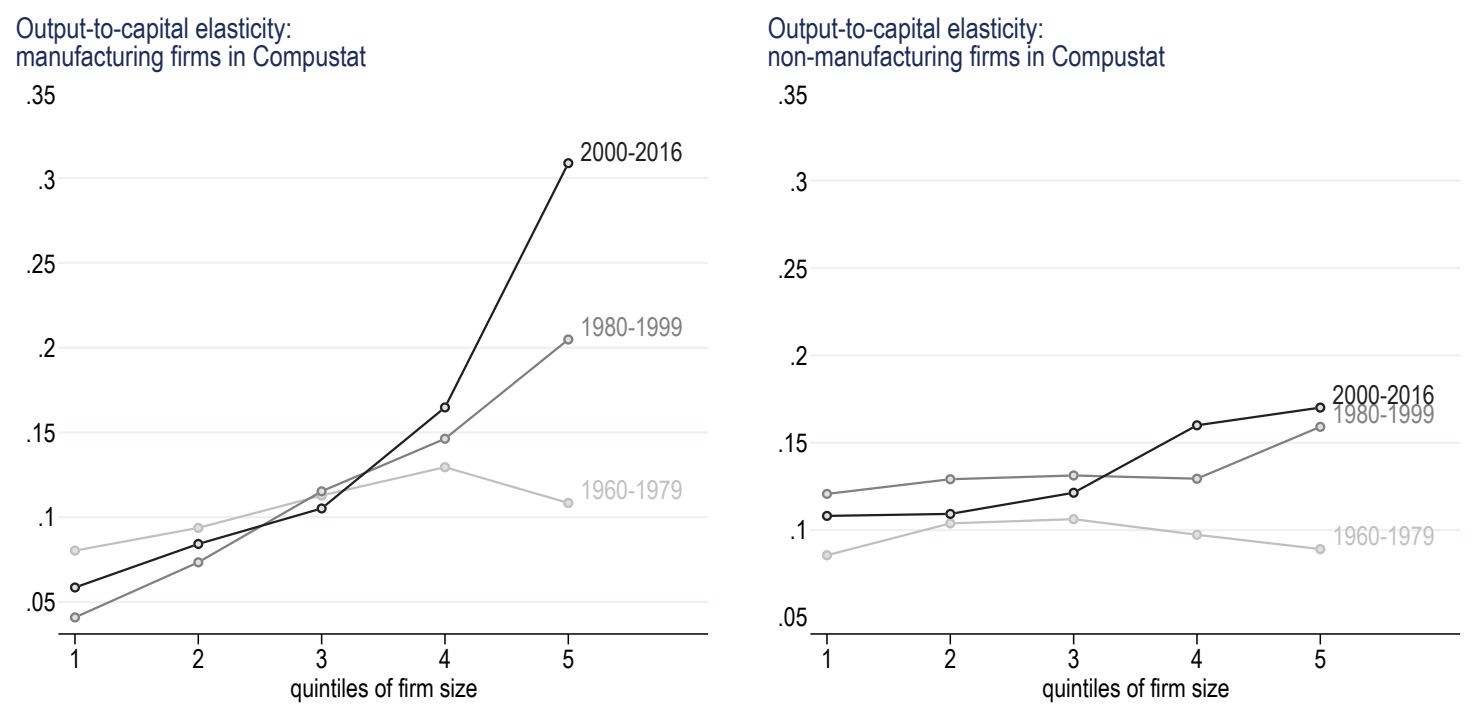

Figure 3: OutPut-to-CAPital elasticities for Compustat firms. The left panel presents estimates for Compustat manufacturing firms. The right panel presents estimates for Compustat nonmanufacturing firms.

production relies on capital-intensive technologies. One interpretation of these findings is that adopting and integrating automation technologies involves fixed costs. ${ }^{8}$ This assumption is plausible. Consider a car-manufacturing firm that wishes to automate welding. Besides purchasing the industrial robots required to complete this task, the firm must also hire a team of engineers to reorganize its plant and redesign some of their products, so that robots can be integrated. In the case of industrial robots, these integration costs far exceed the cost of the robot system itself (Acemoglu and Restrepo, 2020). Likewise, a firm that wants to deploy a new software to automate its logistics and inventory management must pay a fixed cost for developing the software and rearranging its operations to use it.

\section{CAPITAL-LABOR SUBSTITUTION With ADOPTION COSTS}

We augment a firm-dynamics model (as in Hopenhayn, 1992) to include firms' decisions to automate tasks (as in Acemoglu and Restrepo, 2018). Our key innovation is to endogenize firms' automation decisions as being determined by payment of a fixed cost per task or process. These fixed costs ensure that firms automate more tasks as they grow, which allows us to match the evidence in Section 1.

\footnotetext{
${ }^{8} \mathrm{~A}$ different interpretation is that firms differ in their ability to adopt automation technologies, with those that can adopt then becoming larger as a result. Acemoglu et al. (2021) provide some evidence against this interpretation: according to the ABS, adopters were larger and have been growing more rapidly than non-adopters before the arrival and diffusion of these technologies.
} 


\subsection{Model and theoretical properties}

Environment: Consider an economy in discrete time indicated by the subscript $t$. Existing firms, $f$, produce differentiated varieties $y_{t f}$ combined via a CES aggregator to produce a final good $y_{t}$, whose price we normalize to 1 :

$$
y_{t}=\left(\int_{f} y_{t f}^{\frac{\sigma-1}{\sigma}} \cdot d f\right)^{\frac{\sigma}{\sigma-1}}
$$

Here $\sigma>1$ denotes the elasticity of substitution across varieties. Firms are atomistic and charge a common and constant markup $\mu=\sigma /(\sigma-1)>1$.

Firms differ in their productivity $z_{t f}$ and in the fraction of tasks or processes they have automated, $\alpha_{t f} \in[0,1]$. A firm produces output $y_{t f}$ by combining a continuum of tasks indexed by $x$ with task substitution elasticity $\eta \geq 0$ :

$$
y_{t f}=z_{t f} \cdot\left(\int_{0}^{1} y_{t f}(x)^{\frac{\eta-1}{\eta}} \cdot d x\right)^{\frac{\eta}{\eta-1}}
$$

Tasks in $\left[0, \alpha_{t f}\right]$ are automated and can be produced by capital or labor. Non-automated tasks in $\left(\alpha_{t f}, 1\right]$ must be produced by labor. The quantity of task $x$ is then given by

$$
y_{t f}(x)= \begin{cases}\psi(x) \cdot \ell_{t f}(x)+\phi_{t}(x) \cdot k_{t f}(x) & \text { if } x \in\left[0, \alpha_{t f}\right] \\ \psi(x) \cdot \ell_{t f}(x) & \text { if } x \in\left(\alpha_{t f}, 1\right]\end{cases}
$$

where $\ell_{t f}(x)$ and $k_{t f}(x)$ denote labor and capital employed to produce task $x$ with taskspecific productivity $\psi(x)$ and $\phi_{t}(x)$.

Firms compete for a mass $\ell$ of workers hired at a wage rate $w_{t}$. On the other hand, the capital used for task $x$ is produced from the final good, with a unit of the final good yielding $q_{t}^{I}(x)$ units of capital. We refer to

$$
q_{t}(x)=q_{t}^{I}(x) \cdot \phi_{t}(x)
$$

as the effective productivity of capital and to $1 / q_{t}(x)$ as the effective price of capital at task $x$. Without loss of generality, assume that capital is produced instantly and fully depreciates after use, so that the effective price of capital gives the units of consumption that must be foregone to produce 1 unit of task $x$ with capital. Moreover, assume $\psi(x) / q_{t}(x)$ is increasing in $x$, so that labor has a comparative advantage at high-indexed tasks.

Incumbents begin a period with productivity $z_{t f}$ and automation level $\alpha_{t f}$, make optimal employment and capital utilization decisions, and collect profits $\pi_{t f}$. Firms then draw a 
fixed operating cost $c_{o} \cdot y_{t}$, where $c_{o} \sim G\left(c_{o}\right)$, and decide whether to exit or continue. ${ }^{9}$ If they continue, they draw next period's productivity level $z_{t+1, f}$, which follows an exogenous first-order Markov process with $z_{t+1, f}$ increasing in $z_{t f}$ (in a stochastic sense). We assume that, for any increasing and unbounded function $M, \mathbb{E}\left[M\left(z_{t+1, f}\right) \mid z_{t f}\right]$ converges to infinity when $z_{t f} \rightarrow \infty$ and to $f(0)$ when $z_{t f} \rightarrow 0$.

The key ingredient of our model are the endogenous automation decisions by firms. Incumbents can expand the set of automated tasks to include $\left(\alpha_{t f}, \alpha_{t+1, f}\right]$ at a cost $c_{a} \cdot y_{t}$. $\left(\alpha_{t+1, f}-\alpha_{t f}\right)$, which implies a fixed cost of automation per task of $c_{a} \cdot y_{t}$. We also allow these technologies to diffuse gradually through the entry of new firms, as we explain next.

Every period a unit mass of potential entrants draw a productivity signal $z \sim G_{e}(z)$. After observing $z$ and the realization of the fixed operating $\operatorname{cost} c_{o}$, entrants decide whether to pay the fixed cost and enter. Firms enter with a common level of automation $\bar{\alpha}_{t}$, equal to the unweighted average of $\alpha_{t f}$ among incumbents. This is a common specification in models of technology diffusion (see Perla, Tonetti and Waugh, 2021). Diffusion simplifies our analytical results, but is not required for our quantitative results. ${ }^{10}$

Finally, when making entry and adoption decisions, incumbents and new entrants discount the future at a constant interest rate $r$, which we take as exogenous. We assume that $r>g_{t}$, where $g_{t}$ is the growth rate of output between two consecutive periods.

Equilibrium: Denote by $p_{t f}(w)$ the price charged by a firm facing a wage $w$, by $c_{t f}(w)$ its cost, and by $\pi_{t f}(w)$ its profits. Given a path for capital productivity $q_{t}(x)$ and an initial distribution of firms $\left\{\alpha_{0 f}, z_{0 f}\right\}$, an equilibrium is given by a path for wages $w_{t}$ and output $y_{t}$, and a path for the distribution of firms $\left\{\alpha_{t f}, z_{t f}\right\}$, such that for all $t \geq 0$ :

E1. The ideal-price index condition holds

$$
\int_{f} p_{t f}\left(w_{t}\right)^{1-\sigma} \cdot d f=1
$$

E2. The labor market clears

$$
\int_{f} y_{t} \cdot p_{t f}\left(w_{t}\right)^{-\sigma} \cdot \frac{\partial c_{t f}\left(w_{t}\right)}{\partial w_{t}} \cdot d f=\ell
$$

\footnotetext{
${ }^{9}$ Fixed costs are scaled by aggregate output to ensure that there is no mechanical relationship between the GDP level in the economy and firms' incentives to produce or automate tasks. Moreover, the assumption that fixed costs are paid in units of the final good ensures that there is no mechanical relationship between firm size and its labor share. Firms' labor shares will differ only due to markups and technology.

${ }^{10}$ Diffusion through entry might be important for capturing other aspects of the ABS that are not our focus. E.g., Acemoglu et al. (2021) show that, conditional on size, younger firms use more automation technologies, which suggests that entrants start with a higher $\alpha_{t f}$ than incumbents of the same size.
} 
E3. Automation and exit decisions maximize the value function of incumbents

$$
\begin{aligned}
V_{t f}= & \pi_{t f}\left(w_{t}\right)+ \\
& \int \max \left\{0,-c_{o} \cdot y_{t}+\max _{\alpha_{t+1, f} \in\left[\alpha_{t, f}, 1\right]}\left\{-c_{a} \cdot y_{t} \cdot\left(\alpha_{t+1, f}-\alpha_{t, f}\right)+\frac{1}{1+r} \mathbb{E}\left[V_{t+1, f} \mid z_{t, f}\right]\right\}\right\} d G\left(c_{o}\right) .
\end{aligned}
$$

E4. Entry decisions maximize the value function of entrants

$$
V_{t f}^{e}=\int \max \left\{0,-c_{o} \cdot y_{t}+\max _{\alpha_{t+1, f}\left[\bar{\alpha}_{t}, 1\right]}\left\{-c_{a} \cdot y_{t} \cdot\left(\alpha_{t+1, f}-\bar{\alpha}_{t}\right)+\frac{1}{1+r} \mathbb{E}\left[V_{t+1, f} \mid z_{t f}\right]\right\}\right\} d G\left(c_{o}\right),
$$

where $z_{t f}$ denotes an entrant's productivity signal, and $\bar{\alpha}_{t} \equiv\left(\int_{f} \alpha_{t f} \cdot d f\right) /\left(\int_{f} d f\right)$.

E5. Starting from a distribution $\left\{\alpha_{0 f}, z_{0 f}\right\}$, the evolution of $\left\{\alpha_{t f}, z_{t f}\right\}$ is governed by the exogenous process for $z$, the endogenous process for $\alpha$, and optimal entry and exit decisions.

Firms' cost structures and factor shares: To save on notation, we focus on an equilibrium where firms produce all tasks in $\left[0, \alpha_{t f}\right]$ with capital, which will be the relevant scenario in our calibration. The unit cost of firm $f$ at time $t$ is

$$
c_{t f}=\frac{1}{z_{t f}} \cdot\left(\Gamma_{t}^{k}\left(\alpha_{t f}\right)+\Gamma^{\ell}\left(\alpha_{t f}\right) \cdot w_{t}^{1-\eta}\right)^{\frac{1}{1-\eta}} .
$$

This is the usual CES cost function, with the difference that the share parameters $\Gamma_{t}^{k}\left(\alpha_{t f}\right)$ and $\Gamma^{\ell}\left(\alpha_{t f}\right)$ are now endogenous and depend on the mass of tasks that are automated:

$$
\Gamma_{t}^{k}\left(\alpha_{t f}\right)=\int_{0}^{\alpha_{t f}} q_{t}(x)^{\eta-1} \cdot d x, \quad \quad \Gamma^{\ell}\left(\alpha_{t f}\right)=\int_{\alpha_{t f}}^{1} \psi(x)^{\eta-1} \cdot d x .
$$

The share of capital in cost for a firm $\varepsilon_{t f}^{k}$ - which equals the output-to-capital elasticityand the share of labor in $\operatorname{cost} \varepsilon_{t f}^{\ell}$-which equals the output-to-labor elasticity-depend on firm automation decisions, $\alpha_{t f}$, and are given by

$$
\varepsilon_{t f}^{k}=\frac{\Gamma_{t}^{k}\left(\alpha_{t f}\right)}{\Gamma_{t}^{k}\left(\alpha_{t f}\right)+\Gamma^{\ell}\left(\alpha_{t f}\right) \cdot w_{t}^{1-\eta}}, \quad \quad \varepsilon_{t f}^{\ell}=\frac{\Gamma^{\ell}\left(\alpha_{t f}\right) \cdot w_{t}^{1-\eta}}{\Gamma_{t}^{k}\left(\alpha_{t f}\right)+\Gamma^{\ell}\left(\alpha_{t f}\right) \cdot w_{t}^{1-\eta}} .
$$

Likewise, the labor share in value added is $s_{t f}^{\ell}=\varepsilon_{t f}^{\ell} / \mu$, which also decreases in $\alpha_{t f}$.

Let $\alpha_{t}^{*}$ denote the common level of automation that minimizes $c_{t f}$. This is the point at 
which the unit cost of producing a task with labor equals that of producing it with capital:

$$
\frac{w_{t}}{\psi\left(\alpha_{t}^{*}\right)}=\frac{1}{q_{t}\left(\alpha_{t}^{*}\right)} \text {. }
$$

Because of the fixed cost of automating tasks, not all firms will automate all the tasks up to $\alpha_{t}^{*}$. The following Proposition shows that, in line with the evidence in Section 1, larger firms automate more of their tasks. As a result, these firms will have a higher output-to-capital elasticity $\varepsilon_{t f}^{k}$ and lower labor shares.

Proposition 1 Suppose that the economy is transitioning to its steady state and $\alpha_{t f}<\alpha_{t+1}^{*}$ for a firm. Optimal automation decisions are given by $\alpha_{t+1, f}=\tilde{\alpha}_{t}\left(\alpha_{t f}, z_{t f}\right)$, where $\tilde{\alpha}_{t}\left(\alpha_{t f}, z\right)$ is an increasing function of $z$ that satisfies

$$
\lim _{z \rightarrow 0} \tilde{\alpha}_{t}\left(\alpha_{t f}, z\right)=\alpha_{t f}, \quad \quad \quad \lim _{z \rightarrow \infty} \tilde{\alpha}_{t}\left(\alpha_{t f}, z\right)=\alpha_{t+1}^{*}
$$

The proposition shows that automation increases with firm size and is episodic. Firms that are highly productive and large will choose an automation level $\alpha_{t+1, f}$ close to $\alpha_{t+1}^{*}$. Moreover, firms go through episodes of automation when, following a large increase in $z$, $\tilde{\alpha}_{t}\left(\alpha_{t f}, z\right)$ exceeds $\alpha_{t f}$. These episodes of automation (and declining firm labor shares) coincide with periods of firm expansion.

The effect of a $q$ shock on labor shares and wages: We now explore the effects of $q$ shocks - technological advances that increase the productivity of capital or reduce the cost of capital. We model these advances as a permanent decrease in the effective price of capital $1 / q_{t}(x)$. This can be the result of improvements in the investment technology - an increase in $q_{t}^{I}(x)$ reflected in lower capital prices $1 / q_{t}^{I}(x)$ - or advances in the productivity of capital at certain tasks - an increase in $\phi_{t}(x)$ reflected in a higher quality of capital.

We consider two types of $q$ shocks: a uniform decrease in effective capital prices at all tasks, and a skewed decrease in effective capital prices that is more pronounced for higherindex tasks. Both shocks can generate the patterns seen in manufacturing, but skewed shocks reduce the manufacturing labor share for a wider range of parameters.

The effects of both shocks can be expressed in terms of two elasticities: the elasticity of substitution between capital and labor holding the level of automation constant, which coincides with the elasticity of substitution across tasks $\eta$, and the induced elasticity of 
substitution:

$$
\eta_{t}^{*}=\eta+\frac{\partial \ln \left[\Gamma_{t}^{k}(\alpha) / \Gamma^{\ell}(\alpha)\right]}{\partial \ln \alpha} / \frac{\partial \ln \left[\psi(\alpha) / q_{t}(\alpha)\right]}{\partial \ln \alpha} .
$$

The induced elasticity accounts for substitution across tasks (given by $\eta$ ) and the automation of additional tasks (given by the change in $\alpha_{t}^{*}$ ) in response to factor prices. Because optimal automation decisions are increasing in the wage and decreasing in the effective price of capital (from 2), this second term is always non-negative and the induced elasticity exceeds $\eta$. We let $\eta^{*}$ denote the steady-state value of the induced elasticity. The induced elasticity $\eta^{*}$ corresponds to the long-run elasticity of substitution that an econometrician exploiting permanent differences in wages across labor markets would estimate.

The following propositions characterize configurations of $\eta^{*}$ and capital shocks capable of generating a decline in the aggregate labor share and a simultaneous increase in a typical firm's labor share. We consider an economy that is in a steady state with all firms having a common $\alpha^{*}$, and we denote the common cost shares for labor and capital across firms by $\varepsilon^{\ell}$ and $\varepsilon^{k}$, respectively. In our discussion, we focus on the empirically relevant case with $\eta<1$, so that tasks are complements.

Proposition 2 (UNIFORM $q$ SHOCK) Following a permanent and uniform increase in $q(x)$ by $d \ln q(x)=d \ln q>0$, the economy converges to a new steady state with wages rising by $d \ln w=\left(\varepsilon^{k} / \varepsilon^{\ell}\right) \cdot d \ln q>0$, and automation rising by $d \ln \alpha^{*}>0$. The aggregate share of labor in cost (or in value added) changes by

$$
d \ln \varepsilon^{\ell}=\frac{\varepsilon^{k}}{\varepsilon^{\ell}} \cdot\left(1-\eta^{*}\right) \cdot d \ln q
$$

Along the transition, firms automate $d \ln \alpha_{t f} \in\left[0, d \ln \alpha^{*}\right)$ tasks, depending on their productivity draws, and their labor share changes by

$$
d \ln \varepsilon_{t f}^{\ell}=\frac{\varepsilon^{k}}{\varepsilon^{\ell}} \cdot\left[(1-\eta)-\left(\eta^{*}-\eta\right) \cdot \frac{d \ln \alpha_{t f}}{d \ln \alpha^{*}}\right] \cdot d \ln q
$$

Suppose that $\eta^{*}>1$, so that capital and labor become substitutes for firms that adjust their $\alpha$ optimally. The proposition shows that the response of the aggregate labor share to a uniform $q$ shock is controlled by the induced elasticity of substitution $\eta^{*}$, and that it will decline as capital becomes cheaper. ${ }^{11}$

\footnotetext{
${ }^{11}$ In steady state, the aggregate elasticity of substitution is exactly $\eta^{*}$ due to diffusion. But even without diffusion, the aggregate elasticity of substitution will be close to $\eta^{*}$ because large firms will automate almost all the way up to $\alpha^{*}$, as we show in more detail in our numerical analysis.
} 
The second part of the proposition shows that lower capital prices generate dispersed labor share changes along the transition. At one extreme, we have firms that receive positive productivity shocks and reach the scale to justify automating $d \ln \alpha^{*}$ more tasks. For these firms, capital and labor become substitutes and their labor share falls. At the other extreme, some incumbents do not reach a big enough scale to justify investments in automating additional tasks and will keep their $\alpha$ fixed at its initial value. The response of these firms to lower capital prices is controlled by the elasticity of substitution across tasks $\eta$, since these firms only alter the intensity with which they combine tasks but not the way in which they allocate tasks between capital and labor. For these firms, capital and labor are complements and their labor share rises as capital prices drop and wages increase. The median firm is in between, and will experience an increase in its labor share if the fixed cost of automation is enough to prevent it from automating a large fraction of tasks.

Proposition 3 (SKewed $q$ SHOCK) Following a permanent increase in $q(x)$ of $d \ln q(x)=$ $d \ln q>0$ for all $x \geq \alpha^{*}$, the economy converges to a new steady state with wages rising by $d \ln w>0$, and automation rising by $d \ln \alpha^{*}>0$. The aggregate share of labor in costs (or value added) changes by

$$
d \ln \varepsilon^{\ell}=\varepsilon^{k} \cdot(1-\eta) \cdot d \ln w-\varepsilon^{k} \cdot\left(\eta^{*}-\eta\right) \cdot(d \ln q+d \ln w)
$$

which is negative for small $d \ln q$. Along the transition, firms automate $d \ln \alpha_{t f} \in\left[0, d \ln \alpha^{*}\right]$ tasks, depending on their productivity draws, and their labor share changes by

$$
d \ln \varepsilon_{t f}^{\ell}=\varepsilon^{k} \cdot(1-\eta) \cdot d \ln w_{t}-\varepsilon^{k} \cdot\left(\eta^{*}-\eta\right) \cdot \frac{d \ln \alpha_{t f}}{d \ln \alpha^{*}} \cdot\left(d \ln q+d \ln w_{t}\right)
$$

The proposition shows that a skewed decline in capital prices can generate an aggregate labor share decline accompanied by rising labor shares for the median firm even if the induced elasticity of substitution $\eta^{*}$ is below 1 .

To understand the difference with Proposition 2, consider the effects of a general change in effective capital prices across tasks on the labor share.

Lower capital prices have two effects. On the one hand, the reduction in capital prices for tasks above $\alpha^{*}$ leads to the automation of additional tasks (or an increase in $\alpha^{*}$ ), which always reduces the labor share. On the other hand, the reduction in capital prices for tasks below $\alpha^{*}$ reduces the price of these tasks. This price effect lowers the share of these tasks in value added and raises the labor share.

A uniform decrease in the price of capital triggers both effects. As shown in Proposition 
2, the substitution effect dominates on aggregate and for firms that automate their tasks up to the new optimal level if and only if $\eta^{*}>1$. The price effect on the labor share is positive and dominates for incumbents that do not automate.

On the other hand, a skewed decline in capital prices for tasks above $\alpha^{*}$ only brings an automation effect, which lowers the aggregate labor share and the labor share of firms that automate their tasks up to the new optimal level. This is partly counteracted by a positive price effect generated by higher wages - the term $\left(1-\varepsilon^{\ell}\right) \cdot(1-\eta) \cdot d \ln w$ in the equation for $d \ln \varepsilon^{\ell}$ in Proposition 3, and which captures the fact that higher wages increase the price of tasks produced by labor, raising their share in value added. However, the proof of the proposition shows that this effect is second order and dominated by the automation effect. At the same time, smaller incumbents that do not automate additional tasks will see their labor shares increasing due to this positive price effect coming from higher wages.

Propositions 2 and 3 show that lower capital prices can drive the labor share decline independently of whether the elasticity of substitution is above or below 1 . Through the lens of a task model, we have one of two interpretations: (i) we have a uniform $q$ shock and $\eta^{*}>1$, as emphasized in Karabarbounis and Neiman (2013); Hubmer (2020) and in Proposition 2; or (ii) we have a skewed $q$ shock, as emphasized in Proposition 3. In this last case we could have $\eta^{*} \leq 1$, so that an econometrician exploiting variation in wages would estimate an elasticity of substitution below 1, as in Oberfield and Raval (2021). In both cases, the labor share of a typical firm can increase in response to $q$ shocks depending on the fixed cost of automating tasks.

In our quantitative exercise we consider different scenarios for $\eta^{*}$ and explore the combined effects of uniform and skewed $q$ shocks on the aggregate and firms' labor shares.

\subsection{Calibration and quantitative results}

This subsection shows that a calibrated version of our model reproduces the firm-level patterns in the US manufacturing sector in response to $q$ shocks of a magnitude that aligns with the available data on capital prices.

We take the economy in 1982 to be in steady state with all firms having the same level of automation $\alpha_{0}$. We calibrate the parameters of our model to match key moments of the US manufacturing sectors in the 1982 steady state and explore the implications of a reduction in effective capital prices from 1982 to 2012. This timing is motivated by the fact that the decline of the manufacturing labor share of value added starts in 1982, after 
being constant in the decades preceding it. ${ }^{12}$

Calibration of initial steady state: As emphasized in the previous section, a combination of a uniform and a skewed $q$ shock can generate a decline in the manufacturing labor share even if $\eta^{*}$ - the elasticity of substitution - is less than or equal to one. To demonstrate this novel aspect of our model, we consider a parametrization with $\eta^{\star}=1$ as our baseline and report results for a calibration with $\eta^{*}>1$ at the end of this section. In particular, we normalize initial capital prices by task $q_{t}^{I}(x)$ to 1 and parametrize capital and labor productivity across tasks as:

$$
\phi(x)=x^{\frac{1-\gamma_{k}}{1-\eta}} \cdot(1-x)^{\frac{1+\gamma_{k}}{1-\eta}} \quad \psi(x)=A \cdot x^{\frac{1+\gamma_{\ell}}{1-\eta}} \cdot(1-x)^{\frac{1+\gamma_{\ell}}{1-\eta}}
$$

where $\gamma_{k}, \gamma_{\ell}>0$ control the strength of the comparative advantage of labor at higher indexed tasks. With this specification, the production function of a firm $f$ that automates all tasks up to $\alpha_{f}$ and rents $k_{f}$ units of capital and $\ell_{f}$ units of labor becomes

$$
y_{f}=z_{f} \cdot\left(\gamma_{k}^{-\frac{1}{\eta}} \cdot\left(\frac{\alpha_{f}}{1-\alpha_{f}}\right)^{\frac{\gamma_{k}}{\eta}} \cdot k_{f}^{\frac{\eta-1}{\eta}}+\gamma_{\ell}^{-\frac{1}{\eta}} \cdot\left(\frac{\alpha_{f}}{1-\alpha_{f}}\right)^{-\frac{\gamma_{\ell}}{\eta}} \cdot\left(A \cdot \ell_{f}\right)^{\frac{\eta-1}{\eta}}\right)^{\frac{\eta}{\eta-1}}
$$

Maximizing (3) with respect to $\alpha$ yields the optimal production function

$$
y_{f}^{*}=z_{f} \cdot \mathcal{A} \cdot k_{f}^{\frac{\gamma_{\ell}}{\gamma_{k}+\gamma_{\ell}}} \cdot \ell_{f}^{\frac{\gamma_{k}}{\gamma_{k}+\gamma_{\ell}}}
$$

where $\mathcal{A}$ is a constant. This shows that, in the initial steady, the induced elasticity of substitution equals 1 and all firms operate a Cobb-Douglas production function with share parameters $\gamma_{\ell} /\left(\gamma_{k}+\gamma_{\ell}\right)$ and $\gamma_{k} /\left(\gamma_{k}+\gamma_{\ell}\right)$ for capital and labor, respectively. ${ }^{13}$

We pick the constant $\mathcal{A}$ to normalize baseline wages in the 1982 steady state to 1 . We set $\eta=0.5$ to match the estimate of the task-level elasticity of substitution in Humlum (2019). Initial factor shares depend only on $\gamma_{\ell} / \gamma_{k}$, and so we normalize $\gamma_{k}=1$ and set $\gamma_{\ell}=0.3$ to match an initial labor share in manufacturing of $67 \%$. This parametrization is

\footnotetext{
${ }^{12}$ Appendix A.7 shows that this is also the case for most economic sectors. After having labor shares that were stable for the 1947-1982 period, some sectors experienced a decline in their labor share of value added after this period. Available measures of capital prices also point to a more rapid decline starting in the early 80s (see, for example, Cummins and Violante, 2002; Hubmer, 2020). Moreover, as shown in Section 1, firms of different sizes in the same industry had similar capital intensities before 1980, which suggests that they had a similar level of automation $\alpha_{0}$.

${ }^{13}$ Equation (3) also relates task models to Putty-Clay and production technique models a-la Caselli and Coleman (2006). In Putty-Clay models one can think of vintages of capital indexed by $\alpha$ as having different labor requirements captured by the CES shares in (3). In models a-la Caselli and Coleman (2006), one can think of $\alpha$ as indexing the choice over different production techniques.
} 
consistent with papers that estimate elasticities of substitution between capital and labor below 1. For example, exploiting differences in wages across regions, Oberfield and Raval (2021) estimate elasticities of substitution in the $0.5-1$ range. In our model, these estimates should lie between $\eta$ - for firms that have not adjusted their $\alpha_{f}$ 's - and 1 - for firms that set $\alpha_{f}$ optimally in response to wage changes.

TABLE 1: Calibration of the CES demand model for manufacturing

\begin{tabular}{|c|c|c|c|c|c|}
\hline & PARAMETER & & Moment & DATA & MODEL \\
\hline & \multicolumn{5}{|c|}{ I. Parameters related to the production function } \\
\hline$\eta$ & $\begin{array}{l}\text { Task substitution } \\
\text { elasticity }\end{array}$ & 0.5 & From Humlum (2019) & 0.5 & 0.5 \\
\hline \multirow[t]{2}{*}{$\gamma_{\ell}$} & Comparative advantage & 0.30 & $\begin{array}{l}\text { Manufacturing labor share } \\
\text { (BLS/BEA) }\end{array}$ & 0.67 & 0.67 \\
\hline & \multicolumn{5}{|c|}{ II. Parameters governing firm dynamics and productivities } \\
\hline$\sigma$ & Demand elasticity & 7.67 & $\begin{array}{l}\text { Aggregate markup from } \\
\text { Barkai }(2020)\end{array}$ & 1.15 & 1.15 \\
\hline$\underline{\mathrm{c}}_{o}$ & Scale operating cost & $4.0 \cdot 10^{-7}$ & $\begin{array}{l}\text { Entry (=exit) rate from } \\
\text { Lee and Mukoyama }(2015)\end{array}$ & 0.062 & 0.063 \\
\hline$\xi_{o}$ & Tail index operating cost & 0.250 & $\begin{array}{l}\text { Relative exiter size from } \\
\text { Lee and Mukoyama (2015) }\end{array}$ & 0.490 & 0.490 \\
\hline$\mu_{e}$ & Entrant productivity & 0.905 & $\begin{array}{l}\text { Relative entrant size from } \\
\text { Lee and Mukoyama (2015) }\end{array}$ & 0.600 & 0.600 \\
\hline$\sigma_{z}$ & $\begin{array}{l}\text { Std. dev. of } \ln z \\
\text { innovations }\end{array}$ & 0.105 & $\begin{array}{l}\text { Top } 4 \text { firms' sales share in } \\
1982 \text { from Autor et al. } \\
\text { (2020) }\end{array}$ & $40.0 \%$ & $40.0 \%$ \\
\hline$\rho_{z}$ & Productivity persistence & 0.95 & $\begin{array}{l}\text { Revenue TFP persistence } \\
\text { among manufacturing firms } \\
\text { (see Section 1) }\end{array}$ & & \\
\hline
\end{tabular}

Notes: The annual entry rate, as well as relative sizes of entrants and exiters, are from Lee and Mukoyama (2015) and based on the Annual Survey of Manufactures. The model equivalent to the top 4 firms' sales share refers to the top $1.1 \%$ of firms, since there are on average 364 firms per 4-digit industry in the manufacturing sector as reported in Autor et al. (2020). The parameters in Panel II are jointly calibrated to match the corresponding moments.

We calibrate the demand system, the productivity process, and operating costs to match moments from the US manufacturing sector in 1982. Panel II of Table 1 lists the calibrated parameters and moments targeted. We set the demand elasticity to $\sigma=7.67$, which generates a common markup of 1.15. Turning to the process for productivities and firm dynamics, we assume that firm productivity follows an AR1 process in logs:

$$
\ln z_{t+1, f}=\rho_{z} \cdot \ln z_{t, f}+\varepsilon_{t+1, f}
$$

where $\rho_{z} \in(0,1), \varepsilon_{t+1, f} \sim N\left(\mu_{z}, \sigma_{z}\right)$, and $\mu_{z}=-\frac{\left(1-\rho_{z}\right) \cdot \sigma_{z}^{2}}{2 \cdot\left(1-\rho_{z}^{2}\right)}$ so that the long-run mean of $z_{t f}$ is normalized to one. We pick the dispersion of firm productivity to match the share of sales among the top 4 firms within 4-digit manufacturing industries reported by Autor et al. (2020), which corresponds to the top $1.1 \%$ of firms in each industry (based on the number 
of firms per industry reported by Autor et al.). We calibrate the fixed cost of operation and entry (as well as their dispersion) to match entry rates, exit rates, and the relative size of exiters and entrants reported in Lee and Mukoyama (2015) for US manufacturing. ${ }^{14}$ Finally, we set the persistence of productivity $\rho_{z}$ to 0.95 , which we obtained from our estimates for the persistence of revenue TFP for manufacturing firms from the production function estimates in Section 1. This aligns with estimates using US Census data in Foster, Haltiwanger and Syverson (2008).

Decline in the price of capital and fixed cost of automation: We study the effects of a decline in capital prices given by a combination of uniform and skewed $q$ shocks. This captures the possibility that capital prices did not decline uniformly at all tasks, but the decline could have been more pronounced at tasks assigned to labor. We model these as advances in the productivity of the investment sector, $q_{I, t}(x)$, which vary across tasks:

$$
q_{I, t}(x)= \begin{cases}q_{u, t} & \text { if } x \leq \alpha_{0}^{*} \\ q_{u, t} \cdot \min \left\{\psi(x) / \phi(x), q_{s, t}\right\} & \text { if } x>\alpha_{0}^{*}\end{cases}
$$

The term $q_{u, t}$ captures the uniform component of the $q$ shock and $q_{s, t}$ captures the skewed component. The formulation of the skewed component mimics a sequence of small skewed shocks as the one considered in Proposition 3. $q_{u, t}$ and $q_{s, t}$ increase log-linearly from a level of 1 in 1982 to new steady state levels $\bar{q}_{u}$ and $\bar{q}_{s}$ in 2012, with $d \ln q_{u}=\ln \bar{q}_{u}>0$ and $d \ln q_{s}=\ln \bar{q}_{s}>0$ summarizing these improvements in investment technologies. ${ }^{15}$

To discipline the extent of technological progress in the production of capital goods, captured by $d \ln q_{u}$ and $d \ln q_{s}$, we use data on investment-good prices from the BEA and adjust it for quality improvements using the methodology of Cummins and Violante (2002), extended to recent years by DiCecio (2009). ${ }^{16}$ This approach yields an average price decline for capital goods used in the manufacturing sector of 108 log points.

\footnotetext{
${ }^{14}$ Following Clementi and Palazzo (2016), we impose a Pareto distribution for the operating and entry cost with scale parameter $\underline{\mathrm{c}}_{o}$ and tail coefficient $\xi_{o}$ to match the frequency and relative size of exiters. We also match the relative size of entrants by modeling the entrant distribution as a log-normal that differs from the long-run distribution of $z$ only insofar as it has a lower mean $\mu_{e}<1$.

${ }^{15}$ Appendix A.4 shows that the induced elasticity of substitution $\eta^{*}$ is below 1 in the new steady state.

${ }^{16}$ Cummins and Violante (2002) estimate a statistical model explaining Gordon (1990)'s price indices as a function of those by the BEA/NIPA, their lags, and time trends. They then extrapolate this model to produce quality-adjusted price indices for 1947-2000. DiCecio (2009) follows the same procedure and updates this series until 2012 (for equipment and software). We use the estimates from DiCecio (2009) to compute a quality adjustment for equipment and software of $2.6 \%$ per year for 1980-2011. We then compute the decline in investment-good prices for manufacturing using a user-cost weighted Törnqvist index of the prices for equipment and software (quality adjusted) and for structures using data from the BEA Fixed Asset Tables. We also account for changes in effective capital taxes using the data from Acemoglu, Manera and Restrepo (2020). Appendix A.7 provides the details of our measurement exercise.
} 
We calibrate $d \ln q_{u}$ and $d \ln q_{s}$ to match: i. the average decline in quality-adjusted capital prices in manufacturing of 108 log points; and ii. the 20 pp decline in the manufacturing labor share observed from 1982 to 2012. Intuitively, a larger labor share decline requires a $q$ shock that loads more on the skewed component $d \ln q_{s}$. On the other hand, a large drop in capital prices that is not associated with a large labor share decline signals a uniform $q$ shock. ${ }^{17}$ Our procedure ensures that the total amount of technological improvements in capital are consistent with the observed decline in capital prices, and then shows that one can match the labor share decline via a combination of a skewed and uniform $q$ shocks.

In addition, we calibrate the fixed cost of automating tasks required to match the uneven adoption of automation technologies in the ABS. By the end of our sample, firms in the top percentile of the employment distribution were 1.71 times more likely to have adopted new automation technologies than firms between the 50th and 75th percentile (see Acemoglu et al., 2021). We calibrate $c_{a}$ so that

$$
\frac{\mathbb{E}\left[\Delta \alpha_{t f} \mid \text { firm } f \text { in employment } \mathrm{P} 99+\right]}{\mathbb{E}\left[\Delta \alpha_{t f} \mid \text { firm } f \text { in employment } \mathrm{P} 50-75\right]}=1.71
$$

where we take the increase in $\alpha_{t f}$ relative to the 1982 steady state as a measure of the adoption of new automation technologies.

Panel I in Table 2 reports our calibrated shocks and fixed cost of automation. A decrease in effective capital prices of $d \ln q_{u}=0.67$ at infra-marginal tasks and a greater decrease of $d \ln q_{s}=4.81$ at marginal tasks between 1982 and 2012 match $\mathrm{i}$ and ii. In our calibration, most of the decline in capital prices in manufacturing occurs at marginal tasks, explaining the large drop in the labor share of this sector. This finding is in line with evidence pointing to the pervasive use of capital-intensive technologies for automation in manufacturing, which in our model corresponds to the use of capital in a widening range of tasks previously performed by labor. ${ }^{18}$

The fixed cost of automation of 0.19 required to match the adoption rates in the ABS data is of a reasonable magnitude. This fixed cost can be thought of as an investment in $R \& D$ required to design and integrate automation equipment or software. In response to lower capital prices, aggregate spending on automation fixed costs as a share of manufac-

\footnotetext{
${ }^{17}$ Observed price series for capital are informative of average advancements in capital but not of the skewness of the $q$ shock: they do not tell us whether these advances are uniform, take place at inframarginal tasks below $\alpha_{0}^{*}$, or concentrate in tasks that were previously assigned to labor. This precludes a direct measurement of $d \ln q_{u}$ and $d \ln q_{s}$.

${ }^{18}$ For example, Acemoglu and Restrepo (2020) provide evidence of the use of industrial robots in manufacturing for automation and document that their use was associated with a declining labor share. Zolas et al. (2020) provide survey evidence showing that $52 \%$ of US manufacturing workers are employed at firms using advanced technologies for automation; while this share is $28.3 \%$ outside of manufacturing.
} 
TABLE 2: Transitional dynamics and decomposition of the manufacturing labor share using the CES demand system (1982-2012)

\begin{tabular}{|c|c|c|c|c|c|}
\hline & \multirow[b]{2}{*}{$\begin{array}{l}\text { DATA } \\
(1)\end{array}$} & \multicolumn{3}{|c|}{ MODEL } & \multirow[b]{2}{*}{$\begin{array}{r}\text { INDUCED } \\
\text { ELASTICITY } \\
\eta^{*}=1.45 \\
(5)\end{array}$} \\
\hline & & $\begin{array}{r}\text { BASELINE CES } \\
\text { MODEL } \\
(2) \\
\end{array}$ & $\begin{array}{r}\text { No } \\
\text { AUTOMATION } \\
\text { FIXED COST } \\
(3)\end{array}$ & $\begin{array}{r}\text { No } \\
\text { TECHNOLOGY } \\
\text { DIFFUSION } \\
(4) \\
\end{array}$ & \\
\hline & \multicolumn{5}{|c|}{ I. Parameters and inferred aggregate shocks } \\
\hline$d \ln q_{u}$ & & 0.67 & 0.67 & 0.67 & 0.86 \\
\hline$d \ln q_{s}$ & & 4.81 & 4.81 & 4.75 & 0.77 \\
\hline$c_{a}$ & & 0.19 & 0 & 0.09 & 0.32 \\
\hline \multicolumn{6}{|c|}{ II. Targeted moments, 1982-2012 } \\
\hline$\Delta$ aggregate labor share & -0.20 & -0.20 & -0.20 & -0.20 & -0.20 \\
\hline$\Delta \log$ average capital price & -1.08 & -1.08 & -1.10 & -1.08 & -1.09 \\
\hline Relative adoption & 1.71 & 1.71 & 1.00 & 1.69 & 1.70 \\
\hline \multicolumn{6}{|c|}{ III. Concentration, 1982-2012 } \\
\hline$\Delta \log 4$ firms' sales share & 0.140 & 0.105 & -0.022 & 0.059 & 0.055 \\
\hline$\Delta \log 20$ firms' sales share & 0.072 & 0.104 & -0.017 & 0.062 & 0.054 \\
\hline$\Delta \log$ productivity dispersion & 0.050 & 0.061 & -0.001 & 0.085 & 0.041 \\
\hline \multicolumn{6}{|c|}{ IV. Typical firm labor share from Kehrig and Vincent (2020), 1982-2012 } \\
\hline$\Delta$ median labor share & 0.030 & -0.005 & -0.202 & 0.085 & -0.042 \\
\hline$\Delta$ unweighted mean & -0.017 & -0.039 & -0.203 & -0.026 & -0.055 \\
\hline \multicolumn{6}{|c|}{ V. Melitz-Polanec decomposition from Autor et al. (2020) } \\
\hline$\Delta$ aggregate labor share & -0.185 & -0.198 & -0.202 & -0.198 & -0.202 \\
\hline$\Delta$ unweighted incumbent mean & -0.002 & -0.015 & -0.202 & -0.062 & -0.029 \\
\hline Exit & -0.055 & -0.006 & 0.000 & -0.003 & -0.004 \\
\hline Entry & 0.059 & 0.006 & 0.000 & 0.004 & 0.006 \\
\hline Covariance term & -0.187 & -0.183 & 0.000 & -0.138 & -0.174 \\
\hline \multicolumn{6}{|c|}{ VI. Covariance decomposition from Kehrig and Vincent (2020) } \\
\hline Market share dynamics & 0.047 & 0 & 0 & 0 & 0 \\
\hline Labor share by size dynamics & -0.043 & -0.134 & -0.202 & -0.155 & -0.123 \\
\hline Cross-cross dynamics & -0.232 & -0.066 & 0 & -0.044 & -0.083 \\
\hline
\end{tabular}

Notes: Column (2) reports the findings from our benchmark model, which calibrates the capital price $\operatorname{shocks} d \ln q_{s}$ and $d \ln q_{u}$ (log-linear over 1982-2012) as well as the automation fixed cost to replicate (i) the change in the aggregate labor share, (ii) the decline in the average price of capital (BEA Fixed Asset Tables and our calculations), and (iii) the relative adoption of automation technologies by firm size (from Acemoglu et al., 2021). Column (3) displays a counterfactual economy with no fixed cost of automation. Column (4) displays a re-calibrated economy with no diffusion through entry. Column (5) features a calibration with an induced elasticity of substitution above one $\left(\eta^{*}=1.45\right)$. The change in industry concentration in Panel III is from Autor et al. (2020, Table 1) and refers to the average change 1982-2012 across 4-digit manufacturing industries. The model equivalent is the top $1.1 \%$, respectively top $5.5 \%$, firm sales share. The change in the standard deviation of log productivity (log unit cost) is from Decker et al. (2020, Figure 3a), and computed analogously as the difference between the 2000s and 1980s. Panel V reproduces the Melitz-Polanec decomposition from Autor et al. (2020, Table 4 Panel B), reported as the sum of consecutive 5-year changes 1982-2012. Panel VI reproduces the covariance decomposition from Kehrig and Vincent (2020, Figure 5), conducted for a balanced sample of firms and one long change 1982-2012.

turing output reaches a peak of $1.9 \%$ by 2005. This amounts to less than one fifth of total R\&D expenditure in manufacturing during this period, which is reassuring since not all $\mathrm{R} \& \mathrm{D}$ expenditure in practice is linked to automation.

Lower capital prices and concentration: Our model generates $75-144 \%$ of the observed increase in sales concentration in manufacturing over 1982-2012 and all of the ob- 
served increase in productivity dispersion in response to the calibrated $q$ shocks. As shown in Panel III of Table 2, by 2012, the uneven adoption of automation technologies by the most productive firms leads to a $10.5 \log$ points $(4.4 \mathrm{pp})$ increase in the share of sales among the top $1.1 \%$ firms, and a $10.4 \log$ points $(7.6 \mathrm{pp})$ increase in the share of sales among the top $5.5 \%$ firms in manufacturing. ${ }^{19}$ Empirically, Autor et al. (2020) document increases of $14 \log$ points for the share of sales by the top 4 firms in each manufacturing industry (corresponding to the top $1.1 \%$ in our model) and $7.2 \mathrm{log}$ points for the share of sales by the top 20 firms (the top 5.5\% in our model). ${ }^{20}$ The model also generates an increase in the dispersion of total factor productivity across firms of 6.1 log points over 1980-2000, which matches the 5 log points increase estimated by Decker et al. (2020) using Census data for the US manufacturing sector for this period.

Lower capital prices and firms' labor shares: Column 2 of Panel IV show that our model matches the decline in the manufacturing labor share at the same time as the median labor share remains unchanged and the unweighted mean labor share among manufacturing firms decreases by $3.9 \mathrm{pp}$ - comparable to the data, where it decreased by $1.7 \mathrm{pp}$.

To illustrate this point, Figure 4 depicts the evolution of the labor share across the distribution of firm productivity $z_{t f}$. The lines trace the average labor share for firms at each percentile of the distribution at various points in time. In 1982, all firms have the same labor share independently of their size, since all operate technologies with the same level of automation. As capital prices decline, we see a clockwise rotation of this curve, with the labor share rising at the middle and the bottom of the firm-productivity distribution, but decreasing at the top, in line with Proposition 2.

This clockwise rotation in labor shares at the top coincides with the counter-clockwise increase in output-to-capital elasticities documented for Compustat firms in Section 1. Our model generates an increase in the output-to-capital elasticity for large firms in manufacturing of 20 pp, in line with the 20 pp increase estimated in Compustat.

Our model also generates the firm-level labor share patterns documented by Autor et al. (2020) and Kehrig and Vincent (2020). Autor et al. decompose the decline in the

\footnotetext{
${ }^{19}$ Because of the assumed diffusion of automation technologies, these trends eventually revert over time. Without diffusion, the divergence in labor shares and the increase in sales dispersion are permanent.

${ }^{20}$ The model also generates a larger increase in sales than in employment concentration, which aligns with the manufacturing data, since growing firms automate tasks and rely on capital more intensively.
} 


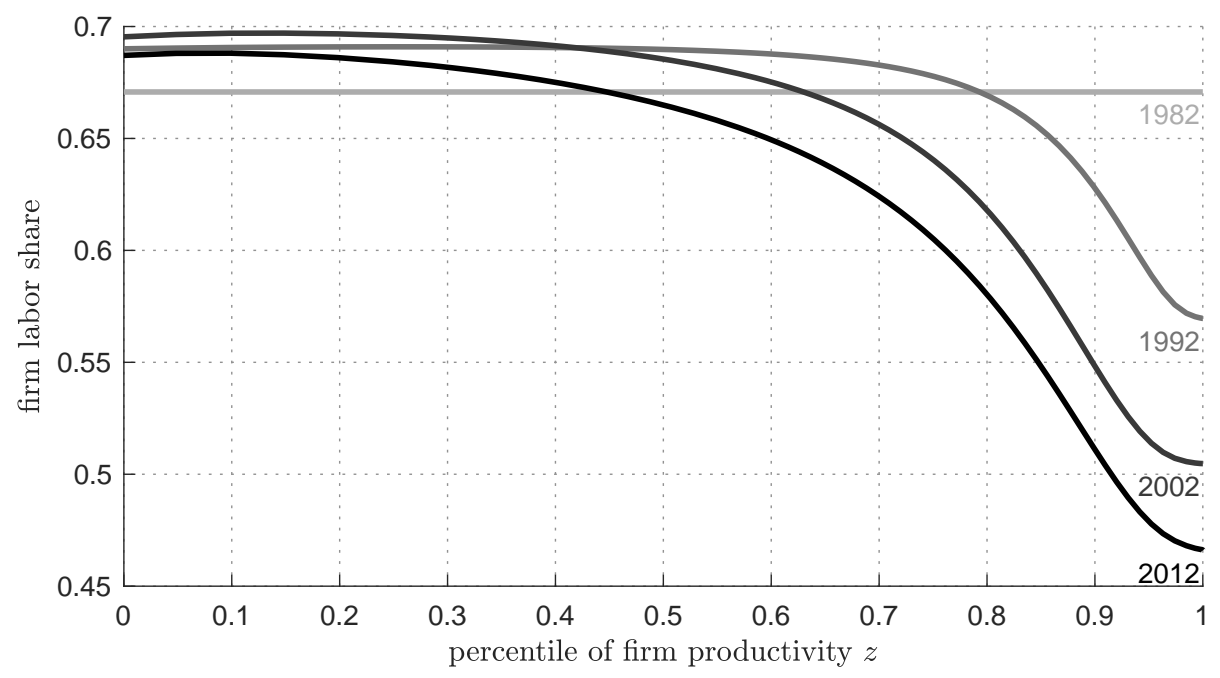

Figure 4: Cross-Sectional labor Shares over the transition. Firm labor shares in value added by firm productivity $z_{t f}$ from the benchmark model with CES demand.

manufacturing labor share using a Melitz-Polanec decomposition:

$$
\begin{aligned}
\Delta s_{t}^{\ell} & =\Delta \bar{s}_{t}^{\ell} & & \text { (Change in unweighted incumbents' mean }) \\
& +\omega_{t X} \cdot\left(s_{t S}^{\ell}-s_{t X}^{\ell}\right)+\omega_{t^{\prime} E} \cdot\left(s_{t^{\prime} E}^{\ell}-s_{t^{\prime} S}^{\ell}\right) & & \text { Contribution of exit and entry) } \\
& +\Delta \sum_{f}\left(\omega_{t f}-\bar{\omega}_{t}\right) \cdot\left(s_{t f}^{\ell}-\bar{s}_{t}^{\ell}\right) & & \text { (Change in covariance). }
\end{aligned}
$$

Here, $\Delta s_{t}^{\ell}$ denotes the change in the manufacturing labor share between two periods, $t$ and $t^{\prime}$, corresponding to five-year periods. This can be decomposed into the change in the unweighted mean of labor shares among continuing firms, $\Delta \bar{s}_{t}^{\ell}$; two terms accounting for the contributions of exit and entry; and the change in the covariance among continuing firms between their share of value added, $\omega_{t f}$, and their labor share, $s_{t f}^{\ell} \cdot{ }^{21}$

We conduct the same decomposition in our model for 5-year differences spanning the 1982-2012 period. Panel V in Table 2 reproduces Autor et al.'s manufacturing data and reports the decomposition from our model. In data and model, the covariance term fully accounts for the aggregate decline in the labor share, with exit and entry and the change in the unweighted mean of incumbents' labor shares playing minor roles. ${ }^{22}$

\footnotetext{
${ }^{21}$ The contribution of exit is given by the baseline share of exiting firms in value added, $\omega_{t X}$, multiplied by the difference in the average labor share of continuing firms, $s_{t S}^{\ell}$, and firms that exit, $s_{t X}^{\ell}$. The contribution of entry is given by their share of value added in the end period, $\omega_{t^{\prime} E}$, multiplied by the difference in the average labor share of firms that enter, $s_{t^{\prime} E}^{\ell}$, and continuing firms, $s_{t^{\prime} S}^{\ell}$.

${ }^{22}$ Exit and entry exhibit the same qualitative patterns as in the data, with both entering and exiting firms having labor shares that are higher than those of incumbents. However, these differences are not as pronounced as in the data, where many entering or exiting firms have labor shares that exceed 1 , reflecting other elements of the life cycle of firms that are not in our model.
} 
Kehrig and Vincent show that the covariance term can be further decomposed into three terms capturing the joint dynamics of firms' labor shares and sales:

$$
\begin{array}{rlrl}
\Delta \sum_{f}\left(\omega_{t f}-\bar{\omega}_{t}\right) \cdot\left(s_{t f}^{\ell}-\bar{s}_{t}^{\ell}\right) & =\sum_{f} \Delta\left(\omega_{t f}-\bar{\omega}_{t}\right) \cdot\left(s_{t f}^{\ell}-\bar{s}_{t}^{\ell}\right) & & \text { (market share dynamics) } \\
& +\sum_{f}\left(\omega_{t f}-\bar{\omega}_{t}\right) \cdot \Delta\left(s_{t f}^{\ell}-\bar{s}_{t}^{\ell}\right) \quad & \text { (labor share by size dynamics) } \\
& +\sum_{f} \Delta\left(\omega_{t f}-\bar{\omega}_{t}\right) \cdot \Delta\left(s_{t f}^{\ell}-\bar{s}_{t}^{\ell}\right) & \text { (cross-cross dynamics). }
\end{array}
$$

A decrease in the covariance can be driven by a reallocation of value added towards firms with lower labor shares at baseline (the "market share dynamics" term); a more pronounced reduction in the labor share of large firms (the "labor share by size dynamics" term); or the possibility that firms that reduce their labor shares expand at the same time (the "cross-cross dynamics" term). Using a balanced sample of firms for 1982-2012, Kehrig and Vincent document that the cross-cross dynamics contributed -23.2 pp to the decline in the manufacturing labor share, the labor share dynamics by size account for a 4.3 pp decline, and the market share dynamics increased the manufacturing labor share by $4.7 \mathrm{pp}$.

Panel VI in Table 2 compares the contributions of these components in data and model. ${ }^{23}$ In our CES model, the labor share dynamics by size contributed a 13.4 pp decline to the labor share, and the cross-cross dynamics contributed a $6.6 \mathrm{pp}$ decline to the labor share (by construction, the market share dynamics is zero since all firms had the same labor shares in the 1982 steady state). The reason why the cross-cross dynamics contribute to the decline of the labor share in our model is that firms automate tasks following high productivity draws. Because these firms simultaneously gain market share and reduce their labor shares, this shows up as part of the covariance term in the Melitz-Polanec decomposition in Autor et al. and as part of the cross-cross term in the decomposition in Kehrig and Vincent. Although our model with CES demand and constant markups matches the covariance decomposition qualitatively, it does not generate the large cross-cross term seen in the data. Our model with endogenous markups in the next section solves this shortcoming and generates cross-cross dynamics comparable to the data.

Additional specifications: Columns 3-5 in Table 2 report variants of our calibration.

Column 3 summarizes the transitional dynamics of our model in response to the calibrated $q$ shocks but now assuming that firms faced no fixed costs of automating additional

\footnotetext{
${ }^{23}$ We compute the model moments in this panel exactly as in Kehrig and Vincent (2020), reporting the cumulative change over 30 years in a balanced sample. Therefore, both in model and data, the three terms in Panel V do not exactly add up to the covariance term in Panel IV.
} 
tasks. The aggregate labor share evolves similarly in this counterfactual economy, but the firm-level behavior of labor shares and sales concentration are at odds with the data. The comparison between Columns 2 and 3 shows that a small fixed cost of automating tasks is needed to make sense of the manufacturing firm-level data.

Column 4 shuts down the diffusion of automation technologies through entry (so that entrants start with the same level of automation as in the initial steady state) and recalibrates the $q$ shocks and the fixed cost of task automation required to match the labor share, capital price and technology adoption data. Diffusion is not crucial for our findings for the 1982-2012 period, but it facilitates characterizing the steady state of our model.

Column 5 explores the implications of using a calibration with an induced elasticity of substitution above 1. Our model can also match the facts if one adopts a parametrization with an induced elasticity of substitution of $\eta^{*}=1.45$, as estimated by (see Karabarbounis and Neiman, 2013; Hubmer, 2020). ${ }^{24}$ Appendix A.4 provides the details of this parametrization. As expected, the $q$ shock required to explain the data is more uniform and less skewed, since the uniform shock now generates a large reduction in the labor share by itself. This calibration also matches the aggregate and firm-level labor share patterns seen in the manufacturing data, though it generates a somewhat larger decline in the median and unweighted mean of the labor share. ${ }^{25}$

Taking stock: Our approach assumes that the decline in the manufacturing labor share is driven by $q$ shocks, and infers the extent and nature of this technical progress to match the manufacturing labor share behavior. Because of this, the results in this section are possibility results. They show that it is possible to have a coherent description of the manufacturing labor share decline driven by lower capital prices that: i. fits both the macro and micro patterns of the labor share decline; ii. is consistent with the available data on capital prices; and iii. does not require an elasticity of substitution between labor and capital greater than one. Our exercise also shows that a small fixed cost of automating tasks is necessary and sufficient to make sense of the manufacturing data, and explain most of the increase in sales concentration in the sector as a response to lower capital prices.

\footnotetext{
${ }^{24}$ Hubmer (2020) documents that a reduction of capital prices of $1 \%$ lowers the labor share by about $0.10 \%$. A reduction of capital prices by $d \ln q$ changes the labor share in costs by $\varepsilon^{k} \cdot\left(\eta^{*}-1\right) \cdot d \ln q$. When the average markup is 1.15 , we get $\varepsilon^{k}=0.23$, and the estimates in Hubmer (2020) imply $\eta^{*}=1.45$.

${ }^{25}$ The comparison between columns 2 and 5 in Table 2 (as well as the discussion of Propositions 2 and 3) reveal an important property of task models. In these models, the effect of lower capital prices on factor shares depends on the skewness of the shocks and not only on the elasticity of substitution $\eta^{*}$. Skewed shocks, which are more about automation than pure capital deepening, always lower the labor share. The elasticity of substitution is relevant for signing the effects of uniform $q$ shocks and changes in wages on the labor share, but is not helpful for signing the effects of skewed $q$ shocks (or automation shocks).
} 


\section{CAPITAL-LABOR SUBSTITUTION VS. RISING COMPETITION}

This section extends our model to allow for differences in firms' markups. This allows us to match the decline in the labor share and the rise in sales concentration and decompose them into a part driven by rising competition and another driven by capital-labor substitution.

\subsection{Model and theoretical properties}

Environment: We retain the production side of the model in section 2 and modify the demand system to allow for endogenous markups. We work with a model of monopolistic competition in which firms produce differentiated varieties and face a demand derived from a Kimball aggregator (Kimball, 1995). There is a mass 1 of customers indexed by $j$ whose flow utility $u_{t j}$ from consuming a set of varieties $\mathcal{F}_{t j}$ is defined implicitly by

$$
\int_{f \in \mathcal{F}_{t j}} H\left(\frac{y_{t f j}}{u_{t j}}\right) \cdot d f=1
$$

where $H$ is an increasing and concave function. ${ }^{26}$

Firms and customers are randomly matched to each other, with each customer matched to a mass $\lambda_{t}$ of firms. This implies that total demand for firm $f$ is

$$
y_{t f}=y_{t} \cdot \lambda_{t} \cdot D\left(\frac{p_{t f}}{\rho_{t}}\right)
$$

where $y_{t}$ denotes total expenditure in the economy. Here, $D$ is decreasing and given by the inverse function of $H^{\prime}(x)$, and $\rho_{t}$ is an endogenous summary measure of competitors' prices, which is common to all customers and is defined implicitly by

$$
\lambda_{t} \cdot \int_{f} H\left(D\left(\frac{p_{t f}}{\rho_{t}}\right)\right) \cdot d f=1
$$

Adding (4) up across firms we get $y_{t}=\int_{f} y_{t f} \cdot p_{t f} \cdot d f$, which implies that firm prices satisfy the ideal-price index condition

$$
1=\lambda_{t} \cdot \int_{f} p_{t f} \cdot D\left(\frac{p_{t f}}{\rho_{t}}\right) \cdot d f
$$

This section considers the effects of $q$ shocks and an exogenous increases in $\lambda_{t}$ - or $\lambda$

\footnotetext{
${ }^{26}$ Note that this general demand system nests the CES one used in the previous section. When $H(x)=$ $x^{1-1 / \sigma}$, we obtain the typical CES demand system. The demand function $D(p)$ is simply given by the $\log$-linear function $p^{-\sigma}$, the competitors price index is equal to 1 and equations (5) and (6) collapse to the ideal price index condition in the previous section.
} 
shocks. This captures an increase in market access: each firm now competes against more firms for each customer. For example, one might think of advances in online marketing and platforms as allowing each firm to reach a larger set of customers (see, for example, Akerman, Leuven and Mogstad, 2021). Or advances in IT allowing firms to enter into additional markets at a lower overhead cost, raising competition for customers in those markets (see, for example, Aghion et al., 2019; Hsieh and Rossi-Hansberg, 2019).

The effects of a $\lambda$ shock depend on the curvature of the demand function. We assume that demand satisfies Marshall's weak and strong second laws:27

(Weak second law)

(Strong second law) $-x \cdot D^{\prime}(x) / D(x)$ is greater than 1 and increasing in $\mathrm{x}$ $x+D(x) / D^{\prime}(x)$ is positive and log-concave

Marshall's weak second law requires that, as firms lower their prices, their demand becomes more inelastic. This implies that firms with lower costs $c_{t f}$ charge lower prices $p_{t f}$ but higher markups $\mu_{t f}$. Thus, larger firms will have higher markups. The strong second law requires marginal revenue to be positive and log-concave. This ensures that markups and prices, $\mu_{t f}$ and $p_{t f}$, are a log-convex function of costs, which implies lower passthroughs for more productive firms. The strong second law also implies that firm sales are a log-concave and decreasing function of costs. ${ }^{28}$

Equilibrium: Given a path for effective capital prices $1 / q_{t}(x)$ and market access $\lambda_{t}$, and an initial distribution of firms, an equilibrium is defined as before. The difference is that now sales and profits depend on the demand curve $D$ in (4) and we also have to solve for the competitors' price index $\rho_{t}$ using (5) and for wages using the price condition in (6).

Effects of rising competition: We now derive the steady-state effects of an increase in market access. As in our baseline model, the equilibrium of the economy converges to a steady state where $\alpha_{t f}=\alpha^{*}$. Because of this, we only keep track of firms that differ in their productivity level $z$. Denote by $\mu_{z}$ the markup charged by a firm of productivity $z_{f}=z$, and by $\omega_{z}$ its sales share. Finally, let $m_{z}$ denote the mass of firms of productivity $z$.

\footnotetext{
${ }^{27}$ Throughout, we say that a function $y=f(x)$ is $\log$-concave if $\ln y$ is concave in $\ln x$.

${ }^{28}$ These assumptions receive support from the data (see Baqaee and Farhi, 2020a) and offer a tractable way of capturing pricing dynamics in oligopolistic competition models, where large firms endogenously face a more inelastic demand curve. More importantly, these assumptions ensure that more productive firms charge higher markups, and that an increase in competition will reallocate economic activity towards these high-markup firms. This is the key mechanism driving the decline of the labor share in theories that see rising competition as the main driving force behind it. For example, Autor et al. (2020) use this model to illustrate how competition can reduce the labor share, but do not explore its quantitative implications.
} 
Proposition 4 A permanent increase in $\lambda_{t}$ has the following effects in the steady state distribution of firm markups and sales:

- $\mu_{z}$ decreases for all $z$;

- for $z>z^{\prime}, \mu_{z} / \mu_{z^{\prime}}$ decreases;

- for $z>z^{\prime}, \omega_{z} / \omega_{z^{\prime}}$ increases.

Market access strengthens firms competition for workers to satisfy their new customers, which leads to higher real wages. This then pushes firms towards the more elastic segments of their demand curves and firms respond by reducing their markups (the weak second law). The reduction in markups is not uniform. Because large firms have smaller passthroughs (the strong second law), they respond via a modest increase in their prices (and a large reduction in their markup). Small firms respond via a more sizable increase in their prices (and a smaller reduction in their markups). As a result, the $\lambda$ shock reallocates economic activity and labor towards the largest and most productive firms in the industry.

These responses by firms generate an ambiguous contribution of markups to the aggregate labor share. Firms of a given productivity level reduce their markups, which contributes to an increase in the aggregate labor share. But the reallocation of economic activity from small firms with low markups to large firms with high markups contributes to a decline in the aggregate labor share.

Proposition 5 The aggregate labor share is $s^{\ell}=\varepsilon^{\ell} / \mu$, where the aggregate markup $\mu$ is a sales weighted harmonic mean of firm-level markups:

$$
\frac{1}{\mu}=\int_{z} \frac{1}{\mu_{z}} \cdot \omega_{z} \cdot m_{z} \cdot d z
$$

Holding the distribution of productivity $m_{z}$ constant, an increase in $\lambda$ increases the aggregate markup if the distribution of productivity is log-convex (i.e., more convex than Pareto), lowers it if the distribution of productivity is log-concave (i.e., less convex than Pareto), and leaves it unchanged if the distribution of productivity is log-linear (i.e., Pareto). ${ }^{29}$

The proposition shows that the effect of market access on the labor share via markups depend on the distribution of firm productivity. This insight is well known and recognized in the literature (see for instance Melitz and Ottaviano, 2008; Autor et al., 2020), and is relevant for understanding the effects of a market access shock on the labor share.

\footnotetext{
${ }^{29}$ We refer to a distribution as log-convex (log-concave) if its PDF is log-convex (log-concave).
} 


\subsection{Calibration for manufacturing and retail}

We now explore the transitional dynamics in response to rising market access and lower capital prices in a calibrated version of our model.

Manufacturing: We calibrate the model under the assumption that manufacturing firms were in steady state in 1982. We use the same parametrization of the production function and task productivities from the previous section, summarized in Panel I of Table 3.

Relative to the previous section, we make two modifications. First, following Edmond, Midrigan and $\mathrm{Xu}$ (2018), we parametrize $H$ using the specification from Klenow and Willis (2016), which implies that the demand elasticity faced by a firm with price $p_{t f}$ is

$$
\operatorname{demand} \operatorname{elasticity}\left(p_{t f}\right)=\sigma \cdot D\left(\frac{p_{t f}}{\rho_{t}}\right)^{-\frac{\nu}{\sigma}}
$$

This demand elasticity decreases as $p_{t f}$ falls, so that more productive firms face a more inelastic demand. ${ }^{30}$ Here, $\sigma$ controls the average demand elasticity faced by firms, and the super-elasticity $\nu / \sigma$ controls the extent to which markups rise for more productive firms. (If $\nu=0$, the demand system simplifies to the standard CES aggregator.)

Second, we adopt a new process for firm-level productivities $z_{t f}$. We can no longer assume a log-normal productivity distribution, since, under Marshall's second laws, sales are a log-concave function of costs (and hence productivity). Because the sales distribution is approximately Pareto, we need the productivity distribution to be more log-convex than Pareto to fit the data. To achieve this, we assume that productivity is determined by a latent factor $\tilde{z}_{t f}$ that follows an $\mathrm{AR}(1)$ process as before and that determines productivity as:

$$
z_{t f}=\exp \left(F_{W e i b u l l(n, \zeta)}^{-1}\left(\Phi\left(\tilde{z}_{t f}\right)\right)\right), \quad \text { where } \quad \tilde{z}_{t+1, f}=\rho_{z} \cdot \tilde{z}_{t f}+\varepsilon_{t f}
$$

Here, $\Phi$ denotes the Gaussian cdf, and $F_{W e i b u l l(n, \zeta)}^{-1}$ the inverse CDF of a Weibull random variable with shape parameter $n>0$ and scale parameter $\zeta>0$. The innovations are drawn from $\varepsilon_{t f} \sim N\left(\mu_{z}, \sigma_{z}\right)$, where $\mu_{z}$ and $\sigma_{z}$ are normalized so that the long-run distribution of $\tilde{z}_{t f}$ is a standard normal. This implies that $\ln z_{t f}$ follows a Weibull distribution with CDF

$$
F_{W e i b u l l(n, \zeta)}(x)=1-e^{-\left(\frac{x}{\zeta}\right)^{n}}
$$

\footnotetext{
${ }^{30}$ The full specification for $H$ and the derivation of equation (7) are provided in Appendix A.3.
} 
The Weibull distribution generalizes the exponential distribution by introducing the shape parameter $n$, which controls the log-convexity of the distribution. When $n=1$, the density of $\ln z_{t f}$ is log-linear, or equivalently, the limit distribution for $z_{t f}$ is Pareto with tail index $\zeta$. For $n<1$, the density of $\ln z_{t f}$ is log-convex, or equivalently, the distribution for $z_{t f}$ is more log-convex than Pareto. As shown in Proposition 5, $n$ is the key parameter determining the net effect of rising competition on an industry labor share.

We jointly calibrate the parameters governing markups $\{\sigma, \nu\}$ and the firm productivity distribution $\{\zeta, n\}$ to match the average manufacturing markup, the ratio of the (unweighted) mean firm labor share to the aggregate labor share, and the share of sales among the top 4 and top 20 firms in manufacturing in 1982. These parameters are jointly calibrated with the fixed cost of operation and its dispersion as well as with mean entrant productivity to match the same moments from Lee and Mukoyama (2015) used above, and after setting $\rho_{z}=0.95 .^{31}$ Panel II in Table 3 summarizes the parameters and moments informing their calibration.

TABLE 3: Steady state calibration of the non-CES demand model: Manufacturing

\begin{tabular}{|c|c|c|c|c|c|}
\hline & PARAMETER & & MOMENT & DATA & MODEL \\
\hline & \multicolumn{5}{|c|}{ I. Parameters related to production function } \\
\hline$\eta$ & $\begin{array}{l}\text { Task substitution } \\
\text { elasticity }\end{array}$ & 0.5 & From Humlum (2019) & 0.5 & 0.5 \\
\hline \multirow[t]{2}{*}{$\gamma_{\ell}$} & Comparative advantage & 0.30 & $\begin{array}{l}\text { Manufacturing labor share } \\
\text { (BLS/BEA) }\end{array}$ & 0.67 & 0.67 \\
\hline & \multicolumn{5}{|c|}{ II. Parameters governing firm dynamics and productivities in 1982 steady state } \\
\hline$\nu / \sigma$ & Demand super-elasticity & 0.22 & $\begin{array}{l}\text { Ratio of mean firm to } \\
\text { aggregate labor share }\end{array}$ & 1.10 & 1.09 \\
\hline$\sigma$ & Demand elasticity & 6.00 & Aggregate markup & 1.15 & 1.15 \\
\hline$\zeta$ & Weibull scale & 0.077 & Top 20 firms' sales share & $69.7 \%$ & $69.9 \%$ \\
\hline$n$ & Weibull shape & 0.74 & Top 4 firms' sales share & $40.0 \%$ & $40.0 \%$ \\
\hline$\underline{\mathrm{c}}_{o}$ & Scale operating cost & $2 \cdot 10^{-7}$ & Entry (=exit) rate & 0.062 & 0.062 \\
\hline$\overline{\xi_{o}}$ & Tail index operating cost & 0.24 & Size of exiters & 0.490 & 0.485 \\
\hline$\mu_{e}$ & Entrant productivity & 0.882 & Size of entrants & 0.600 & 0.600 \\
\hline$\rho_{z}$ & Productivity persistence & 0.95 & $\begin{array}{l}\text { Revenue TFP persistence } \\
\text { among manufacturing firms }\end{array}$ & & \\
\hline
\end{tabular}

Notes: The ratio of the (unweighted) mean firm labor share to the aggregate manufacturing labor share is computed based on the replication data from Kehrig and Vincent (2020). The two concentration measures are from Autor et al. (2020) and correspond to the manufacturing sector in 1982 . The model equivalents refer to the top $1.1 \%$ and top $5.5 \%$ of firms ranked by sales (since there are on average 364 firms per 4-digit manufacturing industry). The remaining data moments follow the model with CES demand, see Table 1. Fixing productivity persistence, the remaining seven parameters in Panel II are jointly calibrated to match the seven corresponding moments.

We calibrate $\sigma=6.0$ to match an aggregate markup of 1.15 and a super-elasticity $\nu / \sigma$

\footnotetext{
${ }^{31}$ As before, we assume that entrants draw an initial latent factor $\tilde{z}_{t f}$ from a normal distribution that differs from the long-run distribution of $\tilde{z}$ only insofar as its mean is shifted to the left by $\ln \mu_{e}<0$, which we calibrate to match the relative size of entrants in the data.
} 
of 0.22 to match a 1.1 ratio between the unweighted average of the labor share among manufacturing firms and the aggregate manufacturing labor share before 1982 from Kehrig and Vincent (2020). Our calibration attributes all the differences in labor shares by firm size in the 1982 steady state to markups and sets $\nu / \sigma$ to match these differences. The log-concave demand system implies that smaller firms have lower markups; therefore, the unweighted mean labor share across manufacturing firms will exceed the aggregate labor share of the sector by a factor that increases in the super-elasticity of demand. A superelasticity of zero yields a ratio of 1 , while a higher super-elasticity of 0.22 matches the ratio of 1.1 in the data. ${ }^{32}$

For the productivity distribution, we calibrate $\{\zeta, n\}$ to match the share of sales by the top 4 firms and the top 20 firms within manufacturing industries in 1982, which roughly corresponds to the top $1.1 \%$ and top $5.5 \%$ share of firms in the sales distribution. Intuitively, a higher sales share among the top $5.5 \%$ firms indicates a thicker tail of the productivity distribution - a higher $\zeta$. Moreover, conditional on the top 5.5\% share, a higher sales share among the top $1.1 \%$ firms requires a lower value of $n$, which indicates a more than proportional increase in productivity as we move to the top of the sales distribution. We find that $n=0.74-$ a small deviation from Pareto and thus a moderate degree of logconvexity - fits the manufacturing sales concentration levels in 1982.

Retail: We follow the same calibration approach for retail and report our results in Table 4. Relative to manufacturing, the main difference for retail is that we calibrate a lower value of $n=0.47$ (implying more log-convexity of the productivity distribution), which is necessary to match the high sales share of the top 4 firms in each 4-digit retail industry (the top $0.023 \%$ firms) of $15 \%$ in 1982 relative to the (also high) share of the top 20 firms (the top $0.12 \%$ firms) in each retail industry of $30 \%$. We also set the persistence of productivity $\rho_{z}$ to 0.86 , which matches our estimates for revenue TFP obtained from our production function estimates in Section $1 .{ }^{33}$

\footnotetext{
${ }^{32}$ Our calibrated demand super-elasticity is close to the preferred estimate in Edmond, Midrigan and $\mathrm{Xu}$ (2018) of 0.16, who estimate this super-elasticity to match labor share dispersion by firm size in US Census data. Appendix A.5 provides a robustness exercise where we use a lower value of 0.16 for the super-elasticity of demand, and reach similar quantitative conclusions.

${ }^{33}$ For retail and all sectors outside of manufacturing, we lack data on exit and entry rates, as well as the relative size of entrants and exiters. Thus, we target the same moments as in our calibration for the manufacturing sector from Lee and Mukoyama (2015). Finally, we keep the same super-elasticity of demand of 0.22 and provide robustness checks to using different values in Appendix A.5.
} 
TABLE 4: Steady state calibration of the non-CES demand model: Retail

\begin{tabular}{|c|c|c|c|c|c|}
\hline & PARAMETER & & MOMENT & DATA & MODEL \\
\hline & \multicolumn{5}{|c|}{ I. Parameters related to production function } \\
\hline$\eta$ & $\begin{array}{l}\text { Task substitution } \\
\text { elasticity }\end{array}$ & 0.5 & From Humlum (2019) & 0.5 & 0.5 \\
\hline \multirow[t]{2}{*}{$\gamma_{\ell}$} & Comparative advantage & 0.22 & $\begin{array}{l}\text { Retail labor share } \\
\text { (BLS/BEA) }\end{array}$ & 0.72 & 0.72 \\
\hline & \multicolumn{5}{|c|}{ II. Parameters governing firm dynamics and productivities in 1982 steady state } \\
\hline$\nu / \sigma$ & Demand super-elasticity & 0.22 & $\begin{array}{l}\text { Imputed from } \\
\text { manufacturing }\end{array}$ & & \\
\hline$\sigma$ & Demand elasticity & 8.95 & Aggregate markup & 1.15 & 1.15 \\
\hline$\zeta$ & Weibull scale & 0.0128 & Top 20 firms' sales share & $29.9 \%$ & $29.9 \%$ \\
\hline$n$ & Weibull shape & 0.47 & Top 4 firms' sales share & $15.1 \%$ & $15.1 \%$ \\
\hline$\underline{\mathrm{c}}_{o}$ & Scale operating cost & $4.6 \cdot 10^{-6}$ & Entry (=exit) rate & 0.062 & 0.062 \\
\hline $\bar{\xi}_{o}$ & Tail index operating cost & 0.320 & Size of exiters & 0.490 & 0.494 \\
\hline$\mu_{e}$ & Entrant productivity & 0.855 & Size of entrants & 0.600 & 0.600 \\
\hline$\rho_{z}$ & Productivity persistence & 0.86 & $\begin{array}{l}\text { Revenue TFP persistence } \\
\text { among retail firms }\end{array}$ & & \\
\hline
\end{tabular}

Notes: The two concentration measures are from Autor et al. (2020) and correspond to the retail sector in 1982. The model equivalents refer to the top $0.023 \%$ and top $0.116 \%$ of firms ranked by sales (since there are on average 17,259 firms per 4-digit retail industry). The remaining data moments follow the model with CES demand, see Table 1. Fixing productivity persistence and the demand super-elasticity, the remaining six parameters in Panel II are jointly calibrated to match the six corresponding moments.

\subsection{Quantifying the role of competition and capital-labor substitution}

As before, we treat the economy in 1982 as being in steady state. We then calibrate the $q$ and $\lambda$ shocks required to match (i) the observed decline in the sectoral labor share, (ii) the observed decline in average capital prices by sector, and (iii) the increase in sales concentration. In addition, and as we did in the previous section, we calibrate the fixed cost of automation per task to match (iv) the higher adoption rate of automation technologies among large firms documented in Acemoglu et al. (2021).

The key assumption behind this approach is that there are no other forces affecting sales concentration or reducing the labor share in manufacturing and retail. ${ }^{34}$ Relative to

\footnotetext{
${ }^{34}$ Other relevant forces that could explain the labor share decline and the rise of sales concentration include changes in monopsony power or higher TFP dispersion. The available evidence suggests that labor market concentration has decreased over time, if anything raising the labor share by 3 pp since 1982 (Berger, Herkenhoff and Mongey, 2019). Likewise, the increase in concentration could reflect higher TFP dispersion over time, for example due to shifts in the composition of firms (Hopenhayn, Neira and Singhania, 2018), a widening gaps between leaders and followers in technology diffusion (Akcigit and Ates, 2019) or a reduction in the R\&D efficiency of small firms (Olmstead-Rumsey, 2019). These forces could have contributed to rising concentration, but cannot account for the large manufacturing labor share decline in our calibrated model. In particular, assume that the observed increase in sales concentration in manufacturing was due to rising TFP dispersion (modeled via an increase in $\zeta$ ). This alternative shock also reallocates sales towards high markup firms but this force reduces the manufacturing labor share by only 1.4 percentage points. This shows that to match the facts in manufacturing (including the evidence in Section 1) it is not
} 
the previous section, we now account for the possibility that part of the decline in the labor share is due to rising competition (and part of the increase in sales concentration is due to lower capital prices), and so we now put the decline in capital prices and the increase in competition on equal footing. Our exercise answers the question: if changes in the labor share and sales concentration are due to lower capital prices and rising competition, how important have each of these factors been in explaining the observed outcomes in manufacturing and retail? We conduct this exercise separately for manufacturing and for retail to illustrate that the answer to this question varies by sector.

Manufacturing: Column 1 in Table 5 summarizes the manufacturing data and Column 2 reports our results. To match the trends in (i)-(iv), our model requires a uniform decline in the effective price of capital of $d \ln q_{u}=0.6$, a skewed shock of $d \ln q_{s}=4.57$, and a mild increase in market access of $d \ln \lambda=0.06$. The reason why we calibrate a small increase in $\lambda$ is that the rise in sales concentration in manufacturing has been modest: manufacturing is the sector with the lowest increase in the share of sales accruing to top firms from 19822012 according to the data in Table 1 of Autor et al. (2020). The small increase in $\lambda$ has a negligible effect on the manufacturing labor share, since the productivity distribution in this sector is close to Pareto. The model then requires a large skewed $q$ shock to generate the large decline in the manufacturing labor share.

In response to these shocks, our model provides a good fit to the manufacturing data, matching the aggregate labor share decline, the rise in concentration, and the untargeted behavior of the labor share behavior across firms.

A small fixed cost of automating tasks $c_{a}=0.16$, calibrated to match the ABS adoption data, ensures that the labor share of the typical manufacturing firm increases despite lower capital prices. Panel III shows that the median firm labor share rises by $3.6 \mathrm{pp}$ and the unweighted mean decreases by 0.5 pp during 1982-2012, which match the 3 pp increase in the median and the $1.7 \mathrm{pp}$ decline in the unweighted mean in the data.

Panels IV of Table 5 describe the behavior of the labor share across firms using the Melitz-Polanec decomposition from Autor et al. (2020). In line with the data, we find a crucial role for a decline in the covariance between firm sales and their labor share in explaining the decline in the labor share. The covariance term contributed $18.7 \mathrm{pp}$ to the labor share decline in the data and $21 \mathrm{pp}$ in our model.

Panel V shows that our model with endogenous markups quantitatively matches the enough to have top firms becoming more productive over time, but one also needs them to become more capital-intensive as in our theory. 
TABLE 5: Transitional dynamics and decomposition of the manufacturing labor share using a non-CES demand system (1982-2012)

\begin{tabular}{|c|c|c|c|c|}
\hline & \multirow[b]{2}{*}{$\begin{array}{r}\text { DATA } \\
(1)\end{array}$} & \multicolumn{3}{|c|}{ MODEL } \\
\hline & & $\begin{array}{r}\text { BASELINE } \\
\text { NON-CES MODEL } \\
(2)\end{array}$ & $\begin{array}{r}\text { ONLY EFFECTS OF } \\
d \ln q \\
(3)\end{array}$ & $\begin{array}{r}\text { ONLY EFFECTS OF } \\
d \ln \lambda \\
(4)\end{array}$ \\
\hline \multicolumn{5}{|c|}{ I. Parameters and inferred aggregate shocks } \\
\hline$d \ln q_{u}$ & & 0.60 & 0.60 & 0 \\
\hline$d \ln q_{s}$ & & 4.57 & 4.57 & 0 \\
\hline$d \ln \lambda$ & & 0.06 & 0 & 0.06 \\
\hline$c_{a}$ & & 0.16 & 0.16 & 0.16 \\
\hline \multicolumn{5}{|c|}{ II. Targeted moments, 1982-2012 } \\
\hline$\Delta$ aggregate labor share & -0.199 & -0.199 & -0.209 & 0.004 \\
\hline$\Delta \log$ average capital price & -1.081 & -1.074 & -0.994 & 0 \\
\hline$\Delta \log 4$ firms' sales share & 0.140 & 0.143 & 0.078 & 0.070 \\
\hline Relative adoption & 1.71 & 1.71 & 1.62 & 9.74 \\
\hline \multicolumn{5}{|c|}{ III. Typical firm labor share and other moments } \\
\hline$\Delta$ median labor share & 0.030 & 0.036 & 0.016 & 0.013 \\
\hline$\Delta$ unweighted mean & -0.017 & -0.005 & -0.025 & 0.012 \\
\hline$\Delta \log 20$ firms' sales share & 0.072 & 0.142 & 0.105 & 0.046 \\
\hline$\Delta \log$ productivity dispersion & 0.050 & 0.073 & 0.060 & 0.000 \\
\hline \multicolumn{5}{|c|}{ IV. Melitz-Polanec decomposition from Autor et al. (2020) } \\
\hline$\Delta$ aggregate labor share & -0.185 & -0.195 & -0.205 & 0.003 \\
\hline$\Delta$ unweighted incumbent mean & -0.002 & 0.017 & -0.001 & 0.014 \\
\hline Exit & -0.055 & -0.015 & -0.016 & -0.018 \\
\hline Entry & 0.059 & 0.012 & 0.014 & 0.015 \\
\hline Covariance term & -0.187 & -0.210 & -0.203 & -0.008 \\
\hline \multicolumn{5}{|c|}{ V. Covariance decomposition from Kehrig and Vincent (2020) } \\
\hline Market share dynamics & 0.047 & 0.075 & 0.075 & 0.070 \\
\hline Labor share by size dynamics & -0.043 & -0.056 & -0.072 & 0.082 \\
\hline Cross-cross dynamics & -0.232 & -0.206 & -0.198 & -0.147 \\
\hline \multicolumn{5}{|c|}{ VI. Markups, 1982-2012 } \\
\hline$\Delta$ log aggregate markup & -0.011 & 0.014 & 0.014 & 0.001 \\
\hline Within-firm change in markup & -0.076 & -0.031 & -0.025 & -0.014 \\
\hline Reallocation to high-markup firms & 0.065 & 0.045 & 0.039 & 0.015 \\
\hline
\end{tabular}

Notes: Column (2) reports the findings from our benchmark model, which jointly calibrates (i) the capital price shocks $q_{s}$ and $q_{u}$ (over 1982-2012), (ii) an increase in competition (over 1982-2012), and (iii) the automation fixed cost to replicate (i) the change in the aggregate manufacturing labor share (BLS/BEA integrated industry-level production account), (ii) the decline in the average price of capital (BEA Fixed Asset Tables and our calculations), (iii) the increase in the top 4 firms' sales share within 4-digit manufacturing industries (Autor et al., 2020, Table 1), and (iv) the relative adoption of automation technologies by firm size (from Acemoglu et al., 2021). Column (3) shows results when shutting down the competition shock, column (4) when shutting down instead the price of capital shocks. The change in the standard deviation of log productivity ( $\log$ unit cost) is from Decker et al. (2020, Figure 3a), and computed analogously as the difference between the 2000s and 1980s. Panel IV reproduces the Melitz-Polanec decomposition from Autor et al. (2020, Table 4 Panel B), reported as the sum of consecutive 5-year changes 1982-2012. Panel V reproduces the covariance decomposition from Kehrig and Vincent (2020, Figure 5), conducted for a balanced sample of firms and one long change 1982-2012. Panel VI displays the log change in the aggregate markup and the decomposition into within-firm and reallocation components from Section 3.4.

covariance decomposition in Kehrig and Vincent (2020). In line with the data, the labor share decline is generated by firms that expand at the same time as they reduce their labor shares (the cross-cross dynamics term), and not by the subsequent expansion of firms 
that had low labor shares initially (the market share effect). The cross-cross dynamics term contributed $23.2 \mathrm{pp}$ to the labor share decline in the data and $20.6 \mathrm{pp}$ in our model. This term is now more negative than in the CES model because firms that expand not only automate more tasks when they do so, but also raise their markups during periods of expansion - a feature of Marshall's second law. As in the data, our model now produces a positive market share effect of $7.5 \mathrm{pp}$. This is because firms that had low labor shares in 1982 were already large. Due to mean reversion in the productivity process, these firms lose market share over time, contributing to an increase in the labor share.

The non-CES model also generates a transient behavior of firms' labor shares. Kehrig and Vincent (2020) document that firms experience cycles during which their labor shares decline and partly but not fully recover, and that these cycles have become more pronounced over time. In our model, these cycles are a natural implication of Marshall's second law. In the initial steady, firms that receive a positive productivity shock will raise markups and lower their labor shares. These firms will then lower their markups and raise their labor shares as their productivity mean-reverts over time. Along the transition, these cycles become more pronounced and asymmetric, since firms will also automate some of their tasks upon receiving a positive productivity shock. Figure 5 illustrates this phenomenon by plotting the impulse-response function of firms' labor shares to a productivity shock in the initial steady state and along the transition. ${ }^{35}$

The exercises in this section show that Marshall's second law of demand is an important ingredient needed to quantitatively match the joint dynamics of the labor share and sales shares documented in Kehrig and Vincent (2020). They also shows that our model can generate these dynamics as a response to lower capital prices.

To understand the contribution of the $q$ and $\lambda$ shocks, we provide counterfactual scenarios where we shut them down sequentially. In Column 3, we consider the effect of the $q$ shocks holding $\lambda$ constant at its initial steady state. The decline in effective capital prices generates all of the observed decline in the manufacturing labor share, and 7.8 log points of the observed $14 \mathrm{log}$ points increase in sales concentration among the top 4 firms in the sector. The $q$ shock alone generates all the firm-level patterns in panels IV and V. In Column 4, we consider the effect of the $\lambda$ shock holding $q$ constant at its initial steady state. The increase in competition does not contribute to the decline in the manufacturing labor

\footnotetext{
${ }^{35}$ Kehrig and Vincent (2020) argue that firm prices increase during these cycles using data for a subset of industries for which reliable price and quantity data are available (chemicals, aluminum sheets, and others). One could capture this feature by having firm-level demand shocks in our model on top of the TFP process for $z_{t f}$. It is also important to note that these cycles occur naturally in a steady state (independently of whether they are driven by demand or supply shocks), and so their presence is not necessarily informative of the forces driving the aggregate labor share decline.
} 

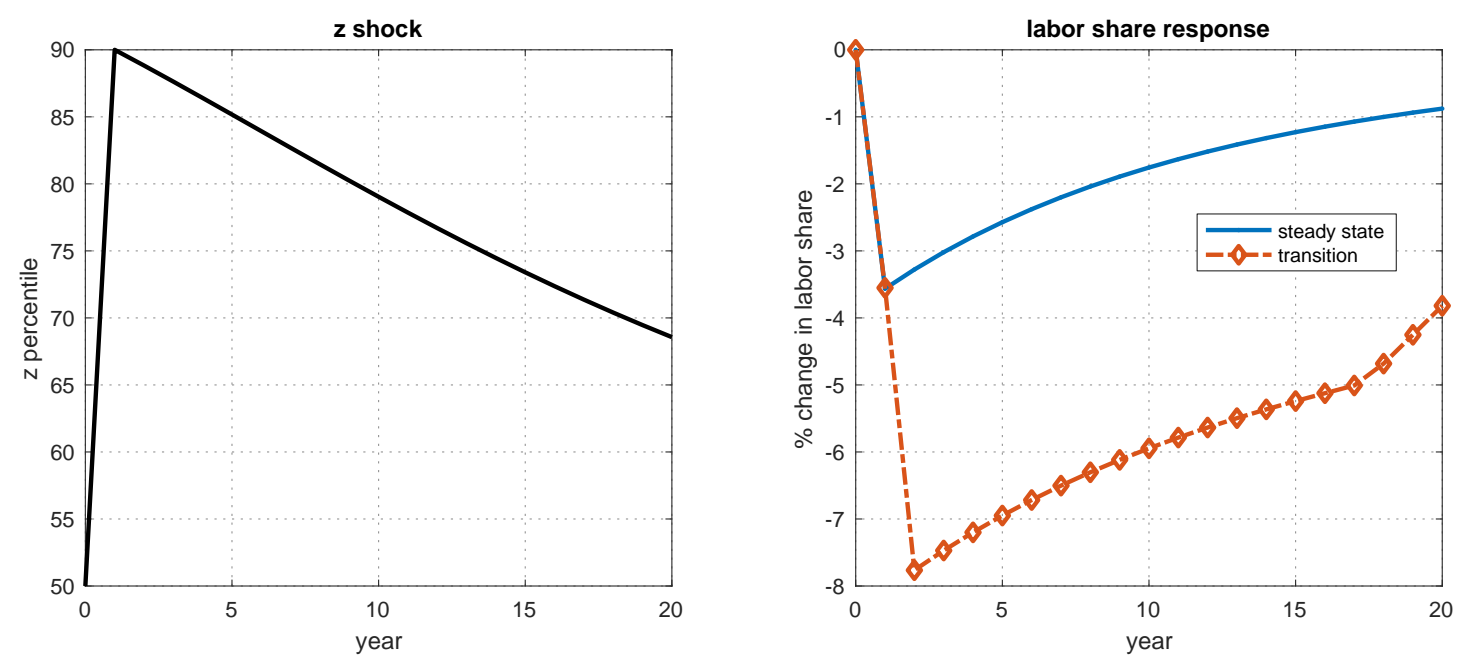

Figure 5: Impulse RESPONSE OF FIRM LABOR SHARE TO PRODUCTIVITY SHOCK. Left panel displays the shock: a firm's productivity $z_{t f}$ jumps from the 50 th to the 90 th percentile on impact, and then meanreverts according to $\rho_{z}$. Right panel displays firms' labor share response (relative to a firm that stays at median productivity), both in steady state and over the transition.

share. Its role is to increase sales concentration among the top 4 firms by 7 log points.

Retail: We now calibrate the decline in capital prices and increase in market access required to match the labor share decline and the rising sales concentration in retail. Table 6 summarizes the retail data and presents the calibrated increase in $q$ (lower capital prices) and $\lambda$ (rising market access). As before, we calibrate the fixed cost of automating tasks to match the higher adoption of automation technologies by large firms in the data. ${ }^{36}$ We also require that the $q$ shocks generate an average decrease in capital prices of 86.5 log points, which is our quality-adjusted estimate for the decline in capital prices in this sector.

In retail, we observe a decline in the labor share of $12.7 \mathrm{pp}$ as well as a rise in sales concentration among the top 4 firms of $14.0 \mathrm{pp}$ and a similar rise among the top 20 firms of $16.3 \mathrm{pp}$. Averaging over these two measures, this represents a vast increase in sales concentration of $54.6 \log$ points $(74 \%)$. For comparison, sales concentration increased by $14 \log$ points in manufacturing. Our model generates the observed patterns for retail with a smaller uniform decline in the price of capital of $d \ln q_{u}=0.48$, an additional skewed shock of $d \ln q_{s}=2.77$, and an increase in market access of $d \ln \lambda=0.30$ - an order of magnitude larger than in manufacturing. ${ }^{37}$

\footnotetext{
${ }^{36}$ Acemoglu et al. (2021) report similar relative adoption rates by size inside and outside of manufacturing. For this reason, we keep the same target as before.

${ }^{37}$ In retail and for other sectors outside of manufacturing, we calibrate the shocks to match the average increase in concentration among the top 4 and top 20 firms in each 4-digit industry. We do this because the top 4 firms are a small fraction $(0.023 \%)$ of all retailers, whereas they account for $1.1 \%$ of all manufacturing firms. Targeting the average top 4 and top 20 sales share increase in manufacturing as well (11 logs points)
} 
TABLE 6: Transitional dynamics and decomposition of the retail labor share using a nonCES demand system (1982-2012)

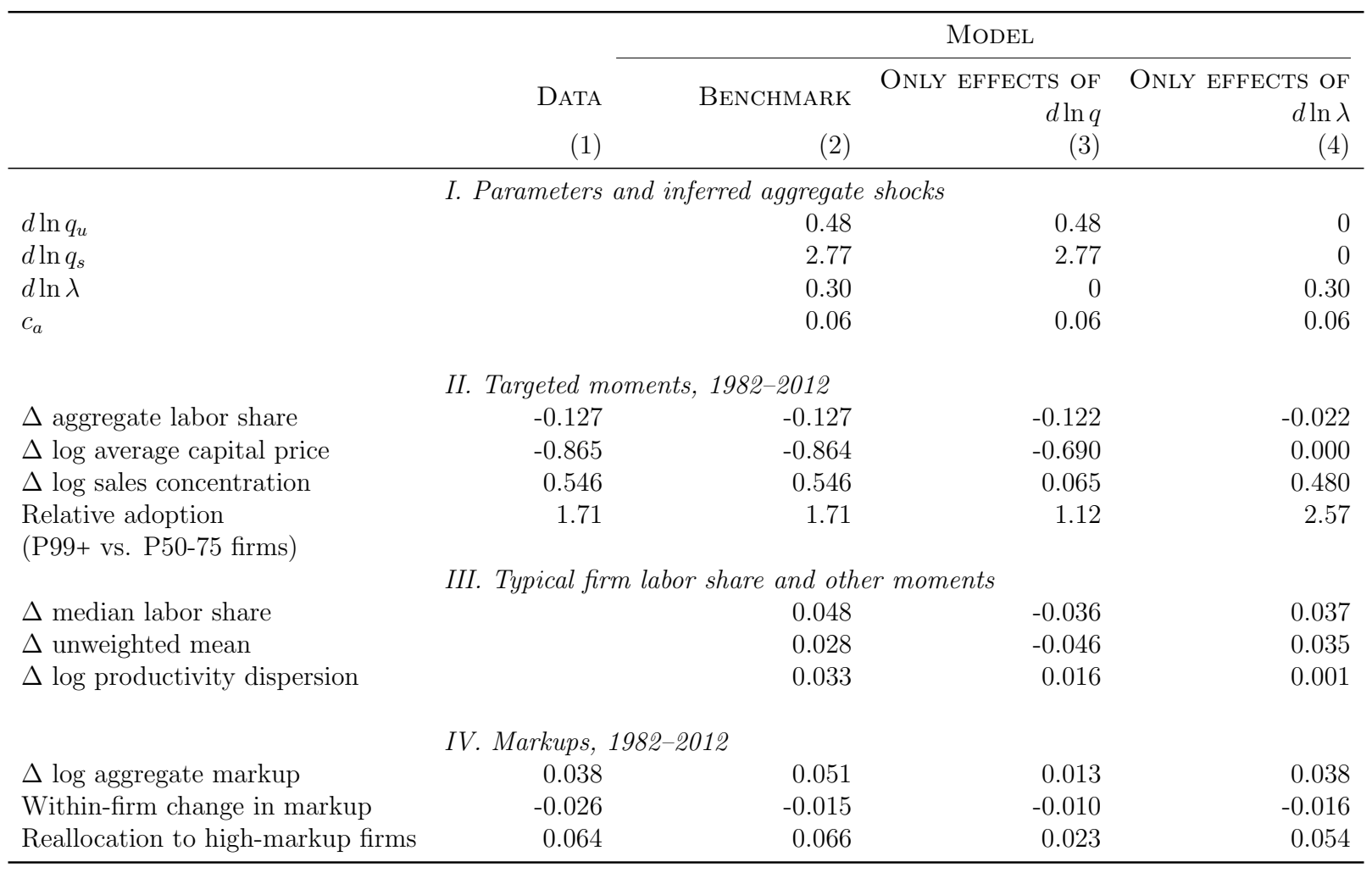

Notes: Column (2) reports the findings from our benchmark model, which jointly calibrates (i) the capital price shocks $q_{s}$ and $q_{u}$ (over 1982-2012), (ii) an increase in competition (over 1982-2012), and (iii) the automation fixed cost to replicate (i) the change in the aggregate retail labor share (BLS/BEA integrated industry-level production account), (ii) the decline in the average price of capital (BEA Fixed Asset Tables and our calculations), (iii) the average log change in the top 4 as well as top 20 firms' sales share within 4-digit retail industries (Autor et al., 2020, Table 1), and (iv) the relative adoption of automation technologies by firm size (from Acemoglu et al., 2021). Column (3) shows results when shutting down the competition shock, and column (4) when shutting down instead the price of capital shock. Panel IV displays the log change in the aggregate markup and the decomposition into within-firm and reallocation components from Section 3.4.

The large increase in market access calibrated for retail aligns with other studies. For example, Hsieh and Rossi-Hansberg (2019) document that retail firms have increased their number of establishments by $21.6 \%$ and locations by $18.6 \%$ during $1977-2013 .{ }^{38}$ Likewise, Aghion et al. (2019) provide a model where lower overhead costs increase the number of markets serviced by top firms in retail, wholesale, and services by $31.3 \%$ since 1990 .

The smaller skewed $q$ shock in retail suggest that, in this sector, a larger share of advances in capital goods took place in infra-marginal tasks, without leading to as much automation (and productivity dispersion) as in manufacturing.

yields a smaller role for the inferred $\lambda$ shock in that sector.

${ }^{38}$ For manufacturing firms, the number of establishments and locations increased by less than $2 \%$, which provides some support for the weaker $\lambda$ shock estimated in that sector. However, the modest increase in the number of establishments and locations for manufacturing firms is not as relevant for understanding changes in market access since manufacturers produce tradeable goods. The small increases in $\lambda$ for manufacturing could also reflect the fact that, precisely because manufacturing goods are tradeable, market access has always been high and has not changed as much in recent years. 
The different inference obtained for manufacturing and retail is due to two key factors: (i) the vast increase in sales concentration in retail vis-a-vis the modest increase in manufacturing, and (ii) the more log-convex distribution of productivity in the retail sector. In retail, our model requires a large increase in market access to match the observed rise in concentration. Moreover, because the productivity distribution in retail is more log-convex than in manufacturing ( $n=0.47$ in retail vs. $n=0.74$ in manufacturing), this increase in competition by itself has a more pronounced effect on the labor share, leaving a smaller role for lower capital prices and the skewed $q$ shock.

Our model provides a good fit to the available data for retail. As before, a small fixed cost of automating tasks is enough to match the adoption data and ensure a rise in the labor share of the typical retail firm. We find that the unweighted mean labor share rises by $2.8 \mathrm{pp}$ and the median by $4.8 \mathrm{pp}$. Though we do not have direct data on these moments, this is in line with the evidence in Autor et al. (2020), who find that the unweighted mean of payroll shares in retail increased by 4.4 pp for 1982-2012.

Columns 3 and 4 report the effects of the increase in $q$ and $\lambda$ shocks separately. The large increase in market access in retail generates $18 \%$ of the decline in the labor share $(-2.2$ pp) and $90 \%$ of the increase in concentration. Increased market access also contributed to a rising labor share for the median and the unweighted mean of firms.

Other sectors: We also conducted our decomposition for other economic sectors, including wholesale, and utilities \& transportation. The results are available in Figure A11 and Table A4 in Appendix A.6. Relative to manufacturing, in wholesale and utilities \& transportation, we infer a larger $\lambda$ shock - required to match the large increase in concentration in these sectors - and a smaller skewed $q$ shock - required to match the less pronounced labor share decline. However, the increase in market access plays a small role for the aggregate labor share of these sectors. The reason is that the calibrated productivity distribution for both sectors is close to Pareto ( $n=0.74$ and $n=0.75$, respectively), which makes the aggregate labor share effects small (an implication of Proposition 4).

\subsection{Implications for Markups}

This sub-section summarizes the predictions of our model for markups and compares them with the data. The labor share in an industry can be written as $s^{\ell}=\varepsilon^{\ell} / \mu$, where $\varepsilon^{\ell}$ is the share of labor in costs for the industry and $\mu$ is the aggregate industry markup, defined as 
the harmonic sales-weighted mean of markups across firms:

$$
\frac{1}{\mu}=\sum_{f} \omega_{f} \cdot \frac{1}{\mu_{f}}
$$

As suggested by this decomposition and Proposition 5, this is the relevant notion of an aggregate markup. ${ }^{39}$

Panel VI of Table 5 summarizes the predictions of our model for markups in manufacturing. Our model predicts a mild increase in the manufacturing markup of $1.4 \%$ (from 1.150 to 1.166). In line with Proposition 5, this net effect masks two opposing forces. On the one hand, firms lower their markups in response to rising competition. The contribution of these within-firm changes is given by

$$
\text { within-firm changes }=\sum_{f} \omega_{f} \cdot \Delta \ln \mu_{f},
$$

which reduced the manufacturing markup by 3.1\% during this period (in this expression, the sum is over all continuing firms). On the other hand, rising competition generates a reallocation of output towards firms with higher markups. The contribution of reallocation to markups is given by

$$
\text { markup reallocation }=\Delta \ln \mu-\sum_{f} \omega_{f} \cdot \Delta \ln \mu_{f}
$$

which increased the manufacturing markup by $4.5 \%$ during this period. The results in columns (3) and (4) show that both lower capital prices and rising competition reallocate economic activity towards firms with large markups. The fact that rising competition leads to this form of reallocation is in line with Proposition 4. Lower capital prices have a similar reallocation effect because automation favors the expansion of large firms, which are precisely the ones with higher markups. ${ }^{40}$ In sum, the net effect of changes in markups and reallocation accounts for $0.9 \mathrm{pp}$ of the $20 \mathrm{pp}$ decline in the manufacturing labor share.

Panel IV of Table 6 summarizes the predictions of our model for markups in retail. Our model predicts an increase in the aggregate retail markup of 5.1\% (from 1.15 to 1.21). This

\footnotetext{
${ }^{39}$ This decomposition follows from the chain of identities $s^{\ell}=\frac{\sum_{f} s_{f}^{\ell} y_{f}}{\sum_{f} y_{f}}=\frac{\sum_{f} s_{f}^{\ell} y_{f}}{\sum_{f} \frac{1}{\mu_{f}} y_{f}} \frac{\sum_{f} \frac{1}{\mu_{f}} y_{f}}{\sum_{f} y_{f}}=\varepsilon^{\ell} \cdot \frac{1}{\mu}$. The last step uses the fact that $\sum_{f} s_{f}^{\ell} y_{f}$ equals the wage bill and $\sum_{f} \frac{1}{\mu_{f}} y_{f}$ equals total cost in the industry.

40 Baqaee and Farhi (2020b) show that shocks that reallocate economic activity towards firms with higher markups increase allocative efficiency and aggregate productivity. Proposition 1 in their paper shows that the contribution of changes in allocative efficiency to TFP are given by $\Delta \ln \mu-\sum_{f} \omega_{f} \Delta \ln \mu_{f}$ - the markup reallocation term. Thus, our model predicts that improvements in allocative efficiency brought by rising competition and lower capital prices generated a 4.5\% increase in manufacturing TFP from 1982 to 2012.
} 
is the result of a $1.5 \%$ decrease in the within-firm component and a $6.6 \%$ increase driven by reallocation to high-markup firms. Most of the rise in markups is explained by the sizable $\lambda$ shock in this sector. ${ }^{41}$ In sum, markups explain $3.6 \mathrm{pp}$ of the $12.7 \mathrm{pp}$ decline in the labor share of retail, with the reallocation component generating $4.6 \mathrm{pp}$ (36\%) of the decline.

We now compare these predictions to estimates of markups from Compustat. We use the production function estimates in Section 1 and compute markups for firm $f$ at time $t$ as $\mu_{t f}=\frac{\varepsilon_{t f}^{v}}{s_{t f}^{v}}$, where $s_{t f}^{v}$ denotes the share of variable input expenditures in revenue and $\varepsilon_{t f}^{v}$ denotes the variable input elasticity (one minus the output-capital elasticity in Section 1).

Figure 6 plots the implied time series for the economy-wide aggregate markup, computed as a sales-weighted harmonic mean of firm-level markups. Our estimates for markups suggest that they have been stable over time at around 1.2. This is in line with our quantitative exercise, which points to a modest increase in markups.

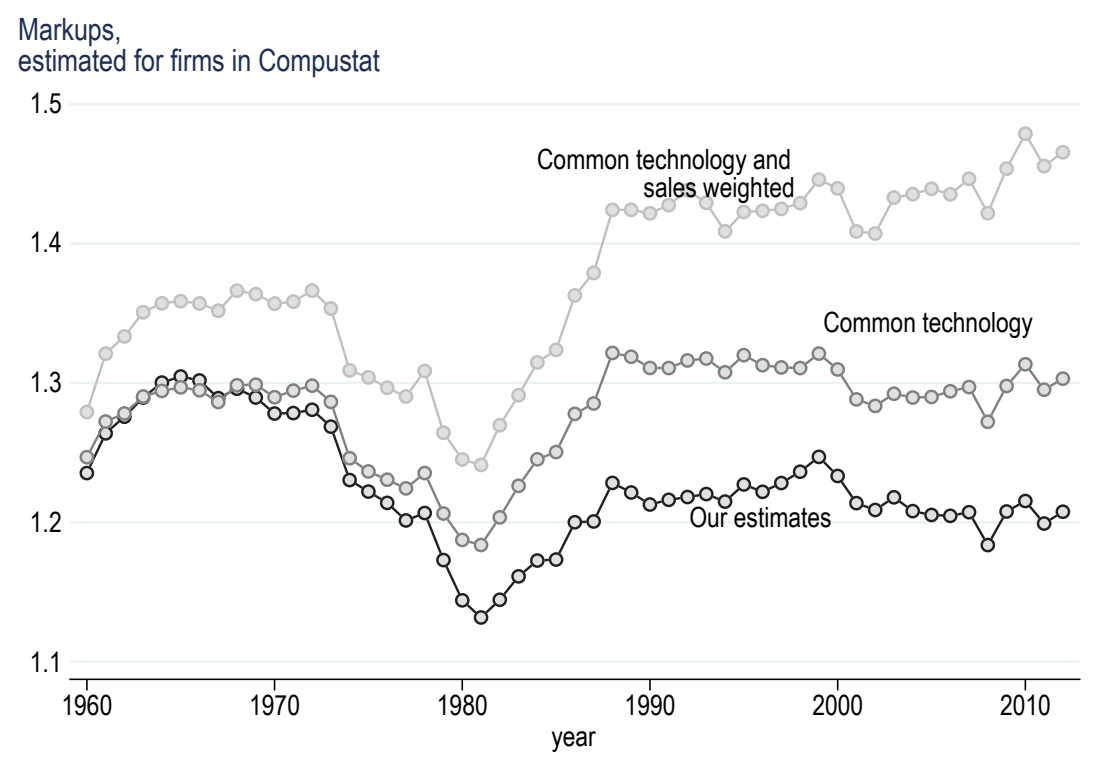

Figure 6: Evolution of MARKuPs. The figure presents the aggregate markup for firms in Compustat. Our estimates are obtained as as a sales-weighted harmonic mean of firm-level markups. The figure also reports the aggregate markup that would result under the assumption of common output elasticities across firms in the same industry, and a version of these estimates that aggregates firms' markups using a salesweighted arithmetic mean.

For comparison, we provide an alternative estimate of the aggregate markup obtained under the assumption that all firms in an industry operated technologies with the same capital intensity (as opposed to letting it vary by size class). This series reveals a mild secular increase in the aggregate markup from 1.25 in 1960 and 1.2 in 1980 to 1.3 in recent

\footnotetext{
${ }^{41}$ Building on footnote 40 , we find that, in retail, improvements in allocative efficiency due to rising competition and lower capital prices contributed a 6.6\% increase in sectoral TFP between 1982 and 2012.
} 
years, which aligns with the harmonic-mean estimates in Edmond, Midrigan and Xu (2018). We also provide estimates for an arithmetic mean of sales-weighted markups obtained under the assumption that all firms in a given industry operate technologies with the same capital intensity, which coincide with the series in De Loecker, Eeckhout and Unger (2020). Despite its increasing trend over time, this series is inappropriate for understanding the contribution of markups to the decline in the labor share because it ignores differences in technology across firm-size classes and uses the wrong weights for aggregation.

We now investigate the contribution of markups to the labor share decline in manufacturing and outside of manufacturing for 1980-2012. Figure 7 plots the cumulative percent change in the inverse markup $1 / \mu_{t}$ for manufacturing industries in the left panel and nonmanufacturing industries in the right panel, decomposed into within-firm changes and the reallocation component. ${ }^{42}$
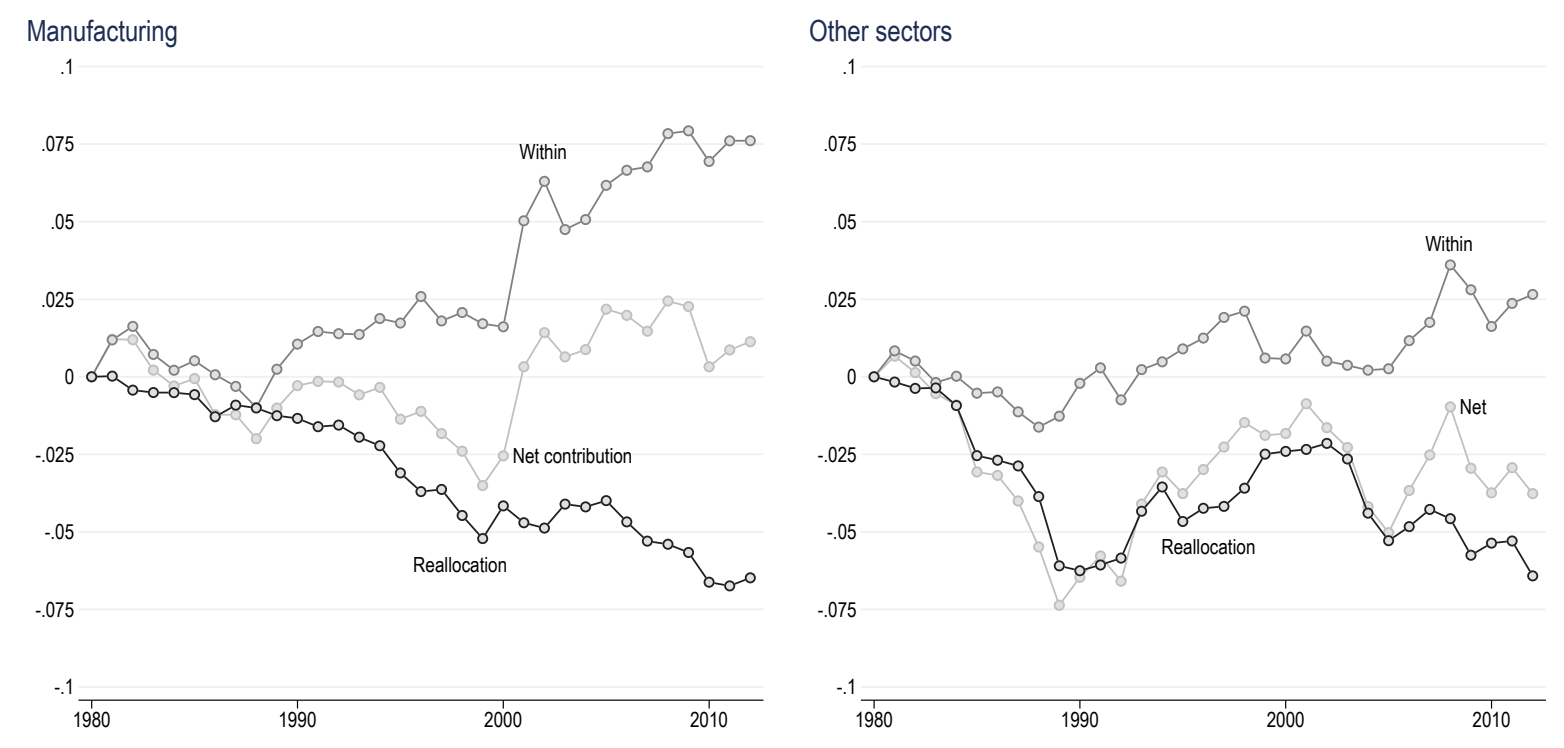

Figure 7: Decomposition of the CONTRIBution of Within-Firm CHANGES in MARKups AND BetWeen-firm REallocation to (PERCEnt) Changes in the labor share. See the main text for details on this decomposition. The left panel provides the decomposition for manufacturing firms in Compustat. The right panel provides the decomposition for Compustat firms in other economic sectors.

In line with our quantitative results, our estimates from Compustat support the conclusion that markups played no role on net in driving the decline of the manufacturing labor share. In this sector, the reallocation component accounts for a decline in the labor share of $6.5 \%$ between 1980 and 2012 (similar to the $4.5 \%$ decline in the labor share due to the reallocation towards large and high markup firms in our model). However, the esti-

\footnotetext{
${ }^{42}$ We compute the within-firm contribution to the percent change in markups in each year as $-\sum_{f} \omega_{f} \Delta \ln \mu_{f}$ and the reallocation component as $-\ln \mu_{t}+\sum_{f} \omega_{f} \Delta \ln \mu_{f}$. We then report the cumulative contribution of within-firm changes and the reallocation component over time.
} 
mated within-firm changes in markups go in the opposite direction and offset most of the reallocation component. This is in line with our calibration, where within-firm changes in markups and the reallocation component roughly cancel each other out in manufacturing (a consequence of the close to Pareto productivity distribution in this sector).

Outside of manufacturing, the reallocation component reduced the labor share by $6.4 \%$ during 1980-2012, which accounts for a third of the observed decline in retail during this period. This is in line with our quantitative model, where we estimate a $6.6 \%$ reduction in the retail labor share due to the reallocation of activity towards high markup firms, most of it in response to the sizable $\lambda$ shock in this sector. Moreover, in these sectors, the within component has been weak and only increased the labor share by $2.6 \%$ (similar to the $1.5 \%$ increase in our model). These estimates support the idea that, outside of manufacturing, rising competition triggered by increased market access reduced the labor share via reallocation towards high markup firms without bringing a similar offsetting reduction in within-firm markups.

\section{Concluding REMarks}

This paper offered a quantitative exploration of the forces driving the decline in the labor share and the rise in sales concentration across US sectors. We considered two prominent explanations for these phenomena: decreasing capital prices (or $q$ shocks) and increasing market access (or $\lambda$ shocks). Our quantitative exercises identify the combinations of these shocks capable of generating the different sectoral patterns, and show that the resulting firm-level patterns in our model align precisely with those in the data.

The exercises in this paper show that it is possible to have a coherent description of the manufacturing labor share decline driven by lower capital prices that fits all the relevant micro and macro facts quantitatively. In particular:

1. Our model generates the large observed decline in the manufacturing and retail labor share in response to $q$ shocks that are of a size that is consistent with the available data on capital prices.

2. Our model generates these large labor share declines even in scenarios where an econometrician would estimate an elasticity of substitution between capital and labor below 1. Our explanation is therefore consistent with the limited substitution of capital for labor in response to higher wages estimated by Oberfield and Raval (2021) and others. Yet, our model is flexible enough to match the labor share data even if 
the elasticity exceeds 1, as in Karabarbounis and Neiman (2013) and Hubmer (2020).

3. The model reproduces the striking fact that while the manufacturing labor share declined by $20 \mathrm{pp}$, the labor share of a typical firm increased or remained unchanged.

4. In response to $q$ shocks, the model generates all of the firm-level patterns documented in Autor et al. (2020) and Kehrig and Vincent (2020) for manufacturing, not only qualitatively but also quantitatively (especially in the non-CES version). The new firm-level facts documented in Autor et al. (2020) and Kehrig and Vincent (2020) do not contradict explanations of the labor share decline driven by lower capital prices.

5. Our model can also account for divergent sectoral experiences through different combinations of shocks. This exercise points to more sizable skewed $q$ shocks in manufacturing and a bigger increase in market access in retail, wholesale, and utilities.

6. Our model suggest that increased market access and competition have a small effect on the aggregate labor share of a sector, due to the offsetting effects of lower withinfirm markups and the reallocation to high markup firms. The exception to this rule is retail, where rising market access lowered the labor share by $2.2 \mathrm{pp}$. Still, $\lambda$ shocks are an important force behind the rise in sales concentration, the benign reallocation towards high-markups firms, and the estimated decline in firm-level markups, especially outside of manufacturing.

\section{REFERENCES}

Acemoglu, D., G. Anderson, D. Beede, C. Buffington, E. Dinlersoz, L. Foster, N. Goldschlag, J. Haltiwanger, Z. K. P. Restrepo, and N. Zolas (2021): "Technology and the Size and Compositionof Workforce in U.S. Firms: First Evidence from the 2019 Annual Business Survey," Discussion paper, US Census.

Acemoglu, D., C. Lelarge, and P. Restrepo (2020): "Competing with Robots: Firm-Level Evidence from France," in AEA Papers and Proceedings, vol. 110, pp. 383-88.

Acemoglu, D., A. Manera, and P. Restrepo (2020): "Does the US Tax Code Favor Automation?," Brookings Papers on Economic Activity, 2020(1), 231-300.

Acemoglu, D., And P. Restrepo (2018): "The Race between Man and Machine: Implications of Technology for Growth, Factor Shares, and Employment," American Economic Review, 108(6), 1488-1542.

- (2019): "Automation and New Tasks: How Technology Displaces and Reinstates Labor," Journal of Economic Perspectives, 33(2), 3-30.

- (2020): "Robots and jobs: Evidence from US labor markets," Journal of Political Economy, 128(6), 2188-2244.

Ackerberg, D. A., K. Caves, and G. Frazer (2015): "Identification Properties of Recent Production Function Estimators," Econometrica, 83(6), 2411-2451. 
Aghion, P., A. Bergeaud, T. Boppart, P. J. Klenow, and H. Li (2019): "A Theory of Falling Growth and Rising Rents," Working Paper 26448, National Bureau of Economic Research.

Akcigit, U., And S. T. Ates (2019): "What Happened to U.S. Business Dynamism?," Working Paper 25756, National Bureau of Economic Research.

Akerman, A., E. Leuven, And M. Mogstad (2021): "Information Frictions, Internet, and the Relationship between Distance and Trade," American Economic Journal: Applied Economics, (forthcoming).

Amiti, M., O. Itskhoki, And J. Konings (2019): "International shocks, variable markups, and domestic prices," The Review of Economic Studies, 86(6), 2356-2402.

Arkolakis, C., A. Costinot, D. Donaldson, and A. Rodríguez-Clare (2018): "The Elusive Pro-Competitive Effects of Trade," The Review of Economic Studies, 86(1), 46-80.

Autor, D., D. Dorn, L. F. Katz, C. Patterson, and J. Van Reenen (2020): "The fall of the labor share and the rise of superstar firms," The Quarterly Journal of Economics, 135(2), 645-709.

Baqaee, D., And E. Farhi (2020a): "The Darwinian Returns to Scale," Working Paper 27139, National Bureau of Economic Research.

BAqAeE, D. R., AND E. FARHi (2020b): "Productivity and misallocation in general equilibrium," The Quarterly Journal of Economics, 135(1), 105-163.

BARKAI, S. (2020): "Declining labor and capital shares," The Journal of Finance, LXXV(5).

Berger, D., K. Herkenhoff, And S. Mongey (2019): "Labor Market Power," Working Paper 25719, National Bureau of Economic Research.

Bond, S., A. Hashemi, G. Kaplan, and P. Zoch (2020): "Some Unpleasant Markup Arithmetic: Production Function Elasticities and their Estimation from Production Data," Discussion paper, University of Chicago.

Bonfiglioli, A., R. Crinò, H. Fadinger, And G. Gancia (2020): "Robot Imports and Firm-Level Outcomes," Discussion paper, CEPR Discussion Papers No. 14593.

Caselli, F., And I. Coleman, Wilbur John (2006): "The World Technology Frontier," American Economic Review, 96(3), 499-522.

Cheng, H., L. A. Drozd, R. Giri, M. Taschereau-Dumouchel, and J. Xia (2021): "The Future of Labor: Automation and the Labor Share in the Second Machine Age," Discussion paper, Mimeo, FRB Philadelphia.

Clementi, G. L., And B. Palazzo (2016): "Entry, Exit, Firm Dynamics, and Aggregate Fluctuations," American Economic Journal: Macroeconomics, 8(3), 1-41.

Cummins, J. G., and G. L. Violante (2002): "Investment-Specific Technical Change in the US (1947-2000): Measurement and Macroeconomic Consequences," Review of Economic Dynamics, $5(2), 243-284$.

DaO, M. C., M. DAs, And Z. Koczan (2019): "Why is labour receiving a smaller share of global income?," Economic Policy, 34(100), 723-759.

De Loecker, J., J. Eeckhout, and G. Unger (2020): "The rise of market power and the macroeconomic implications," The Quarterly Journal of Economics, 135(2), 561-644.

De Ridder, M. (2020): "Market Power and Innovation in the Intangible Economy," Discussion paper, London School of Economics.

Decker, R. A., J. Haltiwanger, R. S. Jarmin, and J. Miranda (2020): "Changing Business Dynamism and Productivity: Shocks versus Responsiveness," American Economic Review, (forthcoming).

DiCecio, R. (2009): "Sticky wages and sectoral labor comovement," Journal of Economic Dynamics and Control, 33(3), 538-553.

Dinlersoz, E. M., AND Z. Wolf (2018): "Automation, Labor Share, and Productivity: Plant- 
Level Evidence from U.S. Manufacturing," Discussion paper, Center for Economic Studies Working Paper CES-WP-18-39.

Dixon, J., B. Hong, AND L. Wu (2020): "The employment consequences of robots: Firm-level evidence," Discussion paper, Mimeo, Statistics Canada.

Edmond, C., V. Midrigan, And D. Y. Xu (2018): "How costly are markups?," Discussion paper, National Bureau of Economic Research.

Eldridge, L. P., C. Garner, T. F. Howells, B. C. Moyer, M. Russell, J. D. Samuels, E. H. Strassner, And D. B. Wasshausen (2020): "'Toward a BEA-BLS integrated industry-level production account for 1947-2016," in Measuring Economic Growth and Productivity, ed. by B. M. Fraumeni, chap. 11, pp. 221-249. Academic Press.

Elsby, M. W., B. HobIJn, ANd A. ŞAHIN (2013): "The decline of the US labor share," Brookings Papers on Economic Activity, 2013(2), 1-63.

Farhi, E., And G. François (2018): "Accounting for Macro-Finance Trends: Market Power, Intangibles, and Risk Premia," Brookings Papers on Economic Activity, p. 147.

Foster, L., J. Haltiwanger, and C. Syverson (2008): "Reallocation, Firm Turnover, and Efficiency: Selection on Productivity or Profitability?," American Economic Review, 98(1), 394-425.

Foster, L. S., J. C. Haltiwanger, And C. Tuttle (2022): "Rising Markups or Changing Technology?," Working Paper 30491, National Bureau of Economic Research.

Gordon, R. J. (1990): The Measurement of Durable Goods Prices. University of Chicago Press, Chicago, IL.

Greenwood, J., Z. Hercowitz, and P. Krusell (1997): "Long-Run Implications of Investment-Specific Technological Change," The American Economic Review, 87(3), 342-362.

Gutierrez, G., And S. Piton (2020): "Revisiting the Global Decline of the (Non-Housing) Labor Share," American Economic Review: Insights, (forthcoming).

Hall, R. E., And D. W. Jorgenson (1967): "Tax Policy and Investment Behavior," The American Economic Review, 57(3), 391-414.

Hopenhayn, H., J. Neira, and R. Singhania (2018): "From Population Growth to Firm Demographics: Implications for Concentration, Entrepreneurship and the Labor Share," Working Paper 25382, National Bureau of Economic Research.

Hopenhayn, H. A. (1992): "Entry, Exit, and Firm Dynamics in Long Run Equilibrium," Econometrica, 60(5), 1127-1150.

Houthakker, H. S. (1955): "The Pareto Distribution and the Cobb-Douglas Production Function in Activity Analysis," Review of Economic Studies, 23(1), 27-31.

Hsien, C.-T., And E. Rossi-Hansberg (2019): "The Industrial Revolution in Services," Working Paper 25968, National Bureau of Economic Research.

Hubmer, J. (2020): "The Race Between Preferences and Technology," Unpublished manuscript, University of Pennsylvania.

Humlum, A. (2019): "Robot Adoption and Labor Market Dynamics," Discussion paper, MIMEO, Princeton University.

Karabarbounis, L., And B. Neiman (2013): "The Global Decline of the Labor Share*," The Quarterly Journal of Economics, 129(1), 61-103.

Kaymak, B., And I. Schotт (2018): "Corporate Tax Cuts and the Decline of the Labor Share," 2018 Meeting Papers 943, Society for Economic Dynamics.

Kehrig, M., And N. Vincent (2020): "The Micro-Level Anatomy of the Labor Share Decline," NBER Working Papers 25275, National Bureau of Economic Research, Inc.

Kimball, M. S. (1995): "The Quantitative Analytics of the Basic Neomonetarist Model," Journal of Money, Credit and Banking, 27(4), 1241-1277.

Klenow, P. J., And J. L. Willis (2016): "Real Rigidities and Nominal Price Changes," 
Economica, 83(331), 443-472.

Koch, M., I. Manuylov, and M. Smolka (2019): "Robots and Firms," Discussion paper, CESifo Working Paper No. 7608.

Kogan, L., D. Papanikolaou, L. D. W. Schmidt, and B. Seegmiller (2021): "TechnologySkill Complementarity and Labor Displacement: Evidence from Linking Two Centuries of Patents with Occupations," Working Paper 29552, National Bureau of Economic Research.

Lashkari, D., A. Bauer, And J. Boussard (2019): "Information Technology and Returns to Scale," Discussion paper, Boston College.

Lee, Y., And T. Mukoyama (2015): "Entry and exit of manufacturing plants over the business cycle," European Economic Review, 77, 20 - 27.

Mariscal, A. (2020): "Firm Organization and Information Technology: Micro and Macro Implications," Discussion paper, Unpublished manuscript, U. Rovira i Virgili.

Melitz, M. J., And G. I. Ottaviano (2008): "Market size, trade, and productivity," The review of economic studies, 75(1), 295-316.

Oberfield, E., AND D. RAval (2021): "Micro data and macro technology," Econometrica, $89(2), 703-732$.

Olley, G. S., And A. Pakes (1996): "The Dynamics of Productivity in the Telecommunications Equipment Industry," Econometrica, 64(6), 1263-1297.

Olmstead-Rumsey, J. (2019): "Market Concentration and the Productivity Slowdown," Discussion paper, Unpublished manuscript, London School of Economics.

Perla, J., C. Tonetti, And M. E. Waugh (2021): "Equilibrium Technology Diffusion, Trade, and Growth," American Economic Review, 111(1), 73-128.

Philippon, T. (2019): The Great Reversal: How America Gave Up on Free Markets. Harvard University Press.

Piketty, T. (2014): Capital in the Twenty-First Century. Harvard University Press, Cambridge.

Smith, M., D. Yagan, O. Zidar, And E. Zwick (2019): "The Rise of Pass-Throughs and the Decline of the Labor Share," Discussion paper, Princeton University.

WAnG, J. (2021): "Robots, Trade, and Offshoring: A Perspective from US Firms," Discussion paper, Harvard University.

ZeIRA, J. (1998): "Workers, Machines, and Economic Growth," The Quarterly Journal of Economics, 113(4), 1091-1117.

Zolas, N., Z. Kroff, E. Brynjolfsson, K. McElheran, D. Beede, C. Buffington, N. Goldschlag, L. Foster, and E. Dinlersoz (2020): "Measuring Technology Adoption in Enterprise-Level Surveys: The Annual Business Survey," Discussion paper, US Census. 


\title{
Online Appendix to "Capital-Labor Substitution and Firms" Labor Shares"
}

\author{
Joachim Hubmer and Pascual Restrepo \\ November 5, 2022
}

\section{A.1 Estimating Output Elasticities}

\section{A.1.1 Data description, sample, and definitions}

We use data from Compustat for 1960-2016. We use the following variable definitions and conventions:

- Revenue $y_{t f}^{R}$ : we measure revenue using firm sales-SALES in Compustat.

- Expenditures in variable inputs $v_{t f}$ : we measure these expenditures using the cost of goods sold-COGS in Compustat.

- Stock of capital $k_{t f}$ : we follow De Loecker, Eeckhout and Unger (2020) and measure the capital stock using the gross value of property, plants, and equipment-PPEGT in Compustat. We obtained similar results using an alternative measure of capital computed using the perpetual inventory method. For this measure, we use the gross value of property, plants, and equipment as our initial stock. We then measure net investment as the difference in the net capital stock-PPENT in Compustat - over consecutive periods and deflate this over time using the investment price deflator to compute the capital stock over time.

- Investment rate $x_{t f}$ : we measure the investment rate as the percent change in capital; that is, $\ln x_{t f}=\ln k_{t+1, f}-\ln k_{t f}$

- Industry and firm groupings $c(f)$ : we conduct our estimation separately for 23 NAICS industries, roughly defined at the 2-digit level. When grouping firms into size quintiles, we do so for each year and within each 3-digit NAICS industry. We also experimented with the classification of industries based on SIC codes used in Baqaee and Farhi (2020b) and obtained very similar results.

- Sample definition and trimming: following De Loecker, Eeckhout and Unger (2020), we trim the sample by removing firms in the bottom 5th and top 5th percentiles of the $C O G S$-to-SALES distribution. In addition, following Baqaee and Farhi (2020b), we 
exclude firms in farm and agriculture, construction, real estate, finance, and utilities from our markup and labor share calculations in Figures 3 to 7.

- Winsorizing: we winsorize the obtained revenue elasticities at zero, and take 5-year moving averages to smooth them. Moreover, following Baqaee and Farhi (2020b), we winsorize our markup estimates at the 5th and 95th percentile of their distribution.

\section{A.1.2 Estimation approach and details}

Consider a firm that produces output by combining capital, $k$, and variable inputs, $v$, such as labor and materials. This section describes our approach for estimating the output-tocapital elasticity $\varepsilon_{t f}^{k}$ and the output-to-variable-input elasticity $\varepsilon_{t f}^{v}$ from firm-level data on revenue $(y)$, expenditures in variable inputs $(v)$, and capital $(k)$. Following Olley and Pakes (1996) and Ackerberg, Caves and Frazer (2015), we make the following assumptions: ${ }^{43}$

A1 Differences across firms in the price of variable inputs reflect quality, which implies that we can treat expenditures in variable inputs as a measure of their qualityadjusted quantity.

A2 Revenue $y_{t f}^{R}$ is given by a revenue production function of the form

$$
\ln y_{t f}^{R}=z_{t f}^{R}+\varepsilon_{t c(f)}^{R v} \cdot \ln v_{t f}+\varepsilon_{t c(f)}^{R k} \cdot \ln k_{t f}+\epsilon_{t f},
$$

where $c(f)$ denotes groups of firms with the same degree of automation and facing a common process for their revenue productivity, which only differ in their revenue productivity, $z_{t f}^{R}$, and an ex-post shock $\epsilon_{t f}$ that is orthogonal to $k_{t f}$ and $v_{t f}$.

A3 Unobserved productivity $z_{t f}^{R}$ evolves according to a Markov process of the form

$$
z_{t f}^{R}=g\left(z_{f t-1}^{R}\right)+\zeta_{t f}
$$

where $\zeta_{t f}$ is orthogonal to $k_{t f}$ and $v_{f t-1}$, and the function $g$ is common to all firms in the same group $c(f)$.

\footnotetext{
${ }^{43} \mathrm{An}$ alternative approach to estimating markups assumes constant returns to scale (as we do) and directly measures the user cost of capital as $R=r+\delta-\pi_{k}$, where $r$ is a required rate of return inclusive of an industry-specific risk premium, $\delta$ is the depreciation rate, and $\pi_{k}$ is the expected change over time in capital prices. One can then compute markups as revenue divided by total cost $(=V+R K)$. The user-cost formula, which goes back to Hall and Jorgenson (1967) requires common and frictionless capital markets and assumes no adjustment costs for capital. This strikes us as restrictive when thinking about firms undergoing a costly automation process. Instead, the approach described below makes no assumptions about the marginal product of capital across firms, or the importance of adjustment costs.
} 
A4 True revenue, $\ln y_{t f}^{R *}=\ln y_{t f}-\epsilon_{t f}$ can be expressed as

$$
\ln y_{t f}^{R *}=h\left(\ln x_{f t}, \ln k_{t f}, \ln v_{t f}\right),
$$

where $\ln x_{t f}=\ln k_{t+1, f}-\ln k_{t f}$ denotes the investment rate of a firm and the function $h$ is common to all firms in the same group $c(f)$.

A5 The gross output production function exhibits constant returns to scale in capital and variable inputs, which implies that output elasticities are given by

$$
\varepsilon_{t f}^{v}=\varepsilon_{t c(f)}^{R v} /\left(\varepsilon_{t c(f)}^{R v}+\varepsilon_{t c(f)}^{R k}\right) \quad \varepsilon_{t f}^{k}=\varepsilon_{t c(f)}^{R k} /\left(\varepsilon_{t c(f)}^{R k}+\varepsilon_{t c(f)}^{R k}\right) .
$$

Assumptions A1-A4 are standard in the literature. Assumption A4 justifies the use of the investment rate as a proxy variable. Economically, this assumption requires that all firms in a given group share the same investment policy function $k_{t+1, f}=\pi\left(k_{t f}, z_{t f}^{R}\right)$, and that this common policy function is invertible. Under these assumptions, and given a grouping of firms $c(f)$, we can estimate revenue elasticities following the usual approach from Ackerberg, Caves and Frazer (2015), which uses the investment rate as a proxy variable to obtain true revenue and then estimates revenue elasticities by exploiting the orthogonality of $\zeta_{t f}$ to $k_{t f}$ and $v_{t-1, f}$.

Assumption A5 is added to deal with the fact that we do not observe prices, such that the usual estimation procedure yields revenue elasticities, not the quantity elasticities that are relevant for computing markups (Bond et al., 2020). Under Assumption A5 we can recover output elasticities from revenue elasticities using (A1). Suppose that revenue is given by $y^{R}=p(q) \cdot q$, where $p(q)$ is the inverse demand curve. Quantity elasticities and revenue elasticities are then linked according to $\varepsilon^{R v}=\left(p^{\prime}(q) \cdot q / p(q)+1\right) \cdot \varepsilon^{v}$ and $\varepsilon^{R k}=$ $\left(p^{\prime}(q) \cdot q / p(q)+1\right) \cdot \varepsilon^{k}$, where $1 / \mu=\left(p^{\prime}(q) \cdot q / p(q)+1\right)$. Assuming constant returns to scale implies that $\varepsilon^{v}=\varepsilon^{R v} /\left(\varepsilon^{R v}+\varepsilon^{R k}\right)$, as wanted.

Given a grouping of firms $c(f)$, we can estimate revenue elasticities following the usual approach from Ackerberg, Caves and Frazer (2015), which uses investment as a proxy variable for unobserved productivity. This requires a first-stage regression where we first compute "true" output as

$$
\ln y_{t f}^{R *}=\mathbb{E}\left[\ln y_{t f}^{R} \mid \ln x_{t f}, \ln k_{t f}, \ln v_{t f}, t, c(f)\right]=h\left(\ln x_{t f}, \ln k_{t f}, \ln v_{t f} ; \theta_{t c(f)}^{h}\right) .
$$

Here $\theta_{t c(f)}^{h}$ is a parametrization for a flexible function $h$ that might vary over time and between groups of firms. For any pair of revenue elasticities $\varepsilon_{t c(f)}^{R v}$ and $\varepsilon_{t c(f)}^{R k}$, one can then 
compute revenue productivity as

$$
z_{t f}^{R}=\ln y_{t f}^{R *}-\varepsilon_{t c(f)}^{R v} \cdot \ln v_{t f}-\varepsilon_{t c(f)}^{R k} \cdot \ln k_{t f},
$$

estimate the flexible model

$$
z_{t f}^{R}=g\left(z_{t-1, f}^{R} ; \theta_{t c(f)}^{g}\right)+\zeta_{t f}
$$

where $\theta_{t c(f)}^{g}$ is a parametrization for a flexible function $g$, and form the following moment conditions that identify the revenue elasticities:

$$
\mathbb{E}\left[\zeta_{t f} \otimes\left(\ln k_{t f}, \ln v_{t-1, f}\right)\right]=0
$$

In our baseline approach, we parametrize the functions $h$ and $g$ using quadratic polynomials and conduct our estimation over 10-year rolling windows. More importantly, and in line with the emphasis in our model that large firms operate different technologies and face a different demand curve, we group firms by quintiles of sales in each industry. Thus, our estimation provides output elasticities that vary over time, by industry, and by quintiles of firm size in each industry. This represents a significant deviation from previous papers which assume that all firms in a given industry share the same output elasticities.

A byproduct of this estimation procedure are series for revenue TFP, $z_{t f}^{R}$. The estimated persistence of revenue TFP is 0.95 for manufacturing and 0.86 for retail, wholesale, utilities and transportation. These justifies the values of $\rho_{z}$ used in our calibration approach.

Besides our main estimation approach, we also explored the following variations:

Estimates parametrizing $g$ and $h$ using cubic polynomials We estimate elasticities under the same assumptions outlined in the main text, but parametrize $g$ and $h$ using cubic polynomials. Figure A1 plots the behavior of the resulting output elasticities over time by firm size quintile. Figure A2 reports the contribution of within-firm changes in markups and between-firm reallocation to (percent) changes in the labor share.

Estimates assuming there are no ex-post shocks $\epsilon$ In the absence of ex-post shocks, we can treat observed revenue as true revenue and there is no need to use a proxy variable to recover productivity. Instead, we can compute revenue productivity directly as

$$
z_{t f}^{R}=\ln y_{t f}^{R}-\varepsilon_{t c(f)}^{R v} \cdot \ln v_{t f}-\varepsilon_{t c(f)}^{R k} \cdot \ln k_{t f}
$$


and proceed with the rest of the estimation in the same way as before.

Figure A3 plots the behavior of the resulting output elasticities over time by firm size quintile. Figure A4 reports the contribution of within-firm changes in markups and between-firm reallocation to (percent) changes in the labor share.

Estimates assuming a linear Markov process for productivity Suppose that productivity follows a linear Markov process

$$
z_{t f}^{R}=\beta z_{t-1, f}^{R}+\zeta_{t f}
$$

Define $v_{t f}=z_{t f}^{R}+\epsilon_{t f}$. Because ex-post shocks are i.i.d, we have that $v_{t f}$ also follows a linear Markov process

$$
v_{t f}=\beta v_{t-1, f}+\underbrace{\zeta_{t f}+\epsilon_{t f}-\beta \epsilon_{t-1, f}}_{=\iota_{t f}} .
$$

Estimation proceeds as follows. First, we can compute $v_{t f}$ directly as

$$
v_{t f}=\ln y_{t f}^{R}-\varepsilon_{t c(f)}^{R v} \cdot \ln v_{t f}-\varepsilon_{t c(f)}^{R k} \cdot \ln k_{t f} .
$$

Then we estimate the linear model

$$
v_{t f}=\beta v_{t-1, f}+\iota_{t f},
$$

and base estimation on the moment conditions

$$
\mathbb{E}\left[\iota_{t f} \otimes\left(\ln k_{t f}, \ln v_{t-1, v}\right)\right]=0
$$

Figure A5 plots the behavior of the resulting output elasticities over time by firm size quintile. Figure A6 reports the contribution of within-firm changes in markups and between-firm reallocation to (percent) changes in the labor share. 

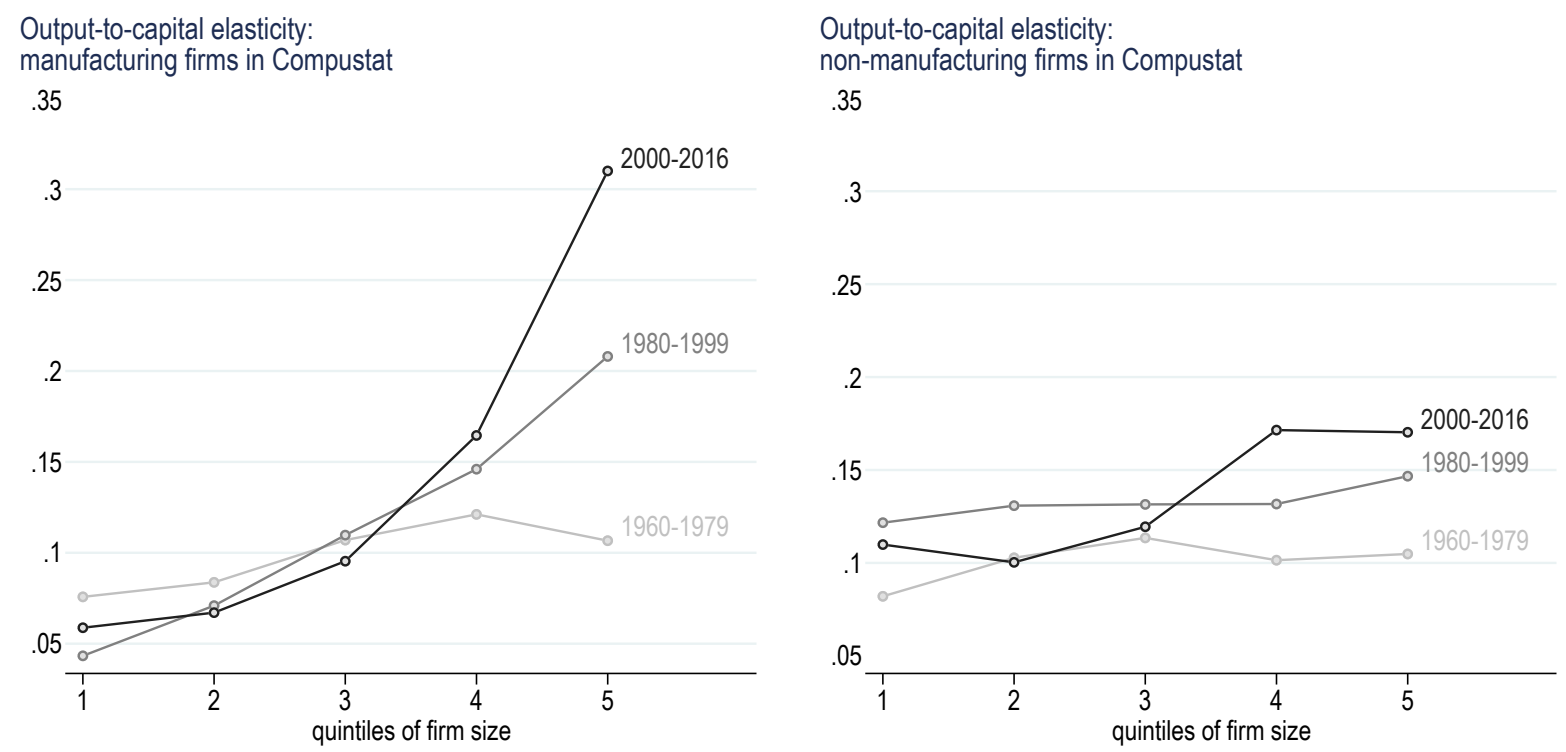

Figure A1: Output-to-CAPital Elasticities for Compustat firms estimated using a CubiC PARAMETRIZATION OF $g$ AND $h$. The left panel presents estimates for Compustat manufacturing firms. The right panel presents estimates for Compustat non-manufacturing firms. Firm-level elasticities are estimated using a cubic parametrization for $g$ and $h$, as explained in Appendix A.1. See figure 3 in the main text for our baseline estimates used in the results reported in the paper.
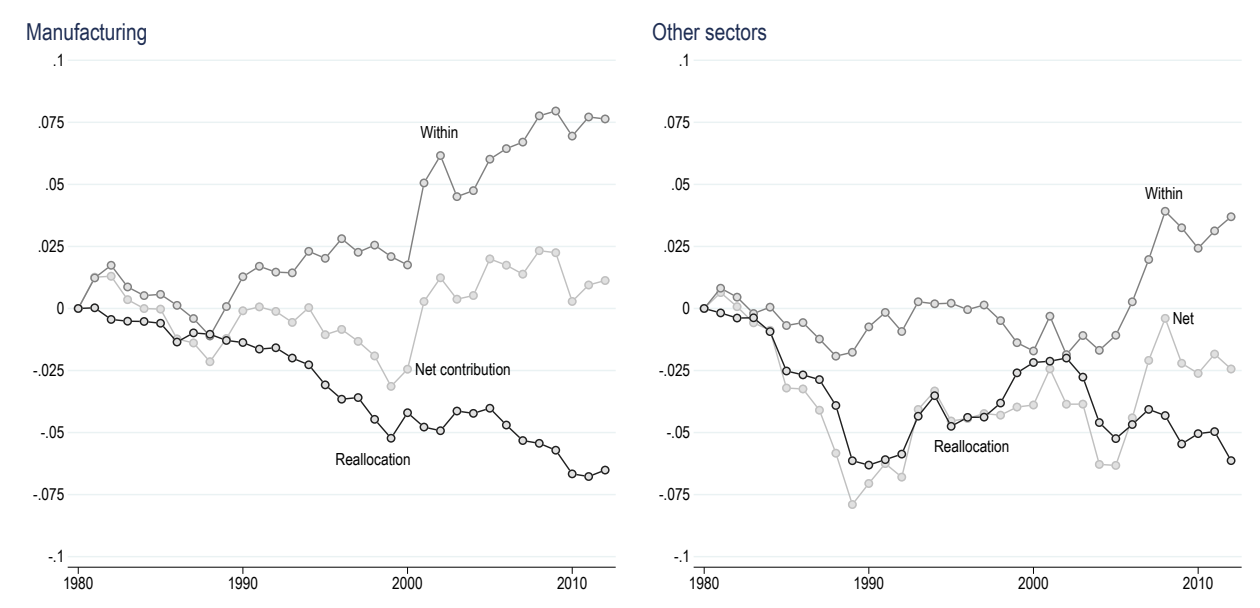

Figure A2: Decomposition of the CONTRIBUtion of Within-Firm CHANGES in MARKups AND BETWEEN-FIRM REALlocation to (PERCENT) CHANGES In THE LABOR SHARE. See the main text for details on this decomposition. Firm-level markups are estimated using a cubic parametrization for $g$ and $h$, as explained in Appendix A.1. The left panel provides the decomposition for manufacturing firms in Compustat. The right panel provides the decomposition for Compustat firms in other economic sectors. See figure 7 in the main text for our baseline estimates reported in the paper. 
Output-to-capital elasticity:

manufacturing firms in Compustat

.35

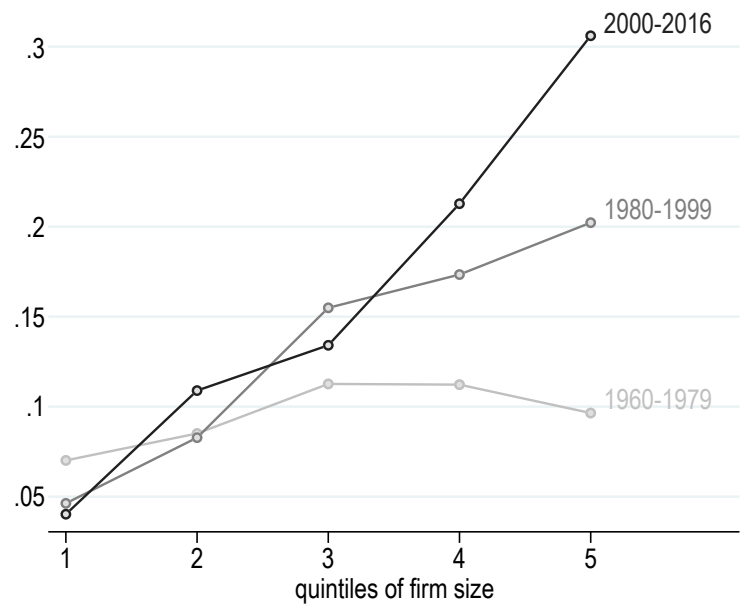

Output-to-capital elasticity:

non-manufacturing firms in Compustat

.35

.3

.25

.2

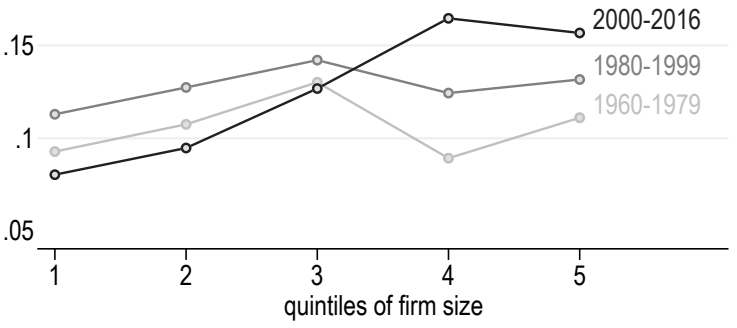


SUMPTION THAT THERE ARE NO EX-POST SHOCKS. The left panel presents estimates for Compustat manufacturing firms. The right panel presents estimates for Compustat non-manufacturing firms. Firmlevel elasticities are estimated under the assumption of no ex-post shocks, as explained in Appendix A.1. See figure 3 in the main text for our baseline estimates used in the results reported in the paper.

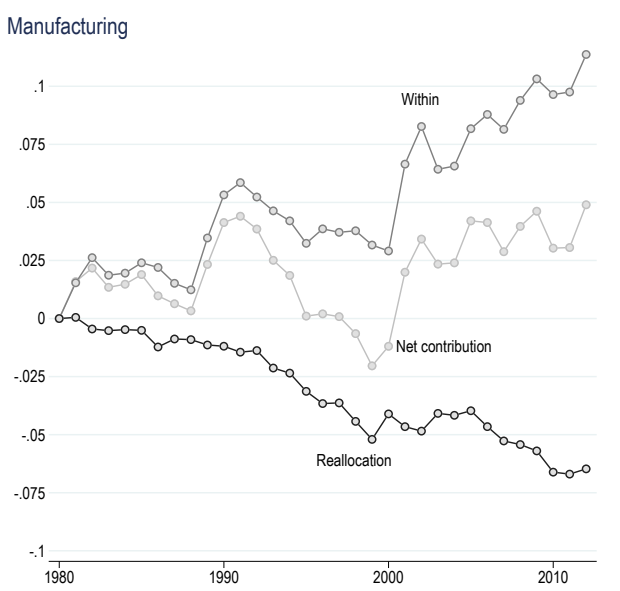

Other sectors

Figure A4: DeCOMPOSITION OF THE CONTRIBUtion OF WITHIN-FIRM CHANGES IN MARKUPS AND BETWEEN-FIRM REALlOCATION TO (PERCENT) CHANGES IN THE LABOR SHARE. See the main text for details on this decomposition. Firm-level markups are estimated under the assumption of no ex-post shocks, as explained in Appendix A.1. The left panel provides the decomposition for manufacturing firms in Compustat. The right panel provides the decomposition for Compustat firms in other economic sectors. See figure 7 in the main text for our baseline estimates reported in the paper. 

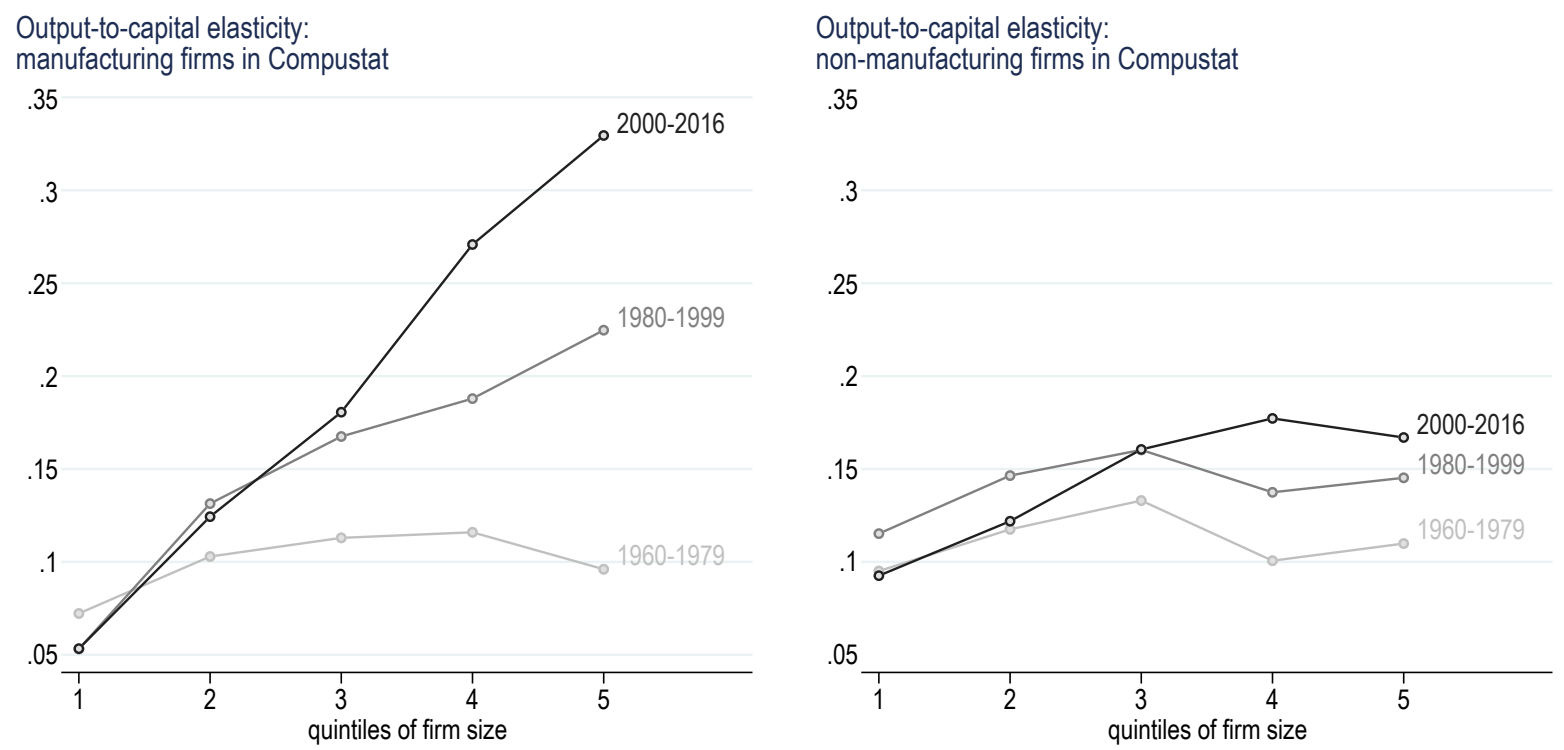

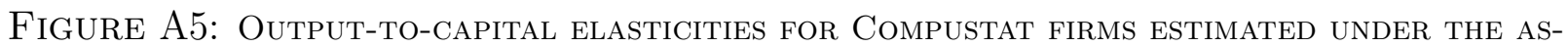
SUMPTION THAT PRODUCTIVITY FOLLOWS A LINEAR MARKOV PROCESS. The left panel presents estimates for Compustat manufacturing firms. The right panel presents estimates for Compustat non-manufacturing firms. Firm-level elasticities are estimated under the assumption that productivity follows a linear Markov process, as explained in Appendix A.1. See figure 3 in the main text for our baseline estimates used in the results reported in the paper.
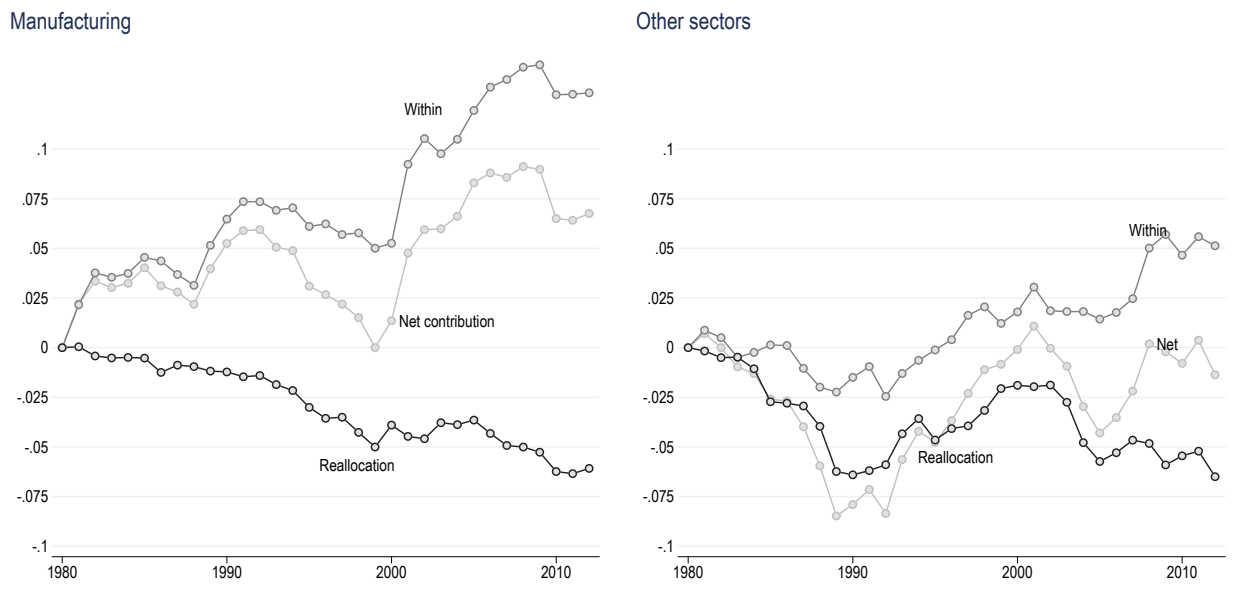

Figure A6: Decomposition of the COntribution of within-Firm Changes in MARkups And BETWEen-Firm REAllocation to (PERCEnt) Changes in the labor share. See the main text for details on this decomposition. Firm-level markups are estimated under the assumption that productivity follows a linear Markov process, as explained in Appendix A.1. The left panel provides the decomposition for manufacturing firms in Compustat. The right panel provides the decomposition for Compustat firms in other economic sectors. See figure 7 in the main text for our baseline estimates reported in the paper. 


\section{A.1.3 Additional evidence from Compustat}

This section provides additional descriptive statistics from Compustat that support the notion that large firms operate more capital-intensive technologies. In what follows, we estimate regression models of the form

$$
\ln y_{t f i}=\alpha_{t i}+\beta_{t c(f)}+\varepsilon_{t f i},
$$

where we explain different measures for the capital intensity $y_{t f i}$ of firm $f$ in industry $i$ at time $t$ as a function of industry and year fixed effects (the $\alpha_{t i}$ ) and size class dummies $\left(\beta_{t c(f)}\right)$ that are allowed to vary over time. In particular, we estimate different size-class dummies for the periods of 1960-1980, 1980-2000 and 2000-2016. We treat firms in the smallest size class of an industry as the excluded category and report estimates weighted by firm sales.

Figure A7 plots estimates of equation (A2) for firms' investment rates, defined as their investment (CAPX in Compustat) normalized by variable cost (top panel), employment (middle panel), and sales (bottom panel). The left panel provides estimates for manufacturing firms and the right panel for firms outside of manufacturing. For the 1980-2000 and 2000-2016 period, the largest manufacturing firms in each industry have had investment rates $60-140 \log$ points higher than those of the smallest firms. Outside of manufacturing, the difference is less pronounced, with the largest firms having 10-90 log points higher investment rates than the smallest firms in their industries. In both cases, the gradient by size has become steeper over time.

Figure A8 plots estimates for firms' capital intensity, defined as their net capital stock (PPENT in Compustat) normalized by variable cost (top panel), employment (middle panel), and sales (bottom panel). For the 1980-2000 and 2000-2016 period, the largest manufacturing firms in each industry had a $55 \log$ point higher capital to variable cost ratio, a $120 \log$ point higher capital per worker, and a $45 \log$ point higher capital to sales ratio than the smaller firms in their industries. Here too, we see some evidence of the gradient by size becoming steeper over time, though the gradient and its rotation are less pronounced outside of manufacturing.

Finally, Figure A9 plots estimates for firms' reliance on capital services. Along a balanced growth path, the flow value of capital services used by a firm can be computed 
$\operatorname{as}^{44}$

flow value of capital services $=(r-g) \cdot$ net capital stock + capital expenditures.

The figure provides estimates normalizing the flow value of capital services by variable costs (so that we get a measure of capital services relative to variable input services), employment, and sales (a measure of capital services in sales). In this exercise, we fix $r-g=2.5 \%$, which aligns with the calibration in Farhi and François (2018). For the 1980-2000 and 2000-2016 period, the largest manufacturing firms in each industry had a 70 log point higher reliance on capital services vs. variable input services when compared to the smallest firms in their industries. Here too, we see some evidence of the gradient by size becoming steeper over time, with the gradient and its rotation being less pronounced outside of manufacturing.

\footnotetext{
${ }^{44}$ In particular, suppose the firm faces no adjustment costs. Then the PDV of capital services equal the PDV of capital costs. The PDV of capital costs are $(1+r) \cdot$ net capital stock $+\frac{1+r}{r-g} \cdot$ capital expenditure, which gives the cost of the initially installed capital and of financing it plus the PDV of capital expenditures. The flow value of capital services is $\frac{r-g}{1+r}$. PDV of capital costs and we get the formula in the text.
} 

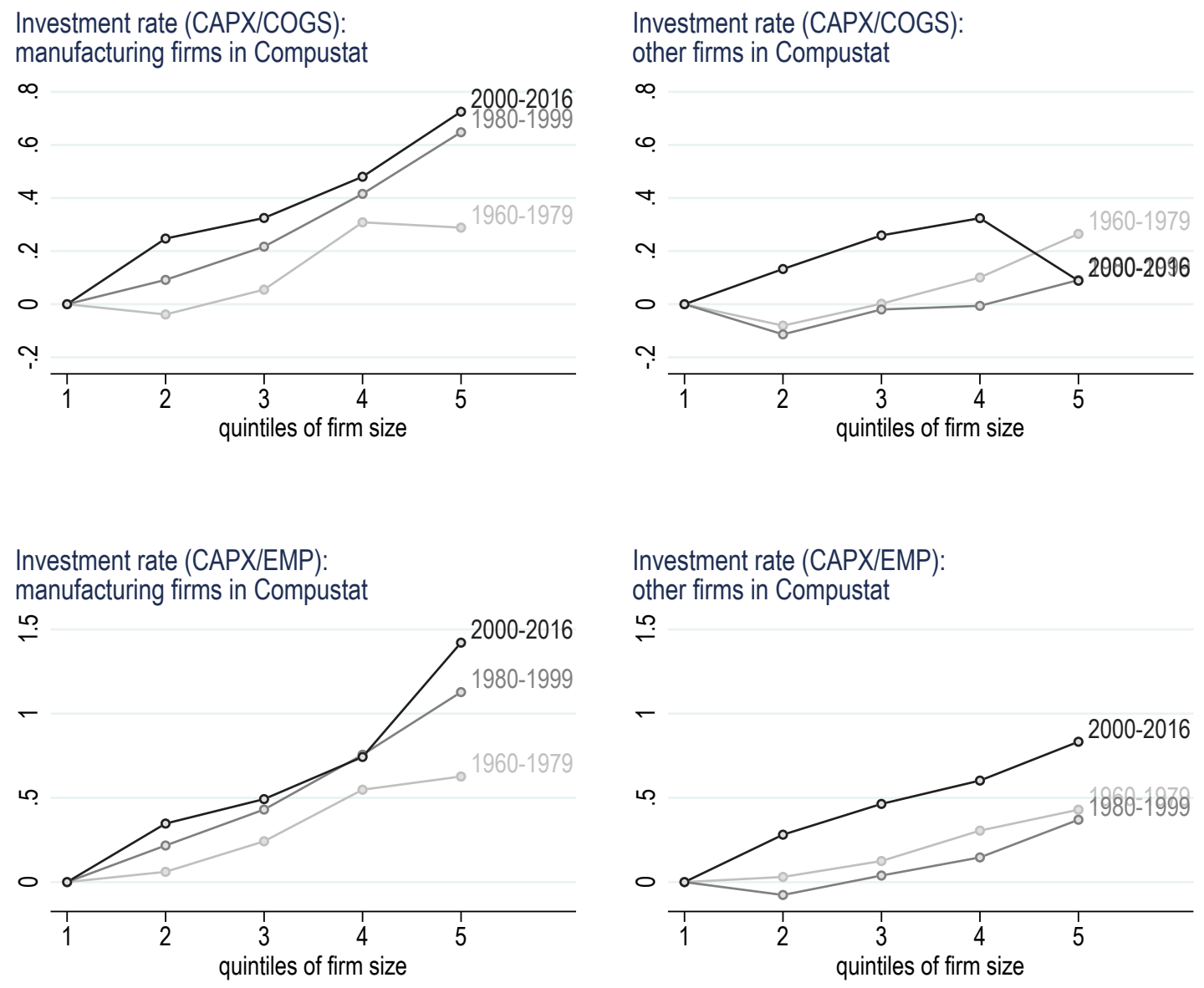

Investment rate (CAPX/SALES):

manufacturing firms in Compustat

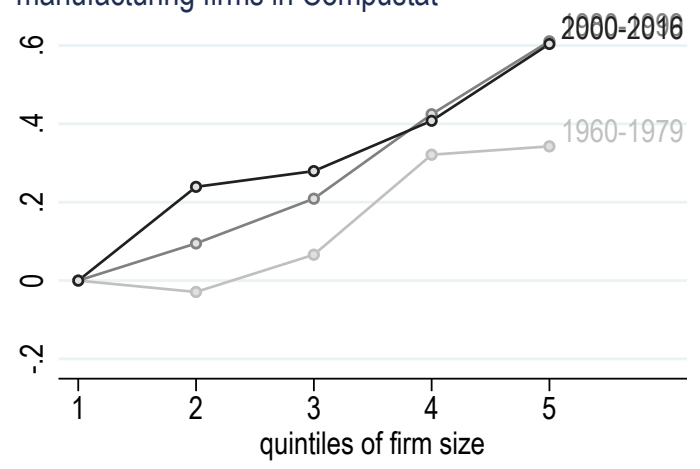

Investment rate (CAPX/SALES): other firms in Compustat

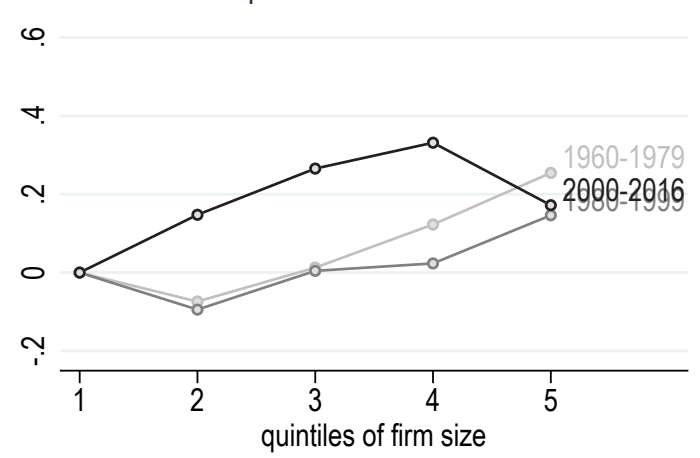

Figure A7: Investment Rates, Compustat. The figure presents estimates of the relative difference in investment rates by firm-size class using Compustat. The left panel presents estimates for Compustat manufacturing firms. The right panel presents estimates for Compustat non-manufacturing firms. 
Capital intensity (PPENT/COGS):

manufacturing firms in Compustat

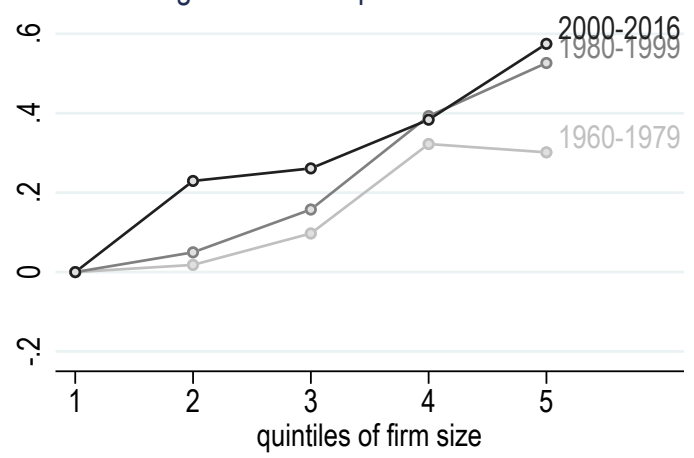

Capital intensity (PPENT/EMP): manufacturing firms in Compustat

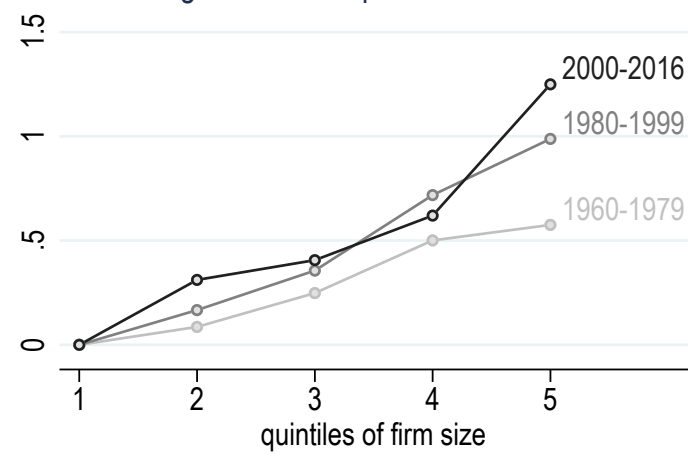

Capital intensity (PPENT/SALES):

manufacturing firms in Compustat

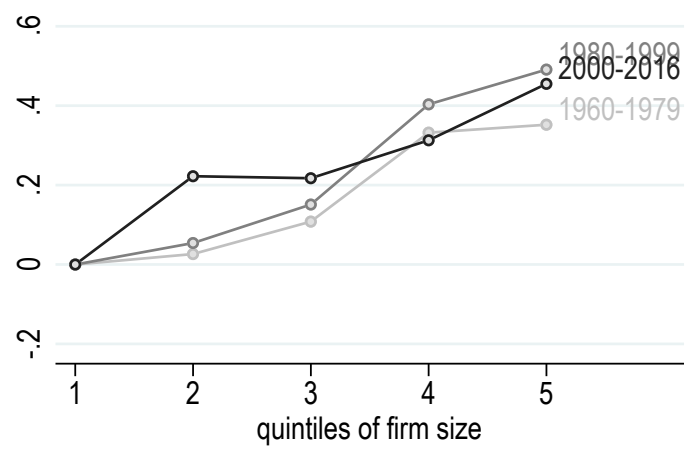

Capital intensity (PPENT/COGS): other firms in Compustat

o.

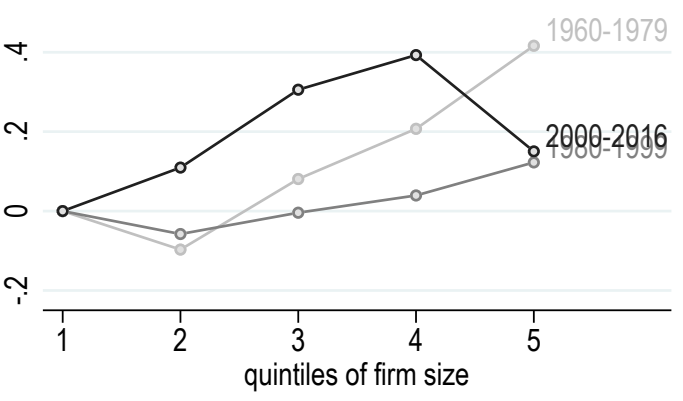

Capital intensity (PPENT/EMP): other firms in Compustat

?․

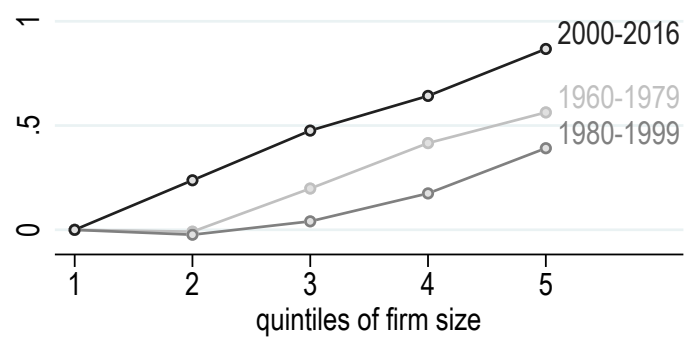

Capital intensity (PPENT/SALES): other firms in Compustat

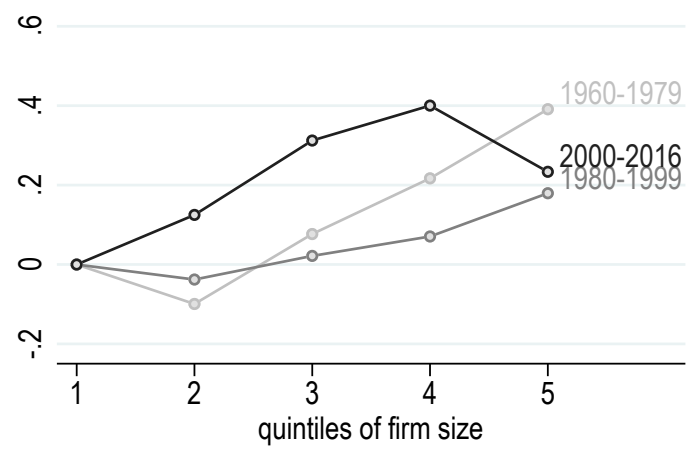

Figure A8: Capital intensity, Compustat. The figure presents estimates of the relative difference in capital intensity by firm-size class using Compustat. The left panel presents estimates for Compustat manufacturing firms. The right panel presents estimates for Compustat non-manufacturing firms. 
Capital services ((r-g)PPENT+CAPX/COGS): manufacturing firms in Compustat

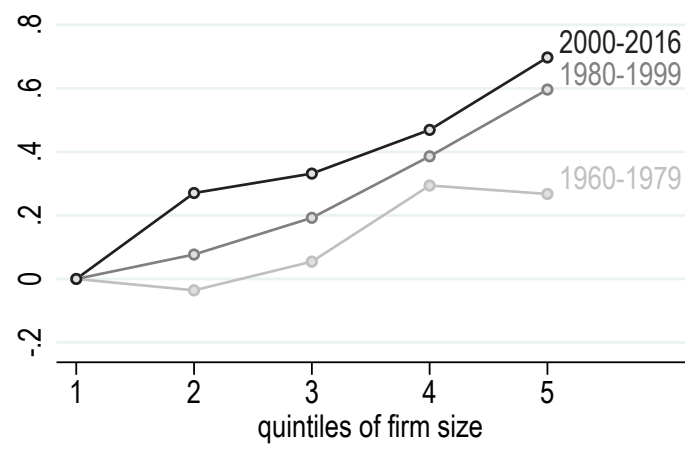

Capital services ((r-g)PPENT+CAPX/EMP): manufacturing firms in Compustat

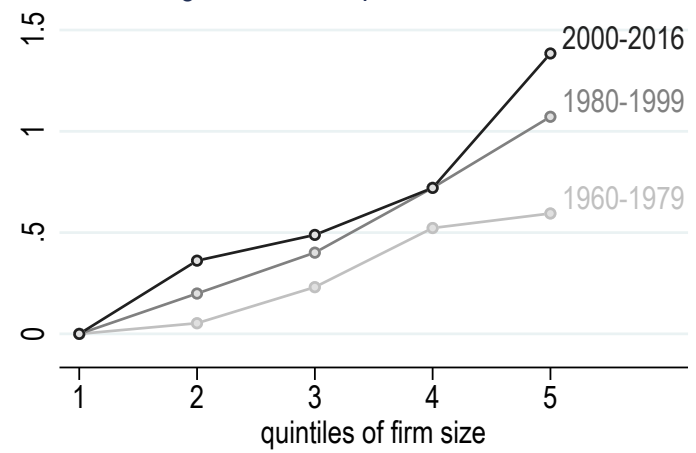

Capital services ((r-g)PPENT+CAPX/SALES): manufacturing firms in Compustat

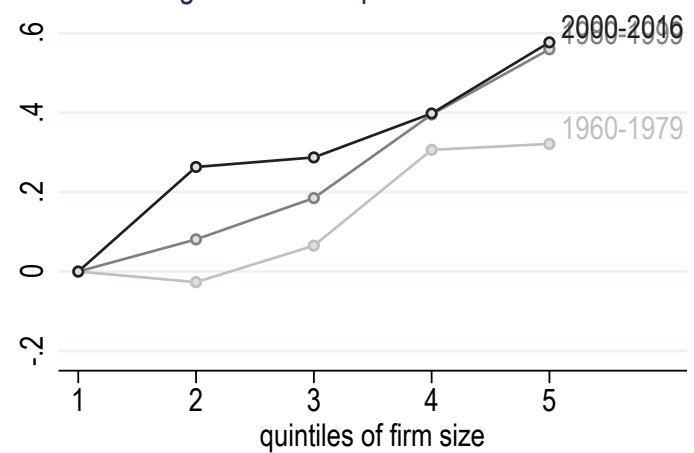

Capital services ((r-g)PPENT+CAPX/COGS): other firms in Compustat
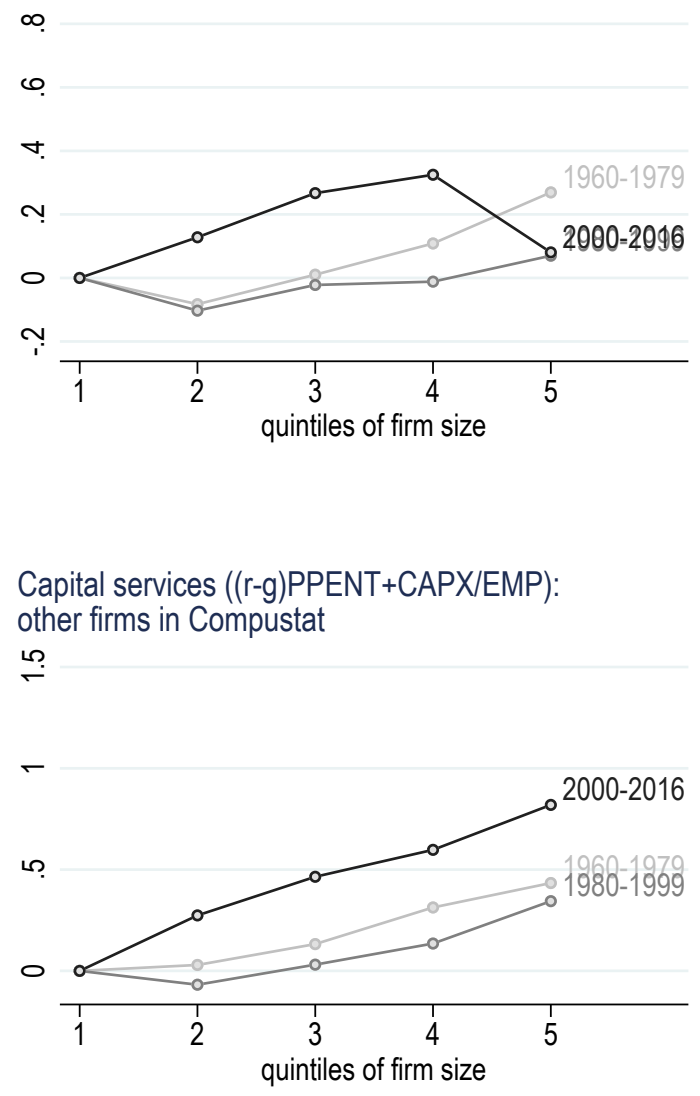

Capital services ((r-g)PPENT+CAPX/SALES): other firms in Compustat

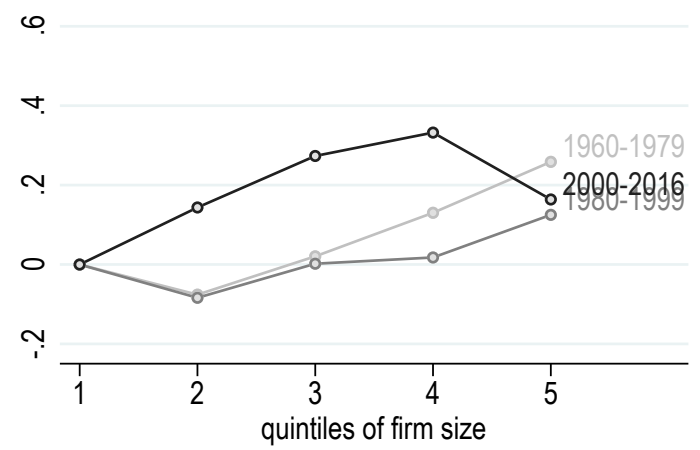

Figure A9: Capital services, Compustat. The figure presents estimates of the relative difference in capital services by firm-size class using Compustat. The left panel presents estimates for Compustat manufacturing firms. The right panel presents estimates for Compustat non-manufacturing firms. 


\section{A.2 Proofs for the CES-Demand Model}

This section provides proofs for Propositions 1, 2, and 3. In addition, we provide an additional lemma characterizing the stationary equilibrium of the economy.

Proof of Proposition 1. We first show that $\tilde{\alpha}_{t}\left(\alpha_{t f}, z\right)$ is weakly increasing in $z$. We have

$$
\tilde{\alpha}_{t}\left(\alpha_{t f}, z\right)=\underset{\alpha \in\left[\alpha_{t f}, 1\right]}{\arg \max }-c_{a} \cdot y_{t} \cdot\left(\alpha-\alpha_{t f}\right)+\frac{1}{1+r} \mathbb{E}\left[V_{t+1, f} \mid z_{t f}=z, \alpha_{t+1, f}=\alpha\right] .
$$

It is therefore sufficient to show that $\mathbb{E}\left[V_{t+1, f} \mid z_{t f}=z, \alpha_{t+1, f}=\alpha\right]$ has increasing differences in $(\alpha, z)$. Ignore firm subscripts for simplicity, let $\Omega_{t+1}(\alpha, z)=\partial_{\alpha} \mathbb{E}\left[V_{t+1, f} \mid z_{t f}=z, \alpha_{t+1, f}=\alpha\right]$, and let $\pi_{t+1}(\alpha)$ denote the profits of a firm with automation level $\alpha$ and unitary productivity. The envelope theorem implies that

$$
\Omega_{t}(\alpha, z)=\pi_{t}^{\prime}(\alpha) \cdot \mathbb{E}\left[z^{\prime \sigma-1} \mid z\right]+\mathbb{E}\left[P_{t}\left(z^{\prime}\right) \cdot \min \left\{c_{a} \cdot y_{t}, \frac{1}{1+r} \Omega_{t+1}\left(\alpha, z^{\prime}\right)\right\} \mid z\right]
$$

where $P_{t}\left(z^{\prime}\right)$ denotes the probability of survival given $z^{\prime}$, and the minimum operator accounts for the fact that the restriction $\alpha_{t+1, f} \geq \alpha_{t, f}$ will bind in some states.

For every $(t, \alpha)$, define the following sequence:

$$
\begin{aligned}
\Omega_{t}^{(1)}(\alpha, z) & =\pi_{t}^{\prime}(\alpha) \cdot \mathbb{E}\left[z^{\prime \sigma-1} \mid z\right] \\
\Omega_{t}^{(n+1)}(\alpha, z) & =\pi_{t}^{\prime}(\alpha) \cdot \mathbb{E}\left[z^{\prime \sigma-1} \mid z\right]+\mathbb{E}\left[P_{t}\left(z^{\prime}\right) \cdot \min \left\{c_{a} \cdot y_{t}, \frac{1}{1+r} \Omega_{t+1}^{(n)}\left(\alpha, z^{\prime}\right)\right\} \mid z\right] .
\end{aligned}
$$

We prove by mathematical induction in $n$ that, for all $(t, \alpha), \Omega_{t}^{(n)}(\alpha, z)$ is weakly increasing in $z$. The base case for $n=1$ follows from the fact that $\mathbb{E}\left[z^{\prime \sigma-1} \mid z\right]$ increases in $z$ and $\pi_{t}^{\prime}(\alpha) \geq 0$ (since firms can always choose to produce automated tasks with labor, and so a larger $\alpha$ weakly reduces their cost). For the inductive step, suppose that $\Omega_{t}^{(n)}(\alpha, z)$ is weakly increasing in $z$ for all $(t, \alpha)$ with $n \leq N$. We have

$$
\Omega_{t}^{(N+1)}(\alpha, z)=\pi_{t}^{\prime}(\alpha) \cdot \mathbb{E}\left[z^{\prime \sigma-1} \mid z\right]+\mathbb{E}\left[P_{t}\left(z^{\prime}\right) \cdot \min \left\{c_{a} \cdot y_{t}, \frac{1}{1+r} \Omega_{t+1}^{(N)}\left(\alpha, z^{\prime}\right)\right\} \mid z\right]
$$

As before, we have that $\pi_{t}^{\prime}(\alpha) \cdot \mathbb{E}\left[z^{\prime \sigma-1} \mid z\right]$ is weakly increasing in $z$. Moreover, $P_{t}\left(z^{\prime}\right) \cdot \min \left\{c_{a}\right.$. $\left.y_{t},(1 /(1+r)) \cdot \Omega_{t+1}^{(N)}\left(\alpha, z^{\prime}\right)\right\}$ is (weakly) increasing in $z^{\prime}$ (due to the inductive hypothesis), and so the term $\mathbb{E}\left[P_{t}\left(z^{\prime}\right) \cdot \min \left\{c_{a} \cdot y_{t},(1 /(1+r)) \cdot \Omega_{t+1}^{(N)}\left(\alpha, z^{\prime}\right)\right\} \mid z\right]$ also (weakly) increases in $z$, which completes the inductive step.

Because the set of weakly increasing functions is closed, $\Omega_{t}(\alpha, z)=\lim _{n \rightarrow \infty} \Omega_{t}^{(n)}(\alpha, z)$ 
is also weakly increasing in $z$. It follows that $\mathbb{E}\left[V_{t+1, f} \mid z_{t f}=z, \alpha_{t+1, f}=\alpha\right]$ has increasing differences in $(\alpha, z)$ as wanted.

Note that optimal automation decisions are guided by $\Omega_{t+1}(\alpha, z)$, which gives the marginal benefit to the firm of automating tasks up to $\alpha_{t+1, f}=\alpha$. Suppose that $\alpha_{t f}<\alpha_{t+1}^{*}$, and take any $\alpha \in\left[\alpha_{t f}, \alpha_{t+1}^{*}\right)$, so that $\pi_{t+1}(\alpha)^{\prime}>0$. We assumed that, for any increasing and unbounded function $f, \mathbb{E}\left[f\left(z_{t+1, f}\right) \mid z_{t f}\right]$ converges to infinity when $z_{t f} \rightarrow \infty$. This assumption implies that the right-hand side of equation (A3) converges to infinity as $z \rightarrow \infty$. Thus, as $z \rightarrow \infty$, the optimal policy involves $\alpha=\alpha_{t+1}^{*}$, which is the only way to ensure that $\pi_{t+1}(\alpha)^{\prime}=0$ and $\Omega_{t+1}(\alpha, z)=0$. Likewise, we assumed that, for any increasing function $f$, $\mathbb{E}\left[f\left(z_{t+1, f}\right) \mid z_{t f}\right]$ converges to $f(0)$ when $z_{t f} \rightarrow 0$. Thus, the right-hand side of equation (A3) converges to zero as $z \rightarrow 0$, which implies that $\Omega_{t+1}(\alpha, z)=0$ for all $\alpha$. In this case, the optimal policy is to keep $\alpha=\alpha_{t f}$ unchanged.

The following lemma will be used in our next results. Before turning to the lemma, we define a series of objects. First, given a constant path for effective capital productivity, $q_{t}(x)=q(x)$, denote by $\alpha^{*}(w ; q)$ the optimal level of automation for firms that face no costs of automation and face a wage $w$. As in the main text, this level is defined implicitly as

$$
\frac{\psi\left(\alpha^{*}(w ; q)\right)}{q\left(\alpha^{*}(w ; q)\right)}=w
$$

Finally, we let $w^{*}(q)$ denote the stationary equilibrium wage in a standard firm-dynamics model with no automation decisions, but with firms costs given by $c_{t f}=\frac{1}{z_{t f}} \cdot c(w ; q)$, where the common cost function satisfies

$$
c(w ; q)=\left(\Gamma^{k}\left(\alpha^{*}(w ; q)\right)+\Gamma^{\ell}\left(\alpha^{*}(w ; q)\right) \cdot w^{1-\eta}\right)^{\frac{1}{1-\eta}} .
$$

The existence and uniqueness of this stationary equilibrium is given in Hopenhayn (1992).

LEMMA A1 Given a constant level of effective capital productivity $q_{t}(x)=q(x)$, the economy admits a unique stationary equilibrium wage $w^{*}(q)$. Moreover, in any stationary equilibrium, $\alpha_{t f} \geq \alpha^{*}\left(q, w^{*}(q)\right)$ for all firms, which implies that the economy behaves as if all firms had a unique level of automation $\alpha_{t f}=\alpha^{*}\left(q^{\prime}, w^{*}\left(q^{\prime}\right)\right)$.

Proof. Consider a steady state with wage $w$. We first show that $\lim _{t \rightarrow \infty} \alpha_{t f} \geq \alpha^{*}(w ; q)$. Consider the path for $\bar{\alpha}_{t}$. Because this is bounded from below, it must eventually lie in an ergodic set with infimum $\bar{\alpha}_{\infty}$. Suppose by way of contradiction that $\bar{\alpha}_{\infty}<\alpha^{*}(w ; q)$. For large $t$, all entrants start with $\alpha_{t f} \geq \bar{\alpha}_{\infty}$, and they can only increase their $\alpha_{t f}$ over time. 
In fact, for any $\bar{\alpha}_{\infty}<\alpha^{*}(w ; q)$, there will be a positive mass of entrants that will draw large realizations of $z_{t f}$ through their lives, and will increase their $\alpha_{t f}$ strictly above $\bar{\alpha}_{\infty}$. This gives a contradiction, since the average $\alpha_{t f}$ would then exceed $\bar{\alpha}_{\infty}$ for all large $t$. This contradiction implies that $\bar{\alpha}_{\infty} \geq \alpha^{*}(w ; q)$, as claimed.

Because $\bar{\alpha}_{\infty} \geq \alpha^{*}(w ; q)$, all firms start with $\alpha_{t f} \geq \alpha^{*}(w ; q)$ and retain this level of automation, producing only the tasks in $\left[0, \alpha^{*}(w ; q)\right]$ with capital. The economy thus converges to a standard firm-dynamics model where firms costs are given by $c_{t f}=\frac{1}{z_{t f}}$. $c\left(w ; q^{\prime}\right)$. The unique steady-state equilibrium of this model then features a wage $w^{*}(q)$ and an automation level $\alpha_{t f} \geq \alpha^{*}\left(q, w^{*}(q)\right)$ as claimed, but only tasks in $\left[0, \alpha^{*}\left(q, w^{*}(q)\right)\right]$ are produced with capital.

Note: Lemma A1 justifies our focus on steady states where all firms operate a technology $\alpha^{*}\left(w^{*}(q) ; q\right)$ and wages are given by $w^{*}(q)$. Propositions 2 and 3 explore how factor shares vary across these steady states in response to different changes in capital prices.

Proof of Proposition 2. Let's write $q(x)=q \cdot q_{0}(x)$ and consider a permanent increase in $q$ by $d \ln q$. We are interested in the comparative statics of the stationary equilibrium with aggregate equilibrium objects $\left(w, y, \alpha^{*}\right)$ as $q$ changes by $d \ln q$.

A firm's cost function can be written as

$$
c\left(z ; w, q, \alpha^{*}\right)=\frac{1}{z} \cdot \tilde{c}\left(w, q, \alpha^{*}\right)
$$

where

$$
\tilde{c}\left(w, q, \alpha^{*}\right)=\left(\Gamma_{0}^{k}\left(\alpha^{*}\right) \cdot q^{\eta-1}+\Gamma^{\ell}\left(\alpha^{*}\right) \cdot w^{1-\eta}\right)^{\frac{1}{1-\eta}}
$$

is the unit cost function of a firm with unitary productivity.

Denote the mass of firms with productivity $z_{t f}=z$ by $m_{z} \geq 0$. We first show that, as $q$ changes, the unit cost of production $\tilde{c}\left(w, q, \alpha^{*}\right)$ and the distribution of productivity among incumbents $m_{z}$ remains unchanged across steady states. We prove this by showing that such an outcome satisfies the required steady-state equilibrium conditions. In particular, suppose that $\tilde{c}$ remains unchanged. Firm profits are then given by

$$
\pi_{t f}=y \cdot \mu^{-\sigma} \cdot(\mu-1) \cdot \tilde{c}\left(w, q, \alpha^{*}\right)^{1-\sigma} \cdot z^{\sigma-1}
$$

which shows that firm profits are proportional to $y$, and so for a given $z$ profits scale with aggregate output. Because fixed costs are also scaled by $y$, the value function of firms is linear in $y$, and across steady states entry and exit decisions as a function of $z$ are unchanged. Consequently, the distribution of firm productivities $m_{z}$ remains unchanged. 
The ideal-price index condition then implies that

$$
\int_{z} \mu^{1-\sigma} \cdot z^{\sigma-1} \cdot \tilde{c}\left(w, q, \alpha^{*}\right)^{1-\sigma} \cdot m_{z} \cdot d z=1
$$

which pins down the constant level for $\tilde{c}\left(w, q, \alpha^{*}\right)$.

We now use the fact that the unit cost function $\tilde{c}\left(w, q, \alpha^{*}\right)$ must be constant across steady-states to characterize the equilibrium response of wages. An application of Shephard's lemma implies that

$$
d \ln \tilde{c}\left(w, q, \alpha^{*}\right)=\varepsilon^{\ell} \cdot d \ln w-\varepsilon^{k} \cdot d \ln q,
$$

where, in addition, the envelope theorem ensures that the effect of changes in $\alpha^{*}$ on $\tilde{c}\left(w, q, \alpha^{*}\right)$ are second order and can be ignored. Because $d \ln \tilde{c}\left(w, q, \alpha^{*}\right)=0$, we can solve for the change in wages as

$$
d \ln w=\frac{\varepsilon^{k}}{\varepsilon^{\ell}} \cdot d \ln q=\frac{1-\varepsilon^{\ell}}{\varepsilon^{\ell}} \cdot d \ln q>0
$$

We now turn to the behavior of cost shares (or equivalently, output elasticities). In steady state, all firms have the same labor cost share, which is given by

$$
\varepsilon^{\ell}=\frac{\Gamma^{\ell}\left(\alpha^{*}\right) \cdot w^{1-\eta}}{\Gamma_{0}^{k}\left(\alpha^{*}\right) \cdot q^{\eta-1}+\Gamma^{\ell}\left(\alpha^{*}\right) \cdot w^{1-\eta}} .
$$

This common cost share for labor will vary with prices and $\alpha^{*}$. Equation (2) implies that the change in the optimal threshold $\alpha^{*}$ satisfies

$$
d \ln \alpha^{*}=\frac{1}{\partial \ln \psi\left(\alpha^{*}\right) / q\left(\alpha^{*}\right) / \partial \ln \alpha}(d \ln q+d \ln w) .
$$

Using this expression for $d \ln \alpha^{*}$ and the definition of $\eta^{*}$, we can compute the change in the cost share of labor as

$$
\begin{aligned}
d \ln \varepsilon^{\ell} & =\varepsilon^{k} \cdot d \ln \frac{\varepsilon^{\ell}}{\varepsilon^{k}} \\
& =\varepsilon^{k} \cdot(1-\eta) \cdot(d \ln q+d \ln w)+\varepsilon^{k} \cdot \frac{\partial \ln \Gamma^{\ell}\left(\alpha^{*}\right) / \Gamma_{0}^{k}\left(\alpha^{*}\right)}{\partial \ln \alpha} \cdot d \ln \alpha^{*} \\
& =\varepsilon^{k} \cdot(1-\eta) \cdot(d \ln q+d \ln w)+\varepsilon^{k} \cdot\left(\eta-\eta^{*}\right) \cdot(d \ln q+d \ln w) \\
& =\varepsilon^{k} \cdot\left(1-\eta^{*}\right) \cdot(d \ln q+d \ln w)
\end{aligned}
$$


which using the formula above for the change in wages can be written as

$$
d \ln \varepsilon^{\ell}=\frac{1-\varepsilon^{\ell}}{\varepsilon^{\ell}} \cdot\left(1-\eta^{*}\right) \cdot d \ln q
$$

Along the transition, firms will differ in the extent to which they will automate their tasks. Let $d \ln \alpha_{t f}$ denote the additional tasks automated by firm $f$ at time $t$ in response to the permanent increase in capital prices. We have that

$$
\begin{aligned}
d \ln \varepsilon_{t f}^{\ell} & =\varepsilon^{k} \cdot d \ln \frac{\varepsilon^{\ell}}{\varepsilon^{k}} \\
& =\varepsilon^{k} \cdot(1-\eta) \cdot\left(d \ln q+d \ln w_{t}\right)+\varepsilon^{k} \cdot \frac{\partial \ln \Gamma^{\ell}\left(\alpha^{*}\right) / \Gamma_{0}^{k}\left(\alpha^{*}\right)}{\partial \ln \alpha} \cdot d \ln \alpha_{t f} \\
& =\varepsilon^{k} \cdot(1-\eta) \cdot\left(d \ln q+d \ln w_{t}\right)+\varepsilon^{k} \cdot \frac{\partial \ln \Gamma^{\ell}\left(\alpha^{*}\right) / \Gamma_{0}^{k}\left(\alpha^{*}\right)}{\partial \ln \alpha} \cdot d \ln \alpha^{*} \cdot \frac{d \ln \alpha_{t f}}{d \ln \alpha^{*}} \\
& =\varepsilon^{k} \cdot(1-\eta) \cdot\left(d \ln q+d \ln w_{t}\right)+\varepsilon^{k} \cdot\left(\eta-\eta^{*}\right) \cdot\left(d \ln q+d \ln w_{t}\right) \cdot \frac{d \ln \alpha_{t f}}{d \ln \alpha^{*}} \\
& =\varepsilon^{k} \cdot\left(1-\eta+\left(\eta^{*}-\eta\right) \frac{d \ln \alpha_{t f}}{d \ln \alpha^{*}}\right) \cdot\left(d \ln q+d \ln w_{t}\right),
\end{aligned}
$$

which using the formula above for the change in wages can be written as

$$
d \ln \varepsilon_{t f}^{\ell}=\frac{\varepsilon^{k}}{\varepsilon^{\ell}} \cdot\left(1-\eta+\left(\eta^{*}-\eta\right) \frac{d \ln \alpha_{t f}}{d \ln \alpha^{*}}\right) \cdot d \ln q
$$

Proof of Proposition 3. Let $q(x)=q \cdot q_{0}(x)$ for $x>\alpha^{*}$ and $q(x)=q_{0}(x)$ otherwise. We are interested in the comparative statics of the stationary equilibrium with aggregate equilibrium objects $\left(w, y, \alpha^{*}\right)$ as $q$ changes from 1 by $d \ln q$.

First, recall that $\tilde{c}\left(w, q, \alpha^{*}\right)$ is the minimum cost of production given $w$ and $q$. An increase in $q$ thus reduces $\tilde{c}$ once we account for changes in $\alpha^{*}$, which implies that $w$ increases. Thus, we have $d \ln w>0$. Note that the first-order approximation used in the proof of Proposition 2 yields $d \ln w=0$. This is because the increase in wages is second order but positive nonetheless.

We now turn to the behavior of cost shares. In steady state, all firms have the same labor cost share, which is given by

$$
\varepsilon^{\ell}=\frac{\Gamma^{\ell}\left(\alpha^{*}\right) \cdot w^{1-\eta}}{\Gamma_{0}^{k}\left(\alpha^{*}\right)+\Gamma^{\ell}\left(\alpha^{*}\right) \cdot w^{1-\eta}} .
$$

This common cost share for labor will vary with prices and $\alpha^{*}$. Equation (2) implies that 
the change in the optimal threshold $\alpha^{*}$ satisfies

$$
d \ln \alpha^{*}=\frac{1}{\partial \ln \psi\left(\alpha^{*}\right) / q\left(\alpha^{*}\right) / \partial \ln \alpha}(d \ln q+d \ln w)
$$

Using this expression for $d \ln \alpha^{*}$ and the definition of $\eta^{*}$, we can compute the change in the cost share of labor as

$$
\begin{aligned}
d \ln \varepsilon^{\ell} & =\varepsilon^{k} \cdot d \ln \frac{\varepsilon^{\ell}}{\varepsilon^{k}} \\
& =\varepsilon^{k} \cdot(1-\eta) \cdot d \ln w+\varepsilon^{k} \cdot \frac{\partial \ln \Gamma^{\ell}\left(\alpha^{*}\right) / \Gamma_{0}^{k}\left(\alpha^{*}\right)}{\partial \ln \alpha} \cdot d \ln \alpha^{*} \\
& =\varepsilon^{k} \cdot(1-\eta) \cdot d \ln w-\varepsilon^{k} \cdot\left(\eta^{*}-\eta\right) \cdot(d \ln q+d \ln w) .
\end{aligned}
$$

Along the transition, firms will differ in the extent to which they automate their tasks. Let $d \ln \alpha_{t f}$ denote the additional tasks automated by firm $f$ at time $t$ in response to the permanent increase in capital prices. We have that

$$
\begin{aligned}
d \ln \varepsilon_{t f}^{\ell} & =\varepsilon^{k} \cdot d \ln \frac{\varepsilon^{\ell}}{\varepsilon^{k}} \\
& =\varepsilon^{k} \cdot(1-\eta) \cdot d \ln w_{t}+\varepsilon^{k} \cdot \frac{\partial \ln \Gamma^{\ell}\left(\alpha^{*}\right) / \Gamma_{0}^{k}\left(\alpha^{*}\right)}{\partial \ln \alpha} \cdot d \ln \alpha_{t f} \\
& =\varepsilon^{k} \cdot(1-\eta) \cdot d \ln w_{t}+\varepsilon^{k} \cdot \frac{\partial \ln \Gamma^{\ell}\left(\alpha^{*}\right) / \Gamma_{0}^{k}\left(\alpha^{*}\right)}{\partial \ln \alpha} \cdot d \ln \alpha^{*} \cdot \frac{d \ln \alpha_{t f}}{d \ln \alpha^{*}} \\
& =\varepsilon^{k} \cdot(1-\eta) \cdot d \ln w_{t}-\varepsilon^{k} \cdot\left(\eta^{*}-\eta\right) \cdot(d \ln q+d \ln w) \cdot \frac{d \ln \alpha_{t f}}{d \ln \alpha^{*}}
\end{aligned}
$$

\section{A.3 ProOfs FOR THE MODEL WITH VARIABLE MARKUPS}

This section provides the proofs of the theoretical results in section 3 .

\section{A.3.1 Implications of Marshall's weak and strong second laws}

We begin with a lemma that characterizes the implications of Marshall's second laws for prices, markups, and passthroughs. We consider a firm with a constant marginal cost $c$ and denote its optimal price by $p^{*}(c)$. Likewise, we define markups by $\mu^{*}(c)$ and firm sales by $\omega^{*}(c)$.

LEMMA A2 Under Marshall's weak second law, firms with lower costs c charge lower 
prices $p^{*}(c)$ but higher markups $\mu^{*}(c)$. Moreover, under Marshall's strong second law, markups and prices, $\mu^{*}(c)$ and $p^{*}(c)$, are a log-convex function of costs, which implies lower passthroughs for more productive firms. Finally, sales $\omega^{*}(c)$ are a log-concave and decreasing function of costs.

Proof of Lemma A2. Prices are given by

$$
p^{*}(c)=\underset{p}{\arg \max } y \cdot \lambda \cdot D\left(\frac{p}{\rho}\right) \cdot(p-c) .
$$

This problem has increasing differences in $p$ and $c$, which implies that $p^{*}(c)$ is increasing in $c$.

Moreover, the first order condition for this problem is

$$
-\frac{1}{\rho} D^{\prime}\left(\frac{p}{\rho}\right) \cdot(p-c)=D\left(\frac{p}{\rho}\right) \Rightarrow \frac{\mu^{*}(c)}{\mu^{*}(c)-1}=-\frac{p^{*}(c)}{\rho} \frac{D^{\prime}\left(\frac{p^{*}(c)}{\rho}\right)}{D\left(\frac{p^{*}(c)}{\rho}\right)} .
$$

Marshall's weak second law combined with the fact that $p^{*}(c)$ increases in $c$ implies that the right-hand side of the above equation increases in $c$. The left-hand side is a decreasing function of $\mu^{*}(c)$, which therefore implies that $\mu^{*}(c)$ is decreasing in $c$ as wanted.

We can rewrite the first-order condition for prices as

$$
\frac{p^{*}(c)}{\rho}+\frac{D\left(p^{*}(c) / \rho\right)}{D^{\prime}\left(p^{*}(c) / \rho\right)}=\frac{c}{\rho} .
$$

Differentiating this expression yields

$$
\frac{\partial \ln p^{*}(c)}{\partial \ln c}=1 / d\left(\frac{p^{*}(c)}{\rho}\right)
$$

where

$$
d(x)=\frac{\partial \ln \left(x+D(x) / D^{\prime}(x)\right)}{\partial \ln x}
$$

is a decreasing function according to Marshall's strong second law. It follows that $\ln p^{*}(c)$ is a convex function in $\ln c$ as wanted. Moreover, $\ln \mu^{*}(c)=\ln p^{*}(c)-\ln c$ will inherit this convexity. 
Turning to sales shares, we have that $\omega^{*}(c)$ can be written as

$$
\omega^{*}(c)=h\left(p^{*}(c)\right) / y,
$$

where $h(x)=x D(x)$ is a log-concave and decreasing function of $x$ (from Marshall's weak second law). Thus, $\omega^{*}(c)$ is the composition of a log-concave and decreasing function $(h(x))$ with a log-convex and increasing function $p(c)$, which results in a log-concave and decreasing function.

\section{A.3.2 Proofs and derivations of results in the main text}

Before turning to the proofs of the propositions in the text, we provide some preliminary derivations and the full formal definition of an equilibrium in the non-CES model.

First, we show that the demand system that results from aggregating customers' demand is equivalent to assuming a single representative customer that demands varieties to produce a final good $y_{t}$ which can then be used for consumption or to produce capital goods. In particular, the customers introduced in the main text could also represent producers of capital goods, and that is why we do not refer to them simply as consumers. This representative customer solves the following cost minimization problem:

$$
\min _{y_{t f}} \int_{f} p_{t f} \cdot y_{t f} \cdot d f \quad \text { s.t: } \int_{f} \lambda \cdot H\left(\frac{y_{t f}}{\lambda_{t} \cdot y_{t}}\right) \cdot d f=1 .
$$

Let $\rho_{t} \cdot y_{t}$ denote the Lagrange multiplier on the constraint. The first-order condition for the choice of $y_{t f}$ is then

$$
p_{t f}=\rho_{t} \cdot H^{\prime}\left(\frac{y_{t f}}{\lambda_{t} \cdot y_{t}}\right) \Rightarrow y_{t f}=y_{t} \cdot \lambda_{t} \cdot D\left(\frac{p_{t f}}{\rho_{t}}\right) .
$$

Moreover, because the price of the final good is normalized to 1 , we must have

$$
1=\int_{f} \lambda_{t} \cdot p_{t f} \cdot D\left(\frac{p_{t f}}{\rho_{t}}\right) \cdot d f .
$$

Likewise, plugging the demand for each variety in the constraint, we obtain

$$
\int_{f} \lambda_{t} \cdot H\left(D\left(\frac{p_{t f}}{\rho_{t}}\right)\right) \cdot d f=1,
$$

which pins down the competitors' price index $\rho_{t}$. These three equations coincide with equations (5), (4), and (6) and establish the aggregation result. 
Denote by $p_{t f}(w)$ the price charged by a firm facing a wage $w$, by $c_{t f}(w)$ its cost, and by $\pi_{t f}(w)$ its profits. Given a path for capital productivity $q_{t}(x)$, market access, $\lambda_{t}$, and an initial distribution of firms $\left\{\alpha_{0 f}, z_{0 f}\right\}$, an equilibrium is given by a path for wages $w_{t}$, aggregate output $y_{t}$, the competitors' price index $\rho_{t}$, as well as a path for the distribution of firms $\left\{\alpha_{t f}, z_{t f}\right\}$, such that for all $t \geq 0$ :

E1. The ideal-price index condition in equation (6) holds.

E2. The competitors' price index condition in equation (5) holds.

E3. The labor market clears

$$
\int_{f} y_{t} \cdot \lambda_{t} \cdot D\left(\frac{p_{t f}}{\rho_{t}}\right) \cdot \frac{\partial c_{t f}\left(w_{t}\right)}{\partial w_{t}} \cdot d f=\ell
$$

E4. Automation and exit decisions maximize the value function of incumbents

$$
\begin{aligned}
V_{t f}= & \pi_{t f}\left(w_{t}\right)+ \\
& \int \max \left\{0,-c_{o} \cdot y_{t}+\max _{\alpha_{t+1, f} \in\left[\alpha_{t, f}, 1\right]}\left\{-c_{a} \cdot y_{t} \cdot\left(\alpha_{t+1, f}-\alpha_{t, f}\right)+\frac{1}{1+r} \mathbb{E}\left[V_{t+1, f} \mid z_{t, f}\right]\right\}\right\} d G\left(c_{o}\right) .
\end{aligned}
$$

E5. Entry decisions maximize the value of entrants

$$
V_{t z}^{e}=\int \max \left\{0,-c_{o} \cdot y_{t}+\max _{\alpha_{t+1, f} \in[\bar{\alpha}, 1]}\left\{-c_{a} \cdot y_{t} \cdot\left(\alpha_{t+1, f}-\bar{\alpha}_{t}\right)+\frac{1}{1+r} \mathbb{E}\left[V_{t+1, f} \mid z_{t f}=z\right]\right\}\right\} d G\left(c_{o}\right),
$$

where $z$ denotes an entrant's productivity signal, and $\bar{\alpha}_{t} \equiv\left(\int_{f} \alpha_{t f} \cdot d f\right) /\left(\int_{f} d f\right)$.

E6. Starting from a distribution $\left\{\alpha_{0 f}, z_{0 f}\right\}$, the evolution of $\left\{\alpha_{t f}, z_{t f}\right\}$ is governed by the exogenous process for $z$, the endogenous process for $\alpha$, and optimal entry and exit decisions.

Proof of Proposition 4. Let $\bar{c}=\widetilde{c} / \rho$, where recall that $\widetilde{c}$ is the constant marginal cost for a firm with unitary productivity. We can rewrite firms' pricing problem as

$$
\max _{\bar{p}} D(\bar{p}) \cdot(\bar{p}-\bar{c} / z)
$$

where $\bar{p}=p / \rho$ denotes the normalized firm price . Lemma A2 implies that firm prices are given by $p_{z}=\rho \cdot p^{*}(\bar{c} / z)$, markups by $\mu_{z}=\mu^{*}(\bar{c} / z)$, and sale shares by $\omega_{z}=\omega^{*}(\bar{c} / z)$.

The implicit definition of the competitors' price index implies

$$
\int_{z} \lambda \cdot H\left(D\left(p^{*}(\bar{c} / z)\right)\right) \cdot m_{z} \cdot d z=1
$$


Consider an increase in $\lambda$. Suppose by way of contradiction that $\bar{c}$ declines. This would increase firm profits, increasing entry and reducing exit. Note also that any effect of $\lambda$ on aggregate output holding $\bar{c}$ constant will not affect entry or exit decisions. This is because, conditional on $\bar{c}$, value functions are linear in aggregate output $y$. As a result, $m_{z}$ would increase and the price index condition would be violated. This contradiction then requires $\bar{c}$ to increase. As a result, the effect of an increase in $\lambda$ on prices, markups, and sales shares can be summarized by the resulting increase in $\bar{c}$.

We now characterize the effects of an increase in $\bar{c}$. First, we have that for a given $z, \mu_{z}=\mu^{*}(\bar{c} / z)$ will be decreasing in $\bar{c}$, as wanted. Second, because the function $\mu^{*}(c)$ is log-convex, we have that, for $z>z^{\prime}$,

$$
\ln \mu_{z}-\ln \mu_{z^{\prime}}=\ln \mu^{*}(\bar{c} / z)-\ln \mu^{*}\left(\bar{c} / z^{\prime}\right)
$$

is decreasing in $\bar{c}$. Third, because the function $\omega^{*}(c)$ is log-concave, we have that, for $z>z^{\prime}$,

$$
\ln \omega_{z}-\ln \omega_{z^{\prime}}=\ln \omega^{*}(\bar{c} / z)-\ln \omega^{*}\left(\bar{c} / z^{\prime}\right)
$$

is increasing in $\bar{c}$.

Proof of Proposition 5. As before, we investigate the implications of an increase in $\bar{c}$. Holding the distribution of productivities constant at $m_{z}=f(z)$, we can write the aggregate markup as

$$
\frac{1}{\mu}=\int_{z} \frac{1}{\mu^{*}(\bar{c} / z)} \cdot \omega^{*}(\bar{c} / z) \cdot f(z) \cdot d z
$$

With the change of variable $x=\bar{c} / z$, we can rewrite this as

$$
\frac{1}{\mu}=\int_{x} \frac{1}{\bar{\mu}(x)} \cdot g(x, \bar{c}) \cdot d x,
$$

where $g(x, \bar{c})$ is a density function given by

$$
g(x, \bar{c})=\omega^{*}(x) \cdot f(\bar{c} / x) \cdot \frac{\bar{c}}{x^{2}} \cdot d x .
$$

First, suppose that $f(z)$ is log-concave. This implies that

$$
\ln g(x, \bar{c})=\ln \omega^{*}(x)+\ln f(\bar{c} / x)+\ln \bar{c}-2 \ln x
$$

has increasing differences in $x$ and $\bar{c}$. This is equivalent to the following monotone likelihood 
ratio property (MLRP):

$$
\frac{g(x, \bar{c})}{g\left(x^{\prime}, \bar{c}\right)} \text { increasing in } \bar{c} \text { for } x>x^{\prime} .
$$

The MLRP property implies that an increase in $\bar{c}$ generates a shift up (in the first-order stochastic dominance sense) in $g(x, \bar{c})$. Because the function $\frac{1}{\mu^{*}(x)}$ is increasing in $x$, the aggregate markup $\mu$ decreases in $\bar{c}$ as wanted.

Second, suppose that $f(z)$ is log-convex. This implies that

$$
\ln g(x, \bar{c})=\ln \omega^{*}(x)+\ln f(\bar{c} / x)+\ln \bar{c}-2 \ln x
$$

has decreasing differences in $x$ and $\bar{c}$. This is equivalent to the following monotone likelihood ratio property (MLRP):

$$
\frac{g(x, \bar{c})}{g\left(x^{\prime}, \bar{c}\right)} \text { decreasing in } \bar{c} \text { for } x>x^{\prime}
$$

The MLRP property implies that an increase in $\bar{c}$ generates a shift down (in the first-order stochastic dominance sense) in $g(x, \bar{c})$. Because the function $\frac{1}{\mu^{*}(x)}$ is increasing in $x$, the aggregate markup $\mu$ increases in $\bar{c}$ as wanted.

Finally, suppose that $f(z)$ is log-linear. This implies that

$$
\ln g(x, \bar{c})=\ln \omega^{*}(x)+\ln f(\bar{c} / x)+\ln \bar{c}-2 \ln x
$$

is a linear function in $\ln \bar{c}$. Equivalently,

$$
\frac{g(x, \bar{c})}{g\left(x^{\prime}, \bar{c}\right)} \text { is independent of } \bar{c} .
$$

Thus, the integral defining $\mu$ is independent of $\bar{c}$ as wanted.

\section{A.3.3 Properties of the Klenow-Willis aggregator}

As a convenient functional form for the Kimball (1995) aggregator $H$ we use the specification from Klenow and Willis (2016), defined as 


$$
H\left(\bar{y}_{t f}\right) \equiv 1+(\sigma-1) \cdot \exp \left(\frac{1}{\nu}\right) \cdot \nu^{\frac{\sigma}{\nu}-1} \cdot\left[\Gamma\left(\frac{\sigma}{\nu}, \frac{1}{\nu}\right)-\Gamma\left(\frac{\sigma}{\nu}, \frac{\bar{y}_{t f}^{\frac{\nu}{\sigma}}}{\nu}\right)\right]
$$

where $\bar{y}_{t f}=y_{t f} /\left(\lambda_{t} \cdot y_{t}\right)$ is the relative quantity of a variety, and $\Gamma(\cdot, \cdot)$ is the upper incomplete Gamma function,

$$
\Gamma(s, x) \equiv \int_{x}^{\infty} t^{s-1} \cdot \exp (-t) d t
$$

This gives rise to the following (relative) demand function $D^{-1}=H^{\prime}$ :

$$
\begin{aligned}
D\left(\bar{p}_{t f}\right) & =\left(1-\nu \cdot \ln \left(\bar{p}_{t f} \cdot \frac{\sigma}{\sigma-1}\right)\right)^{\frac{\sigma}{\nu}} \\
D^{\prime}\left(\bar{p}_{t f}\right) & =\frac{\sigma}{\bar{p}_{t f}} \cdot\left(1-\nu \cdot \ln \left(\bar{p}_{t f} \cdot \frac{\sigma}{\sigma-1}\right)\right)^{\frac{\sigma}{\nu}-1}
\end{aligned}
$$

where $\bar{p}_{t f}=p_{t f} / \rho$ is the normalized price of a variety. The price elasticity of demand is

$$
-\frac{D^{\prime}\left(\bar{p}_{t f}\right) \cdot \bar{p}_{t f}}{D\left(\bar{p}_{t f}\right)}=\frac{\sigma}{1-\nu \cdot \ln \left(\bar{p}_{t f} \cdot \frac{\sigma}{\sigma-1}\right)}=\sigma \cdot D\left(\bar{p}_{t f}\right)^{-\frac{\nu}{\sigma}}
$$

which reduces to the constant $\sigma$ if $\nu=0$ (the benchmark case of a CES aggregator). In general, equation (A4) shows that under this parametrization, the super-elasticity of demand is equal to the constant $-\frac{\nu}{\sigma}$, and that larger firms will face more inelastic demand curves.

To conclude, we show that the Klenow-Willis aggregator satisfies Marshall's second laws. Equation (7) shows that the demand elasticity is increasing in the relative price and greater than 1 (Marshall's weak second law), imposing the restriction that $\sigma>1$ and $\nu>0$. To see that the strong law holds as well, write the logarithm of marginal revenue as

$$
\begin{aligned}
\ln \left(\bar{p}_{t f}+\frac{D\left(\bar{p}_{t f}\right)}{D^{\prime}\left(\bar{p}_{t f}\right)}\right) & =\ln \bar{p}_{t f}+\ln \left(1+\frac{D\left(\bar{p}_{t f}\right)}{D^{\prime}\left(\bar{p}_{t f}\right) \cdot \bar{p}_{t f}}\right) \\
& =\ln \bar{p}_{t f}+\ln \left(\frac{\sigma+\nu \cdot \ln \left(\bar{p}_{t f}\right)+\nu \cdot \ln \left(\frac{\sigma}{\sigma-1}\right)-1}{\sigma}\right)
\end{aligned}
$$

which is a concave function of $\ln \bar{p}_{t f}$ as desired. 


\section{A.4 The induced Elasticity of Substitution $\eta^{*}$}

This section derives the parametrization of the productivity schedule for labor and capital that yields a constant induced elasticity of substitution between capital and labor $\eta^{*}$.

The induced elasticity of substitution is, as usual, defined implicitly by the identity

$$
d \ln \frac{\varepsilon^{\ell}}{\varepsilon^{k}} \equiv\left(1-\eta^{*}\right) \cdot d \ln w
$$

This gives the change in labor-to-capital cost ratios resulting from an increase in wages. Higher wages reduce the labor-to-capital cost ratio if $\eta^{*}>1$ and increase it if $\eta^{*}<1$.

Define $\alpha^{*}(w)$ implicitly as in the text by the solution to

$$
w=\frac{\psi\left(\alpha^{*}(w)\right)}{q\left(\alpha^{*}(w)\right)} .
$$

Define $h_{k}(w)=\Gamma^{k}\left(\alpha^{*}(w)\right)$ and $h_{\ell}(w)=\Gamma^{\ell}\left(\alpha^{*}(w)\right)$. Differentiating these yields

$$
h_{k}^{\prime}(w)=\frac{\partial \alpha^{*}(w)}{\partial w} \cdot q\left(\alpha^{*}(w)\right)^{\eta-1} \quad h_{\ell}^{\prime}(w)=-\frac{\partial \alpha^{*}(w)}{\partial w} \cdot \psi\left(\alpha^{*}(w)\right)^{\eta-1}
$$

which combined yield the differential equation

$$
h_{\ell}^{\prime}(w)=-w^{\eta-1} \cdot h_{k}^{\prime}(w)
$$

In our model, the ratio of labor to capital costs can be computed as

$$
\frac{\varepsilon^{\ell}}{\varepsilon^{k}}=\frac{h_{\ell}(w)}{h_{k}(w)} \cdot w^{1-\eta}
$$

Hence, the induced elasticity of substitution is constant and equal to $\eta^{*}$ if and only if

$$
\frac{h_{\ell}(w)}{h_{k}(w)}=\chi \cdot w^{\eta-\eta^{*}}
$$

This equation implies that $\eta^{*}>\eta$, since $h_{\ell}^{\prime}(w)<0$ and $h_{k}^{\prime}(w)>0$. Rearranging and taking derivatives yields

$$
h_{\ell}^{\prime}(w)=\chi \cdot w^{\eta-\eta^{*}} \cdot h_{k}^{\prime}(w)-\left(\eta^{*}-\eta\right) \cdot \chi \cdot w^{\eta-\eta^{*}-1} \cdot h_{k}(w) .
$$


Combining this equation with (A5) yields the differential equation for $h_{k}(w)$ :

$$
\frac{h_{k}^{\prime}(w)}{h_{k}(w)}=\left(\eta^{*}-\eta\right) \cdot \frac{\chi \cdot w^{-\eta^{*}}}{\chi \cdot w^{1-\eta^{*}+1}} .
$$

This differential equation has two solutions, one for $\eta^{*}=1$ and another one for $\eta^{*} \neq 1$.

Parametrization with $\eta^{*}=1$ : Our baseline calibration focuses on the case with $\eta^{*}=1$. In this case, we can write (A7) as

$$
\frac{h_{k}^{\prime}(w)}{h_{k}(w)}=(1-\eta) \cdot \frac{\chi}{\chi+1} \cdot \frac{1}{w}
$$

Integrating both sides we get

$$
h_{k}(w)=M \cdot w^{(1-\eta) \cdot \frac{\chi}{\chi+1}},
$$

for some $M>0$, and

$$
h_{\ell}(w)=M \cdot \chi \cdot w^{(1-\eta) \cdot \frac{-1}{\chi+1}} .
$$

With the functions $h_{k}(w)$ and $h_{\ell}(w)$ at hand, we can now generate all possible parametrizations of the productivity schedules for capital and labor that induce a constant elasticity of substitution $\eta^{*}=1$. In particular, for any increasing function $\alpha^{*}(w)=f(w)$ from the positive reals to $[0,1]$, capturing the optimal threshold rule, we can define

$$
\phi(x)=\left[\frac{h_{k}^{\prime}\left(f^{-1}(x)\right)}{f^{\prime}\left(f^{-1}(x)\right)}\right]^{\frac{1}{\eta-1}} \quad \psi(x)=\left[-\frac{h_{\ell}^{\prime}\left(f^{-1}(x)\right)}{f^{\prime}\left(f^{-1}(x)\right)}\right]^{\frac{1}{\eta-1}}
$$

which also implies $\Gamma^{k}(x)=h_{k}\left(f^{-1}(x)\right)$ and $\Gamma^{\ell}(x)=h_{\ell}\left(f^{-1}(x)\right)$.

Taking the function $\alpha^{*}(w)=\left(\frac{w}{1+w}\right)^{\frac{1-\eta}{\gamma_{\ell}+\gamma_{k}}}$ yields the parametrization used in the text.

One can also verify that the implied share parameters are

$$
\Gamma^{k}(\alpha)=\frac{1}{\gamma_{k}}\left(\frac{\alpha}{1-\alpha}\right)^{\gamma_{k}}, \quad \Gamma^{\ell}(\alpha)=\frac{1}{\gamma_{\ell}}\left(\frac{\alpha}{1-\alpha}\right)^{-\gamma_{\ell}},
$$

the optimal automation decision satisfies

$$
\alpha^{*}=\left(\frac{w}{1+w}\right)^{\frac{1-\eta}{\gamma_{\ell}+\gamma_{k}}}
$$


and the ratio of labor to capital costs is given by

$$
\frac{s^{\ell}}{s^{k}}=\frac{\Gamma^{\ell}\left(\alpha^{*}\right)}{\Gamma^{k}\left(\alpha^{*}\right)} \cdot w^{1-\eta}=\frac{\gamma_{k}}{\gamma_{\ell}} .
$$

This shows that, once firms are allowed to adjust their tasks, the labor share in costs is constant and equal to $\gamma_{k} /\left(\gamma_{k}+\gamma_{\ell}\right)$.

Parametrization with $\eta^{*} \neq 1$ : Integrating both sides of equation A7 gives the unique solution for $h_{k}(w)$

$$
h_{k}(w)=M \cdot\left(\chi \cdot w^{1-\eta^{*}}+1\right)^{\frac{\eta-\eta^{*}}{\eta^{*}-1}}
$$

Using equation (A6), we also obtain

$$
h_{\ell}(w)=M \cdot \chi \cdot\left(\chi+w^{\eta^{*}-1}\right)^{\frac{\eta-\eta^{*}}{\eta^{*}-1}}
$$

As before, we can now generate all possible parametrizations of the productivity schedules for capital and labor in $[0,1]$ that induce a constant elasticity of substitution $\eta^{*} \neq 1$ by picking an increasing function $\alpha^{*}(w)=f(w)$ from the positive reals to $[0,1]$.

For the exercise reported in Column 5 of Table 1 , we take $\alpha^{*}(w)=h_{k}(w)$, which is an increasing function from the positive reals to $[0,1]$ when $\eta^{*}>1$. This choice of $\alpha^{*}(w)$ implies $\phi(x)=1$ and

$$
\psi(x)=A \cdot\left(x^{\frac{1-\eta^{*}}{\eta^{*}-\eta}}-1\right)^{\frac{1}{1-\eta^{*}}}
$$

where $A$ is a scaling factor that captures labor-augmenting technical change. With this specification, the production function of a firm $f$ that automates all tasks up to $\alpha_{f}$ and rents $k_{f}$ units of capital and $\ell_{f}$ units of labor becomes

$$
y_{f}=z_{f} \cdot\left(\alpha_{f}^{\frac{1}{\eta}} \cdot\left(q_{0} \cdot k_{f}\right)^{\frac{\eta-1}{\eta}}+\Gamma^{\ell}\left(\alpha_{f}\right)^{\frac{1}{\eta}} \cdot\left(A \cdot \ell_{f}\right)^{\frac{\eta-1}{\eta}}\right)^{\frac{\eta}{1-\eta}}, \text { with } \Gamma^{\ell}\left(\alpha_{f}\right)=\left(1-\alpha_{f}^{\frac{\eta^{*}-1}{\eta^{*}-\eta}}\right)^{\frac{\eta^{*}-\eta}{\eta^{*}-1}}
$$


Modeling the $q$-shock: For any parametrization of productivity schedules, we can define the combined $q$ shock as

$$
q_{I, t}(x)= \begin{cases}q_{u, t} & \text { if } x \leq \alpha_{0}^{*} \\ q_{u, t} \cdot \min \left\{\frac{\psi(x) / \psi\left(\alpha_{0}^{*}\right)}{\phi(x) / \phi\left(\alpha_{0}^{*}\right)}, q_{s, t}\right\} & \text { if } x>\alpha_{0}^{*}\end{cases}
$$

for some increasing $\left\{q_{u, t}, q_{s, t}\right\}$ in $(1, \infty)$ converging to $\left\{q_{u}, q_{s}\right\}$.

In the main text, we also normalize baseline wages $w_{0}$ to 1 and assume that $q_{0}^{I}(x)=1$, which implies $\psi\left(\alpha_{0}^{*}\right) / \phi\left(\alpha_{0}^{*}\right)=1$, and simplifies the formulation of the shock.

Figure A10 represents the $q$ shock graphically. Tasks are arranged in $[0,1]$ in the horizontal axis. At time 0 , we have $q_{I, t}(x)=1$ for all tasks. Over time, the productivity with which the economy can produce the capital needed for task $x$ rises, and the increase is more pronounced for more complex tasks. The term $\min \left\{\frac{\psi(x) / \psi\left(\alpha_{0}^{*}\right)}{\phi(x) / \phi\left(\alpha_{0}^{*}\right)}, q_{s, t}\right\}$ ensures that the shock approximates a series of small skewed $q$ shocks like the ones considered in Proposition 3.

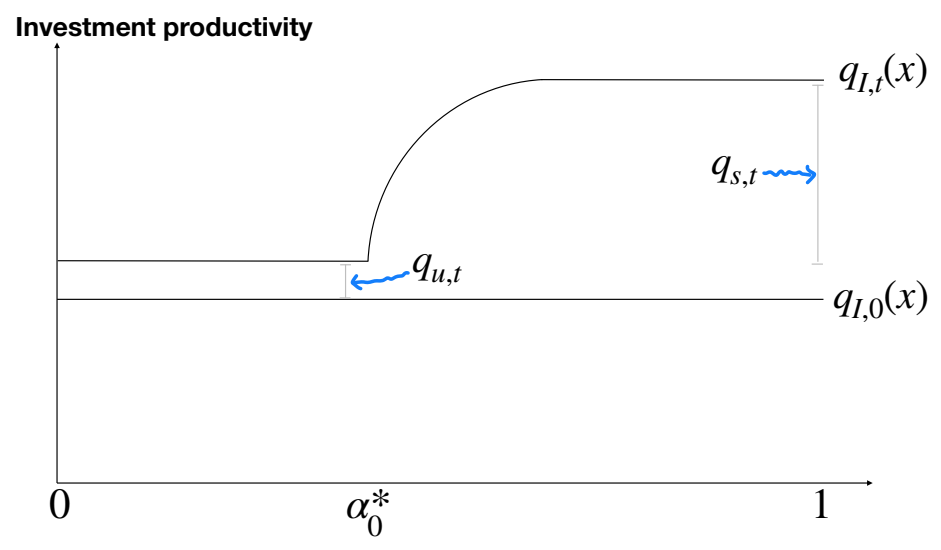

Figure A10: Representation of $q$ shocks. Tasks are arranged in $[0,1]$ in the horizontal axis. At time 0 , we have $q_{I, 0}(x)=1$ for all tasks. Over time, the productivity with which the economy can produce the capital needed for task $x$ rises to $q_{I, t}(x)$.

Let $\alpha_{0}^{*}$ denote the optimal threshold at the initial steady state, $\alpha^{*}$ the new steady-state level after the combined $q$ shock, and $\bar{\alpha}$ the point at which $\frac{\psi(x) / \psi\left(\alpha^{*}\right)}{\phi(x) / \phi\left(x^{*}\right)}=q_{s}$.

$\alpha^{*}$ is defined implicitly by

$$
w \cdot q_{u} \cdot q_{s}=\frac{\psi\left(\alpha^{*}\right)}{\phi\left(\alpha^{*}\right)}
$$

and $\bar{\alpha}$ by

$$
w_{0} \cdot q_{s}=\frac{\psi(\bar{\alpha})}{\phi(\bar{\alpha})} .
$$


This implies that $\alpha_{0}^{*}<\bar{\alpha}<\alpha^{*}$, since wages increase with advances in investment technologies.

After the shock, the task share for labor is $\Gamma_{\ell}\left(\alpha^{*}\right)$, which is lower than before, and the task share for capital is higher than before and given by

$$
\begin{aligned}
\Gamma_{k}\left(\alpha^{*}\right) & =q_{u}^{\eta-1} \cdot \Gamma_{k}\left(\alpha_{0}^{*}\right)+q_{u}^{\eta-1} \cdot w_{0}^{1-\eta} \cdot \int_{\alpha_{0}^{*}}^{\bar{\alpha}} \psi(x)^{\eta-1} \cdot d x+q_{u}^{\eta-1} \cdot q_{s}^{\eta-1} \cdot\left[\Gamma_{k}\left(\alpha^{*}\right)-\Gamma_{k}(\bar{\alpha})\right] \\
& =q_{u}^{\eta-1} \cdot \Gamma_{k}\left(\alpha_{0}^{*}\right)+q_{u}^{\eta-1} \cdot w_{0}^{1-\eta} \cdot\left[\Gamma_{\ell}\left(\alpha_{0}^{*}\right)-\Gamma_{\ell}(\bar{\alpha})\right]+q_{u}^{\eta-1} \cdot q_{s}^{\eta-1} \cdot\left[\Gamma_{k}\left(\alpha^{*}\right)-\Gamma_{k}(\bar{\alpha})\right] .
\end{aligned}
$$

To conclude, we show that in our parametrization with $\eta^{*}=1$ in the initial steady state, the combined $q$ shock takes the economy to a new steady state with: i. a lower labor share and ii. an induced elasticity of substitution below 1 .

To show (i), note that in the new steady state

$$
\begin{aligned}
\frac{\varepsilon_{k}}{\varepsilon_{\ell}} & =\frac{q_{u}^{\eta-1} \cdot \Gamma_{k}\left(\alpha_{0}^{*}\right)+q_{u}^{\eta-1} \cdot w_{0}^{1-\eta} \cdot\left[\Gamma_{\ell}\left(\alpha_{0}^{*}\right)-\Gamma_{\ell}(\bar{\alpha})\right]+q_{u}^{\eta-1} \cdot q_{s}^{\eta-1} \cdot\left[\Gamma_{k}\left(\alpha^{*}\right)-\Gamma_{k}(\bar{\alpha})\right]}{w^{1-\eta} \cdot \Gamma_{\ell}\left(\alpha^{*}\right)} \\
& =\frac{\Gamma_{k}\left(\alpha_{0}^{*}\right)+w_{0}^{1-\eta} \cdot\left[\Gamma_{\ell}\left(\alpha_{0}^{*}\right)-\Gamma_{\ell}(\bar{\alpha})\right]+q_{s}^{\eta-1} \cdot\left[\Gamma_{k}\left(\alpha^{*}\right)-\Gamma_{k}(\bar{\alpha})\right]}{q_{u}^{1-\eta} \cdot w^{1-\eta} \cdot \Gamma_{\ell}\left(\alpha^{*}\right)} \\
& =\frac{1-w_{0}^{1-\eta} \cdot \Gamma_{\ell}(\bar{\alpha})-q_{s}^{\eta-1} \cdot \Gamma_{k}(\bar{\alpha})}{q_{u}^{1-\eta} \cdot w^{1-\eta} \cdot \Gamma_{\ell}\left(\alpha^{*}\right)}+\frac{q_{s}^{\eta-1} \cdot \Gamma_{k}\left(\alpha^{*}\right)}{q_{u}^{1-\eta} \cdot w^{1-\eta} \cdot \Gamma_{\ell}\left(\alpha^{*}\right)} .
\end{aligned}
$$

By construction, the second term is constant and equal to the initial ratio $\frac{\varepsilon_{k}}{\varepsilon_{\ell}}$. The first term is positive, which shows that the labor share is lower in the new steady state.

For (ii), we show that $\frac{\varepsilon_{k}}{\varepsilon_{\ell}}$ decreases in $w$, which implies an induced elasticity below 1 . It is enough to show that the first term in the expression for $\frac{\varepsilon_{k}}{\varepsilon_{\ell}}$ decreases in $w$. This term can be written as

$\frac{1-w_{0}^{1-\eta} \cdot \Gamma_{\ell}(\bar{\alpha})-q_{s}^{\eta-1} \cdot \Gamma_{k}(\bar{\alpha})}{q_{u}^{1-\eta} \cdot w^{1-\eta} \cdot \Gamma_{\ell}\left(\alpha^{*}\right)}=\left(1-w_{0}^{1-\eta} \cdot \Gamma_{\ell}(\bar{\alpha})-q_{s}^{\eta-1} \cdot \Gamma_{k}(\bar{\alpha})\right) \cdot \frac{\Gamma_{k}\left(\alpha^{*}\right)}{q_{u}^{1-\eta} \cdot w^{1-\eta} \cdot \Gamma_{\ell}\left(\alpha^{*}\right)} \cdot \frac{1}{\Gamma_{k}\left(\alpha^{*}\right)}$.

The first term is a positive constant (since this is zero for the higher wage level that would result if all firms automated all tasks up to $\bar{\alpha}$ ), the second term is constant (by construction), and the third term decreases in $w$, as claimed.

\section{A.5 Super-Elasticity of Demand}

In the main text, we calibrated a demand super-elasticity of $\frac{\nu}{\sigma}=0.22$ by matching the ratio of the (unweighted) mean firm labor share to the aggregate sectoral labor share. Here, 
we report results for the main sectors of interest, manufacturing and retail, when instead using a lower super-elasticity of 0.16 as estimated by Edmond, Midrigan and Xu (2018). For this exercise, we re-calibrate the parameters in the initial steady states for both sectors. The main difference is that a lower value of the super-elasticity requires less convexity in the productivity distribution, since the mapping from productivity to firm sales is less logconcave. For manufacturing, we infer $n=0.91$ (instead of $n=0.74$ as in Table 3); for retail, we infer $n=0.63$ (instead of $n=0.47$ as in Table 4 ). Thus, the inferred $z$-distributions are closer to the log-linear Pareto distribution, which is the special case with $n=1$.

Table A1 reports the main results over the transition (1982-2012) for both sectors. Relative to the results in the main text, the inferred rising competition shocks are somewhat larger: in manufacturing, we infer $d \ln \lambda=0.09$ (instead of $d \ln \lambda=0.06$ as in Table 5); in retail, we infer $d \ln \lambda=0.48$ (instead of $d \ln \lambda=0.30$ as in Table 6). Even though the inferred shocks are larger, the lower log-convexity of the $z$-distribution implies that the $\lambda$ shock generates a smaller increase in the aggregate markup, and correspondingly a smaller decrease in the aggregate labor share. As documented in Table A1, we infer a rise in the aggregate markup of $1.0 \%$ in manufacturing (as opposed to $1.4 \%$ in Table 5 ) and of $2.6 \%$ in retail (as opposed to $5.1 \%$ in Table 6). The other main results, in particular the contribution of falling capital prices to the labor share decline, are similar across parameterizations. 
TABLE A1: Model robustness: Transitional dynamics in manufacturing and retail under a non-CES demand system with lower super-elasticity of $\frac{\nu}{\sigma}=0.16$

\begin{tabular}{|c|c|c|c|c|}
\hline & \multirow[b]{2}{*}{$\begin{array}{r}\text { DATA } \\
(1)\end{array}$} & \multicolumn{3}{|c|}{ MODEL } \\
\hline & & $\begin{array}{r}\text { BENCHMARK } \\
(2) \\
\end{array}$ & $\begin{array}{r}\text { ONLY EFFECTS } \\
\text { OF } d \ln q \\
(3) \\
\end{array}$ & $\begin{array}{r}\text { ONLY EFFECTS } \\
\text { OF } d \ln \lambda \\
(4)\end{array}$ \\
\hline \multicolumn{5}{|l|}{ A. Manufacturing (1982-2012) } \\
\hline \multicolumn{5}{|c|}{ I. Parameters and inferred aggregate shocks } \\
\hline$d \ln q_{u}$ & & 0.63 & 0.63 & 0 \\
\hline$d \ln q_{s}$ & & 4.66 & 4.66 & 0 \\
\hline$d \ln \lambda$ & & 0.09 & 0 & 0.09 \\
\hline$c_{a}$ & & 0.17 & 0.17 & 0.17 \\
\hline \multicolumn{5}{|c|}{ II. Targeted moments, 1982-2012 } \\
\hline$\Delta$ aggregate labor share & -0.199 & -0.199 & -0.209 & 0.004 \\
\hline$\Delta \log$ average capital price & -1.081 & -1.074 & -0.994 & 0.000 \\
\hline$\Delta \log 4$ firms' sales share & 0.140 & 0.143 & 0.078 & 0.070 \\
\hline $\begin{array}{l}\text { Relative adoption } \\
\text { (P99+ vs. P50-75 firms) }\end{array}$ & 1.708 & 1.711 & 1.621 & 9.744 \\
\hline \multicolumn{5}{|c|}{ III. Typical firm labor share and other moments } \\
\hline$\Delta$ median labor share & 0.030 & 0.036 & 0.016 & 0.013 \\
\hline$\Delta$ unweighted mean & -0.017 & -0.005 & -0.025 & 0.012 \\
\hline$\Delta \log 20$ firms' sales share & 0.072 & 0.142 & 0.105 & 0.046 \\
\hline$\Delta \log$ productivity dispersion & 0.050 & 0.073 & 0.060 & 0.000 \\
\hline \multicolumn{5}{|c|}{ IV. Markups, 1982-2012 } \\
\hline$\Delta$ log aggregate markup & -0.011 & 0.010 & 0.011 & 0.000 \\
\hline Within-firm change in markup & -0.076 & -0.025 & -0.021 & -0.010 \\
\hline Reallocation to high-markup firms & 0.065 & 0.035 & 0.032 & 0.010 \\
\hline \multicolumn{5}{|l|}{ B. Retail (1982-2012) } \\
\hline \multicolumn{5}{|c|}{ I. Parameters and inferred aggregate shocks } \\
\hline$d \ln q_{u}$ & & 0.44 & 0.44 & 0 \\
\hline$d \ln q_{s}$ & & 3.30 & 3.30 & 0 \\
\hline$d \ln \lambda$ & & 0.48 & 0 & 0.48 \\
\hline$c_{a}$ & & 0.08 & 0.08 & 0.08 \\
\hline \multicolumn{5}{|c|}{ II. Targeted moments, 1982-2012 } \\
\hline$\Delta$ aggregate labor share & -0.127 & -0.127 & -0.142 & -0.008 \\
\hline$\Delta$ log average capital price & -0.865 & -0.869 & -0.656 & 0.000 \\
\hline$\Delta \log$ sales concentration & 0.546 & 0.547 & 0.067 & 0.493 \\
\hline $\begin{array}{l}\text { Relative adoption } \\
\text { (P99+ vs. P50-75 firms) }\end{array}$ & 1.708 & 1.71 & 1.29 & 2.68 \\
\hline \multicolumn{5}{|c|}{ III. Typical firm labor share and other moments } \\
\hline$\Delta$ median labor share & & 0.049 & -0.030 & 0.045 \\
\hline$\Delta$ unweighted mean & & 0.029 & -0.045 & 0.042 \\
\hline$\Delta \log$ productivity dispersion & & 0.040 & 0.018 & 0.001 \\
\hline \multicolumn{5}{|c|}{ IV. Markups, 1982-2012 } \\
\hline$\Delta \log$ aggregate markup & 0.038 & 0.026 & 0.010 & 0.019 \\
\hline Within-firm change in markup & -0.026 & -0.029 & -0.013 & -0.020 \\
\hline Reallocation to high-markup firms & 0.064 & 0.055 & 0.023 & 0.039 \\
\hline
\end{tabular}

Notes: Panels A and B report the equivalents of Tables 5 and 6 in the main text, when imposing instead a lower superelasticity of $\frac{\nu}{\sigma}=0.16$ (instead of $\frac{\nu}{\sigma}=0.22$ as in the main text). The parameters of the respective economies are re-calibrated, both in the steady state to match all other targeted moments, as well as in regards to the inferred $\operatorname{shocks} d \ln q_{s}, d \ln q_{u}, d \ln \lambda$ and the automation fixed $\operatorname{cost} c_{a}$ over the transition. 


\section{A.6 Calibration of The nOn-CES Demand MOdel For other SeCtors}

Table A2 summarizes the steady state calibration of the model with size-dependent markups in the wholesale as well as the utilities \& transportation sector. The calibration strategy is identical to manufacturing and retail, which we describe in the main text. The logconvexity of the $z$-distribution is rather mild in these two sectors ( $n$ only slightly below 1 ), more in line with manufacturing than with retail.

TABLE A2: Steady state calibration of the non-CES demand model: Wholesale, Utilities \& Transportation

\begin{tabular}{|c|c|c|c|c|c|}
\hline & PARAMETER & & Moment & DATA & MODEL \\
\hline & \multicolumn{5}{|c|}{ I. Wholesale: steady state parameters and moments (1982) } \\
\hline$\gamma_{\ell}$ & Comparative advantage & 0.63 & \multirow{2}{*}{$\begin{array}{l}\text { Wholesale labor share } \\
\text { Imputed from } \\
\text { manufacturing }\end{array}$} & \multirow{2}{*}{0.53} & \multirow[t]{2}{*}{0.53} \\
\hline$\nu / \sigma$ & Demand super-elasticity & 0.22 & & & \\
\hline$\sigma$ & Demand elasticity & 9.4 & Aggregate markup & 1.15 & 1.15 \\
\hline$\zeta$ & Weibull scale & 0.071 & Top 20 firms' sales share & $42.9 \%$ & $42.9 \%$ \\
\hline$n$ & Weibull shape & 0.75 & Top 4 firms' sales share & $22.3 \%$ & $22.3 \%$ \\
\hline$\underline{\mathrm{c}}_{o}$ & Scale operating cost & $3.2 \cdot 10^{-7}$ & Entry $(=$ exit $)$ rate & 0.062 & 0.062 \\
\hline $\bar{\xi}_{o}$ & Tail index operating cost & 0.235 & Size of exiters & 0.490 & 0.493 \\
\hline$\mu_{e}$ & Entrant productivity & 0.889 & Size of entrants & 0.600 & 0.601 \\
\hline \multirow[t]{2}{*}{$\rho_{z}$} & Productivity persistence & 0.86 & \multicolumn{2}{|l|}{$\begin{array}{l}\text { Revenue TFP persistence } \\
\text { among wholesale firms }\end{array}$} & \\
\hline & \multicolumn{4}{|c|}{ II. Utilities E Transportation: steady state parameters and moments (1992) } & \\
\hline$\gamma_{\ell}$ & Comparative advantage & 0.72 & Util.\&transp. labor share & 0.51 & 0.51 \\
\hline$\nu / \sigma$ & Demand super-elasticity & 0.22 & $\begin{array}{l}\text { Imputed from } \\
\text { manufacturing }\end{array}$ & & \\
\hline$\sigma$ & Demand elasticity & 10.7 & Aggregate markup & 1.15 & 1.15 \\
\hline$\zeta$ & Weibull scale & 0.066 & Top 20 firms' sales share & $59.1 \%$ & $58.0 \%$ \\
\hline$n$ & Weibull shape & 0.74 & Top 4 firms' sales share & $30.4 \%$ & $31.3 \%$ \\
\hline$\underline{\mathrm{c}}_{o}$ & Scale operating cost & $9.0 \cdot 10^{-8}$ & Entry (=exit) rate & 0.062 & 0.063 \\
\hline$\xi_{o}$ & Tail index operating cost & 0.212 & Size of exiters & 0.490 & 0.489 \\
\hline$\mu_{e}$ & Entrant productivity & 0.891 & Size of entrants & 0.600 & 0.600 \\
\hline$\rho_{z}$ & Productivity persistence & 0.86 & $\begin{array}{l}\text { Revenue TFP persistence } \\
\text { among ut. \& transp. firms }\end{array}$ & & \\
\hline
\end{tabular}

Notes: The two concentration measures are from Autor et al. (2020) and correspond to these two sectors in 1982, respectively 1992. The model equivalents refer to the top $0.074 \%$ and top $0.369 \%$ of firms ranked by sales in wholesale (since there are on average 5,420 firms per 4-digit wholesale industry). For utilities \& transportation, the model equivalents correspond to the top $0.100 \%$ and top $0.499 \%$ of firms ranked by sales (since there are on average 4,010 firms per 4-digit industry in this sector). The remaining data moments follow the model with CES demand, see Table 1. Fixing productivity persistence and the demand super-elasticity, in each of the two sectors the remaining six parameters are jointly calibrated to match the six corresponding moments.

Table A3 shows the model-based decomposition exercise, where we follow the same strategy as for manufacturing and retail. In wholesale and in utilities \& transportation, the labor share decline is mild, while the observed increase in sales concentration is also moderate. Consequently, the inferred decline in skewed capital price shocks $\left(d \ln q_{s}\right)$ is small, 
while the inferred increase in competition $(d \ln \lambda)$ is weaker than in retail but stronger than in manufacturing. The inferred automation fixed costs $\left(c_{a}\right)$ are comparable.

Figure A11 and Table A4 summarize our findings and contrast them with our results for manufacturing and retail.

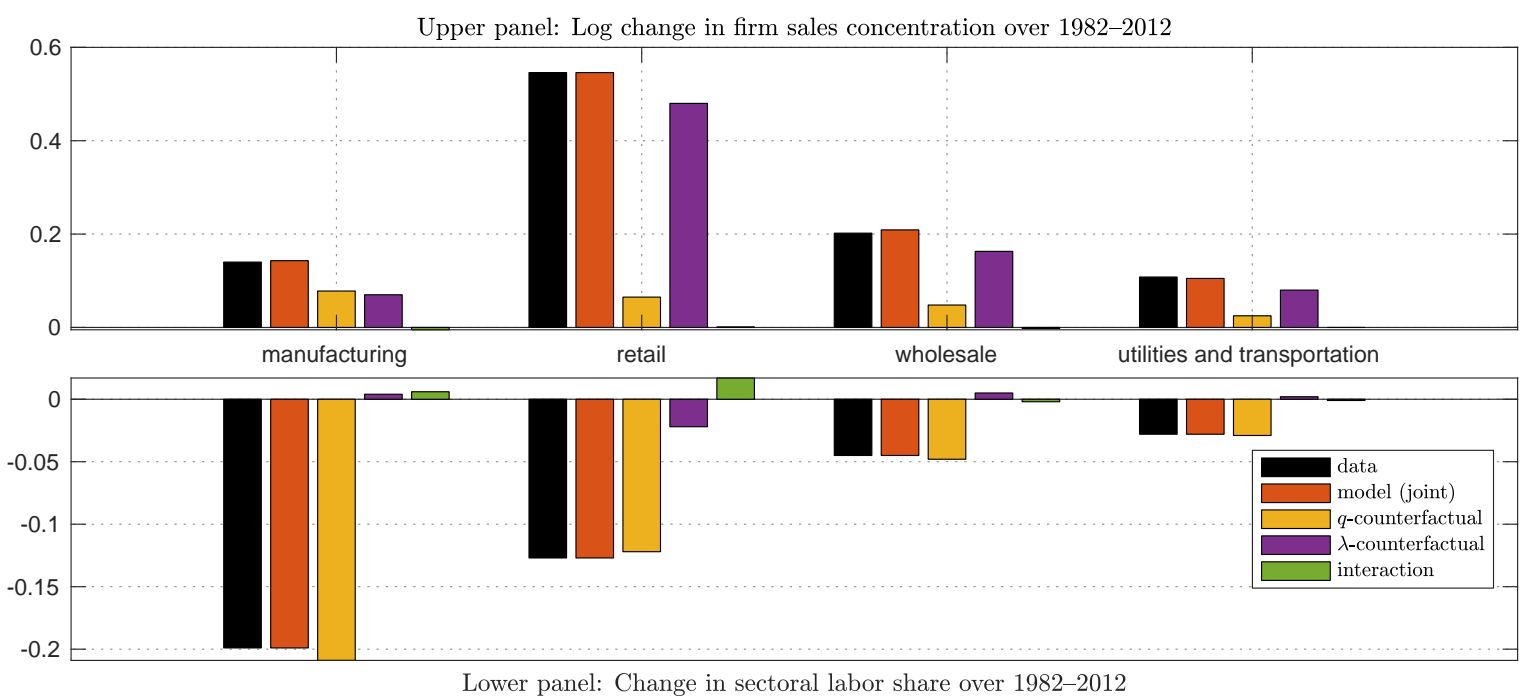

Figure A11: Model-BASEd DECOMPosition OF LABOR SHARE AND SALES CONCENTRATION CHANGES. For each sector, the upper panel displays the log change in firm sales concentration (i) in the data (Autor et al., 2020, Table 1), (ii) in the benchmark model with $q$ and $\lambda$ shocks jointly calibrated, (iii) in a model counterfactual that keeps only the $q$ shock active, (iv) in a model counterfactual that keeps only the estimated $\lambda$ shock active; (v) displays the interaction term, defined as (ii - iii - iv). The lower panel shows sectoral labor share changes in data (BEA-BLS) and model. See Tables 5, 6 and A3 for details.

Comparing the various model versions, we find that declining capital prices fully account for the moderate labor share declines in both sectors, while rising market access accounts for around $80 \%$ of the respective increases in sales concentration. 
TABLE A3: Transitional dynamics and decomposition of the labor share using a non-CES demand system: Wholesale, Utilities \& Transportation

\begin{tabular}{|c|c|c|c|c|}
\hline & \multirow[b]{2}{*}{$\begin{array}{r}\text { DATA } \\
(1)\end{array}$} & \multicolumn{3}{|c|}{ MODEL } \\
\hline & & $\begin{array}{r}\text { BENCHMARK } \\
(2)\end{array}$ & $\begin{array}{r}\text { ONLY EFFECTS OF } \\
d \ln q \\
(3)\end{array}$ & $\begin{array}{r}\text { ONLY EFFECTS OF } \\
d \ln \lambda \\
(4)\end{array}$ \\
\hline \multicolumn{5}{|l|}{ A. Wholesale (1982-2012) } \\
\hline & \multicolumn{4}{|c|}{ I. Parameters and inferred aggregate shocks } \\
\hline$d \ln q_{u}$ & & 1.30 & 1.30 & 0 \\
\hline$d \ln q_{s}$ & & 1.06 & 1.06 & 0 \\
\hline$d \ln \lambda$ & & 0.19 & 0 & 0.19 \\
\hline \multirow[t]{2}{*}{$c_{a}$} & & 0.18 & 0.18 & 0.18 \\
\hline & \multicolumn{4}{|c|}{ II. Targeted moments, 1982-2012 } \\
\hline$\Delta$ aggregate labor share & -0.045 & -0.045 & -0.048 & 0.005 \\
\hline$\Delta \log$ average capital price & -1.596 & -1.593 & -1.563 & 0 \\
\hline$\Delta$ log sales concentration & 0.202 & 0.209 & 0.048 & 0.163 \\
\hline Relative adoption & 1.71 & 1.71 & 1.42 & 3.52 \\
\hline \multicolumn{5}{|l|}{ (P99+ vs. P50-75 firms) } \\
\hline$\Delta$ median labor share & 111. $19 p t$ & 0.187 & 0.156 & 0.033 \\
\hline$\Delta$ unweighted mean & & 0.150 & 0.122 & 0.031 \\
\hline \multirow[t]{2}{*}{$\Delta \log$ productivity dispersion } & & 0.182 & 0.165 & 0.102 \\
\hline & \multicolumn{4}{|c|}{ IV. Markups, 1982-2012 } \\
\hline$\Delta$ log aggregate markup & 0.038 & 0.009 & 0.006 & 0.003 \\
\hline Within-firm change in markup & -0.026 & -0.043 & -0.032 & -0.015 \\
\hline Reallocation to high-markup firms & 0.064 & 0.052 & 0.039 & 0.018 \\
\hline \multicolumn{5}{|c|}{ B. Utilities \& Transportation (1992-2012) } \\
\hline & \multicolumn{4}{|c|}{ I. Parameters and inferred aggregate shocks } \\
\hline$d \ln q_{u}$ & & 0.62 & 0.62 & 0 \\
\hline$d \ln q_{s}$ & & 0.44 & 0.44 & 0 \\
\hline$d \ln \lambda$ & & 0.12 & 0 & 0.12 \\
\hline \multirow[t]{2}{*}{$c_{a}$} & & 0.10 & 0.10 & 0.10 \\
\hline & \multicolumn{4}{|c|}{ II. Targeted moments, 1982-2012 } \\
\hline$\Delta$ aggregate labor share & -0.028 & -0.028 & -0.029 & 0.002 \\
\hline$\Delta$ log average capital price & -0.684 & -0.683 & -0.676 & 0 \\
\hline$\Delta$ log sales concentration & 0.108 & 0.105 & 0.025 & 0.080 \\
\hline Relative adoption & 1.71 & 1.71 & 1.47 & 4.53 \\
\hline (P99+ vs. P50-65 nirms) & \multicolumn{4}{|c|}{ III. Typical firm labor share and other moments } \\
\hline$\Delta$ median labor share & & 0.102 & 0.088 & 0.017 \\
\hline$\Delta$ unweighted mean & & 0.083 & 0.070 & 0.016 \\
\hline \multirow[t]{2}{*}{$\Delta \log$ productivity dispersion } & & 0.117 & 0.107 & 0.089 \\
\hline & \multicolumn{4}{|c|}{ IV. Markups, 1982-2012 } \\
\hline$\Delta$ log aggregate markup & 0.038 & 0.004 & 0.002 & 0.001 \\
\hline Within-firm change in markup & -0.026 & -0.015 & -0.010 & -0.008 \\
\hline Reallocation to high-markup firms & 0.064 & 0.018 & 0.012 & 0.010 \\
\hline
\end{tabular}

Notes: Column (2) reports the findings from our benchmark model, which calibrates a decline in capital prices, an increase in competition, as well as the automation fixed cost to replicate the change in the aggregate sectoral labor share (BEA-BLS integrated industry-level production account), the decline in the average price of capital, the relative adoption of automation technologies by firm size (from Acemoglu et al., 2021), and the average log change in the top 4 as well as top 20 firms' sales share (Autor et al., 2020, Table 1), for each sector. Due to data availability, the transition is over 1982-2012 for wholesale, resp. 1992-2012 for utilities \& transportation. Column (3) shows results when shutting down the competition shock, and column (4) when shutting down instead the price of capital shock. Panel IV displays the log change in the aggregate markup and the decomposition into within-firm and reallocation components from Section 3.4 outside of manufacturing. 
TABLE A4: Inferred sectoral price of capital and market access shocks

\begin{tabular}{lcrrr}
\hline & \multicolumn{2}{c}{ Price of capital decline } & & Market access increase \\
\cline { 2 - 3 } \cline { 5 - 5 } & $d \ln q_{u}$ & $d \ln q_{s}$ & & $d \ln \lambda$ \\
\hline Manufacturing & 0.60 & 4.57 & & 0.06 \\
Retail & 0.48 & 2.77 & & 0.30 \\
Wholesale & 1.30 & 1.06 & & 0.19 \\
Utilities \& transportation & 0.62 & 0.44 & & 0.12 \\
\hline
\end{tabular}




\section{A.7 Additional Data and Measurement Details}

Historical behavior of labor shares: This section provides additional motivation for our focus on the 1982-2012 period. As a starting point, Figure A12 provide data on payroll shares by sector for 1947-1987 and 1987-2016 from the BEA industry accounts. We split the data into these two periods due to changes in industry definitions introduced by the BEA in 1987, as it switched from the Standard Industry Classification to the North American Industry Classification System. As discussed in the main text, Figure A12 shows that payroll shares were constant or increasing up to 1982, and then started a sharp decline both in manufacturing, retail and wholesale. Payroll shares differ from labor shares in that they exclude compensation and self employment. But looking at payroll shares has the advantage of allowing us to go back further in time.
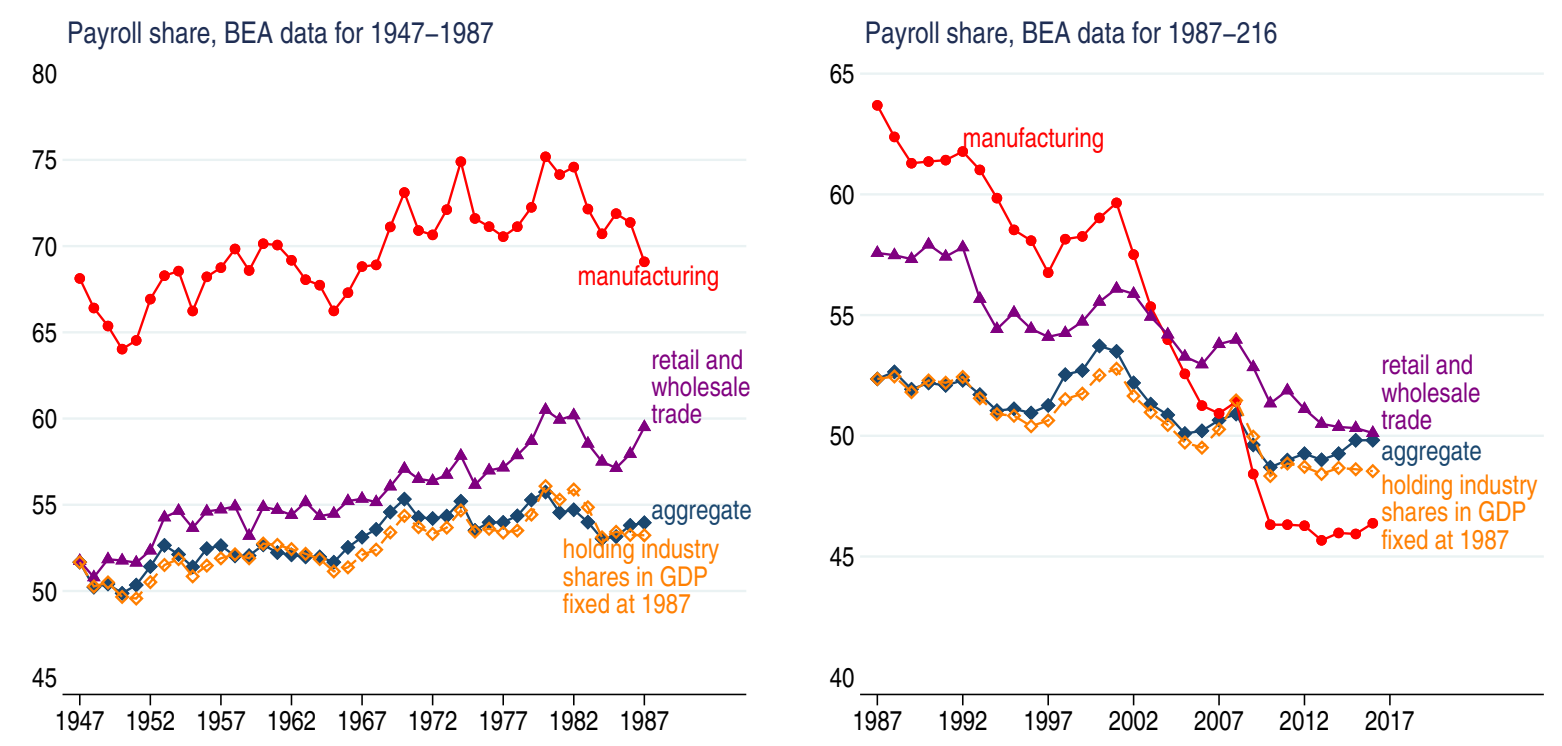

Figure A12: Payroll share in the US for 1947-2016. The figure plots the payroll share of value added, both for some specific sectors and the economy as a whole. Data from the BEA industry accounts. Industry definitions based on SIC in left panel, NAICS in right panel.

Labor shares (which also include non-wage compensation) are available starting in 1963 from the BEA-BLS integrated industry-level production account. Figure A13 confirms that labor shares exhibit the same trend behavior with a flat or slightly increasing trend until 1982 and a subsequent decline. This motivates our focus on the 1982-2012 period and supports our choice of 1982 as the steady state of the model.

Measures of capital prices: We create measures of quality-adjusted capital prices at the sectoral level building on DiCecio (2009), Cummins and Violante (2002), and Gordon 


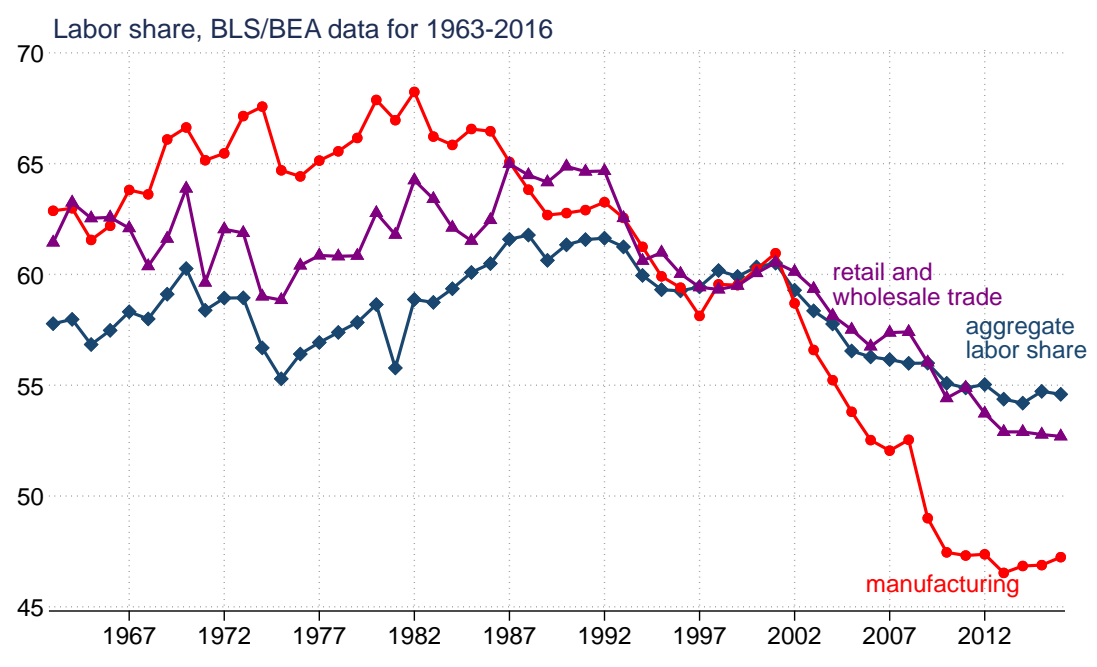

Figure A13: LABOR Share in the US FOR 1963-2016 The figure plots the labor share of value added, both for some specific sectors and the economy as a whole. Data from the BEA-BLS integrated industry-level production account.

(1990).

In the first step, we obtain data on nonresidential asset prices and quantities from the BEA Fixed Asset Tables. These data cover 39 types of equipment, 32 types of structures, 3 types of software, and 22 types of other intellectual property products. We exclude other intellectual property products from our analysis since these would be considered part of the fixed cost of adopting new technologies in our model. The data cover the period from 1947 to 2020 and include information on investment at current nominal prices, investment at constant 2012 prices, stocks, and depreciation.

Using these series, we construct a price index for each detailed asset $a$ as

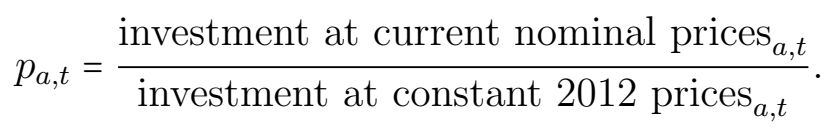

We let $\Delta \ln p_{a, t}$ denote the percent change in asset prices between time $t$ and $t+1$.

Our second step involves adjusting the BEA prices for quality. We follow the work by DiCecio (2009) and Cummins and Violante (2002). These authors use the series for qualityadjusted investment prices from Gordon (1990), and which covered the postwar period up to 1983, and extend it from 1947 to 2011. Cummins and Violante (2002) estimate a statistical model explaining Gordon's quality-adjusted price indices as a function of those by the BEA/NIPA, their lags, and time trends. They then extrapolate this model to produce quality-adjusted price indices for 1947-2000. DiCecio (2009) follows the same procedure and creates an updated series up to 2011 for equipment and software. We use the estimates 
from DiCecio (2009) on the quality adjusted price of equipment and software, obtained via FRED (variable code PERICD), and denote the percent change in the quality-adjusted price of software and equipment as $\Delta \ln p_{t, \mathrm{E} \& \mathrm{~S}}^{*}$. We then compute a user-cost weighted price index for software and equipment from the BEA data using a Törnqvist index

$$
\Delta \ln p_{t, \mathrm{E} \& \mathrm{~S}}=\sum_{a \in \mathrm{E} \& \mathrm{~S}} \frac{1}{2} \cdot\left(s_{t+1, a}^{\mathrm{E} \& \mathrm{~S}}+s_{a, t}^{\mathrm{E} \& \mathrm{~S}}\right) \cdot \Delta \ln p_{a, t}
$$

where $s_{a, t}^{\mathrm{E} \& \mathrm{~S}}$ denotes the share of asset $a$ in equipment and software capital services. ${ }^{45}$ The implied quality adjustment for equipment and software is therefore equal to

$$
\Delta \text { quality adjustment } \mathrm{E \& S}, t=\Delta \ln p_{E \& S, t}-\Delta \ln p_{\mathrm{E} \& \mathrm{~S}, t}^{*}
$$

In the BEA data, the price of equipment and software declined by an average of $3.1 \%$ per year in 1980-2011. The quality-adjusted series from DiCecio (2009) shows a decline on $5.7 \%$ per year, which implies an improvement in the quality of equipment and software of $2.6 \%$ per year.

We then compute a quality adjusted series for the detailed equipment and software products in the BEA data as

$$
\Delta \ln p_{a, t}^{*}=\Delta \ln p_{a, t}-\Delta \text { quality adjustment }{ }_{\mathrm{E} \& \mathrm{~S}, t} .
$$

This assumes a common quality adjustment for all types of software and equipment. For structures, we do not perform quality adjustment.

In the third step, we account for changes in taxation using the estimates in Acemoglu, Manera and Restrepo (2020) of effective taxes on equipment, software, and structures. These authors estimate that the effective tax on equipment decreased from $12.4 \%$ to $4.7 \%$ during 1981-2018, the effective tax on software decreased from $14.6 \%$ to $4.7 \%$ during $1981-$ 2018, and the effective tax on structures increased from $8.3 \%$ to $9 \%$ during 1981-2018. These changes in taxes imply a further reduction in the cost of producing tasks with capital of close to $10 \%$ during the whole 1981-2018 period.

In the fourth step, we compute a measure for the relative price of capital by asset, $\Delta \ln p_{a, t}^{*, r}$ by taking our quality-adjusted price indices adjusted for taxes and subtracting

\footnotetext{
${ }^{45}$ We compute capital services derived from an asset $a$ as

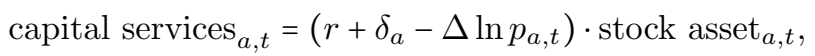

where we take a required rate of return $r=4 \%$, and use the depreciation rate and change in capital prices from the BEA.
} 
changes in the BEA price of consumption expenditures index.

In the final step, we construct a sector-specific measure of capital prices using a user-cost weighted Törnqvist index

$$
\Delta \ln p_{i, t}=\sum_{a} \frac{1}{2} \cdot\left(s_{a, t+1}^{i, k}+s_{a, t}^{i, k}\right) \cdot \Delta \ln p_{a, t}^{*, r}
$$

where $s_{a, t}^{i, k}$ denotes the share of asset $a$ in total capital services in sector $i$, computed also from the industry-level version of the BEA Fixed Asset Tables. This index provides the average decline in capital prices used in sector $i$ over the 1980-2011 period.

Our resulting sectoral price indices imply that the average price of capital used in manufacturing declined by 108 log points from 1980 to 2011. For retail, the average decline was of $86 \log$ points, for utilities $68 \log$ points, and for wholesale of 159 log points. These differences across sectors reflect the different bundles of capital goods used, with manufacturing and wholesale investing more heavily in equipment and software. 